\title{
Description and evaluation of GLOMAP-mode: a modal global aerosol microphysics model for the UKCA composition-climate model
}

\author{
G. W. Mann ${ }^{1}$, K. S. Carslaw ${ }^{2}$, D. V. Spracklen ${ }^{2}$, D. A. Ridley ${ }^{3}$, P. T. Manktelow ${ }^{2, *}$, M. P. Chipperfield ${ }^{2}$, \\ S. J. Pickering ${ }^{2}$, and C. E. Johnson ${ }^{4}$ \\ ${ }^{1}$ National Centre for Atmospheric Science, School of Earth and Environment, University of Leeds, Leeds, UK \\ ${ }^{2}$ School of Earth and Environment, University of Leeds, Leeds, UK \\ ${ }^{3}$ Dept. of Atmospheric Science, Colorado State University, Fort Collins, Colorado, USA \\ ${ }^{4}$ Met Office Hadley Centre, Exeter, UK \\ * now at: Halcrow Group Ltd, Headingley, Leeds, UK
}

Received: 5 May 2010 - Published in Geosci. Model Dev. Discuss.: 28 May 2010

Revised: 13 September 2010 - Accepted: 21 September 2010 - Published: 13 October 2010

\begin{abstract}
A new version of the Global Model of Aerosol Processes (GLOMAP) is described, which uses a twomoment pseudo-modal aerosol dynamics approach rather than the original two-moment bin scheme. GLOMAP-mode simulates the multi-component global aerosol, resolving sulfate, sea-salt, dust, black carbon (BC) and particulate organic matter (POM), the latter including primary and biogenic secondary POM. Aerosol processes are simulated in a size-resolved manner including primary emissions, secondary particle formation by binary homogeneous nucleation of sulfuric acid and water, particle growth by coagulation, condensation and cloud-processing and removal by dry deposition, in-cloud and below-cloud scavenging. A series of benchmark observational datasets are assembled against which the skill of the model is assessed in terms of normalised mean bias $(b)$ and correlation coefficient $(R)$. Overall, the model performs well against the datasets in simulating concentrations of aerosol precursor gases, chemically speciated particle mass, condensation nuclei $(\mathrm{CN})$ and cloud condensation nuclei (CCN). Surface sulfate, sea-salt and dust mass concentrations are all captured well, while BC and POM are biased low (but correlate well). Surface CN concentrations compare reasonably well in free troposphere and marine sites, but are underestimated at continental and coastal sites related to underestimation of either primary particle emissions or new particle formation. The model compares well against a compilation of $\mathrm{CCN}$ observations cover-
\end{abstract}

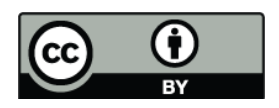

Correspondence to: G. W. Mann (gmann@env.leeds.ac.uk) ing a range of environments and against vertical profiles of size-resolved particle concentrations over Europe. The simulated global burden, lifetime and wet removal of each of the simulated aerosol components is also examined and each lies close to multi-model medians from the AEROCOM model intercomparison exercise.

\section{Introduction}

Aerosol particles play an important role in the Earth's climate system directly by scattering and absorbing short-wave and long-wave radiation and indirectly by affecting the albedo and lifetime of clouds (Forster et al., 2007). Successive IPCC climate assessment reports (e.g. Forster et al., 2007) have identified the indirect radiative forcing of aerosols as having a high level of uncertainty that needs to be better constrained for improved prediction of anthropogenic climate change.

Computational constraints mean that most climate models participating in the IPCC assessments have simulated aerosol in a simplified way, with schemes containing prognostic variables for mass, with particle number concentrations determined from an assumed fixed size distribution for prescribed externally mixed aerosol types (e.g. Jones et al., 2001; Reddy et al., 2005). Simulating processes that conserve particle number (e.g. aqueous sulfate production) with these first generation mass-only schemes is problematic since the fixed size distribution means that any increase in aerosol mass must be accompanied by an increase in particle number.

Aerosols indirectly affect climate via changes in cloud properties which are largely determined by changes in the

Published by Copernicus Publications on behalf of the European Geosciences Union. 
number concentration of aerosol particles large enough to activate to cloud droplets (cloud condensation nuclei, $\mathrm{CCN}$ ). Models using mass-only schemes cannot conserve particle number and may therefore unrealistically perturb cloud properties and autoconversion rates in some regions (through changes in $\mathrm{CCN}$ ), with possible associated biases in the simulated climate forcing. In addition, several studies (e.g. Haywood et al., 1997) have shown that accounting for the mixing of light-absorbing particle components with other aerosol material (e.g. sulfate) changes the simulated aerosol optical properties and direct radiative forcing.

Particle production in the atmosphere can be classified as either primary (e.g. carbonaceous particles from combustion sea-salt from bubble-bursting in the ocean, uplift of mineral dust) or secondary (e.g. nucleation of sulfuric acid and water). Several recent papers (e.g. Spracklen et al., 2008a; Merikanto et al., 2009) have shown the large contribution to global CCN from secondary particles.

A new generation of aerosol microphysics models have now been developed, which transport both particle number concentrations and component masses (e.g. sulfate, BC, etc.) in size classes, resolving differential particle growth and aerosol composition across the particle size range including internal mixtures. Implementing such schemes into climate models enables aerosol indirect effects to be simulated more realistically, including changes in both primary and secondary $\mathrm{CCN}$.

The most sophisticated of the aerosol microphysics models are sectional or bin-resolved, in which particle number concentration and component mass concentrations in each size class (bin) are transported, allowing the particle size distribution to evolve freely at the specified bin resolution. Although such schemes have been included in regional (e.g. Jacobson et al., 1997) and global aerosol models (e.g. Adams and Seinfeld, 2002; Spracklen et al., 2005), transported tracers often exceed 100, making the models too computationally expensive for use in coupled aerosol-climate simulations with current super-computing resource limits.

Realistic aerosol-climate models then require aerosol schemes with aerosol microphysics with dynamically varying particle size, but at a lower computational cost than sectional schemes. With the modal aerosol dynamics approach (e.g. Whitby and McMurray, 1997), the shape of the particle size distribution is parameterized as a series of lognormal modes, each covering defined regions of the particle radius range. Some aerosol models include 3-moment modal schemes in which mass, number and mode width (standard deviation) are variables (e.g. Debry et al., 2007). However most modal aerosol schemes in regional (Binkowski and Shankar, 1995; Ackermann et al., 1998) and global models (Ghan et al., 2001; Wilson et al., 2001; Liu et al., 2005; Lauer et al., 2005; Stier et al., 2005; Vignati et al., 2010) are doublemoment, with the mode width fixed and only mode number and component mass concentrations varying between gridboxes. A further simplification used in some modal aerosol schemes in global models (e.g. Wilson et al., 2001; Vignati et al., 2004; Stier et al., 2005) is to use a "pseudo-modal" aerosol dynamics approach, where the process rates for each mode are based on a particle size given by a single diameter rather than by integrating over the mode size range.

In this paper, we describe a new version of the GLobal Model of Aerosol Processes (GLOMAP) (e.g. Spracklen et al., 2005) which has the same aerosol microphysical processes as the multi-component bin-resolved version (e.g. Spracklen et al., 2008a) but uses a two-moment pseudomodal aerosol dynamics approach to reduce computational cost. This new version of GLOMAP (GLOMAP-mode) has been developed for longer integrations in the offline chemical transport model and for coupled composition-climate simulations in the latest UK Hadley Centre climate model HadGEM3. The UK Chemistry and Aerosol (UKCA) aerosol-chemistry sub-model (Morgenstern et al., 2009) of HadGEM3 has GLOMAP-mode as its aerosol scheme.

GLOMAP-mode has been used in several recent studies (Manktelow et al., 2007; Woodhouse et al., 2008, 2010; Schmidt et al., 2010), but the model description in these papers was necessarily brief. Here, GLOMAP-mode is described in detail, and evaluated against a series of observational datasets from the literature. Model skill is quantified in terms of normalised mean bias $(b)$ and correlation coefficient $(R)$. The benchmark datasets assembled here will also be used in the upcoming AEROCOM global aerosol microphysics model intercomparison and will help reduce biases and facilitate the documentation of improvements in future model versions. A companion paper (Mann et al., 2010) compares GLOMAP-mode against the sophisticated GLOMAP-bin scheme and explores the extent to which the simplifications degrade model skill against the observations.

\section{Model description}

GLOMAP is an extension of the TOMCAT global 3-D offline chemical transport model (CTM) (Chipperfield, 2006), resolving aerosol chemistry and microphysics. Size-resolved primary emissions, new particle formation, condensation, coagulation, cloud processing, dry deposition, sedimentation, nucleation scavenging and impaction scavenging are solved in an operator-split manner, while the gas phase chemistry and transport are calculated within the host CTM. The Gaussian grid associated with a T42 spectral transform (i.e. 2.8 degrees latitude/longitude) is used in the simulations here with 31 vertical levels on a hybrid $\sigma$-pressure co-ordinate.

Ambient conditions, atmospheric transport and large-scale precipitation rates are based on winds, temperatures and humidities from the European Centre for Medium-Range Weather Forecasts (ECMWF) model interpolated between successive 6-h global re-analysis fields. ECMWF re-analysis fields used in this paper are from ERA-40 for the year 2000. Tracer transport uses the Prather (1986) advection scheme, 
the Tiedtke (1989) convection scheme and a non-local closure scheme for boundary layer turbulence (Holtslag and Boville, 1993). For aqueous chemistry and cloud-processing, low cloud is specified from cloud top pressure and cloud fractions from the International Satellite Cloud Climatology Project (ISCCP) for the year 2000 (Rossow and Schiffer, 1999).

The original version of GLOMAP (Spracklen et al., 2005) uses a two-moment sectional approach, with typically 20 bins covering a $3 \mathrm{~nm}$ to $25 \mu \mathrm{m}$ particle dry diameter range. Initially only sulfate and sea-salt aerosol were included and assumed to behave as a single particle component, but the model now simulates several aerosol components in each internally mixed bin with several externally mixed distributions. For example, Spracklen et al. (2008a, b) and Merikanto et al. (2009) used two 20-bin distributions, the first representing fresh carbonaceous particles resolving black carbon (BC) and organic carbon (OC) components, and the second representing mixed composition bins whose mass consists of sulfate, BC, OC and sea-salt. Manktelow et al. (2009b) also resolved two distributions, one representing fresh dust-only particles, and a second mixed distribution with each bin containing sulfate, sea-salt, BC, OC and dust components. Other studies with the model have used just one mixed distribution, with Manktelow et al. (2009a) resolving bin-resolved sulfate, sea-salt, $\mathrm{BC}$ and $\mathrm{OC}$, and Pringle et al. (2009) and Korhonen et al. (2008a) each simulating just sulfate and sea-salt in each bin.

This work describes a new aerosol module for GLOMAP using the same process descriptions as the original sectional scheme but characterizing the aerosol in several log-normal modes rather than bins. The scheme can represent any number of modes (with fixed standard deviation) and possible components, but here follows the M7/HAM model (Vignati et al., 2004; Stier et al., 2005; Vignati et al., 2010) in carrying aerosol component masses and number concentrations in 7 modes (Table 3 ) using the "pseudo-modal" aerosol dynamics approach.

Although the aerosol dynamics framework used by GLOMAP-mode is the same as in M7/HAM, the aerosol process representations (primary emissions, dry deposition, sedimentation, scavenging, ageing, hygroscopic growth, nucleation, coagulation, condensation, cloud-processing) are those used by GLOMAP-bin (Spracklen et al., 2005, 2008a). The approaches in GLOMAP-mode for ageing (from Wilson et al., 2001) and hygroscopic growth (the ZSR method, Zadanovksii, 1948; Stokes and Robinson, 1966) are common to both GLOMAP-bin and M7/HAM. One area where there is a difference between GLOMAP-mode and GLOMAP-bin is in the treatment of aqueous chemistry. GLOMAP-mode uses an equilibrium Henry's law approach to calculate the dissolution of $\mathrm{SO}_{2}$ to cloud droplets (see Sect. 2.1.2) whereas GLOMAP-bin (Spracklen et al., 2005) uses a diffusionlimited approach. The impact of this and other simplifications in the model will be explored as part of the upcom-
Table 1. Gas phase chemistry used in GLOMAP-mode. An involatile organic species SEC-ORG is generated from MONOTER oxidation at $13 \%$ yield following reaction rates for $\alpha$-pinene.

\begin{tabular}{|c|c|}
\hline Reactions & Reference \\
\hline $\mathrm{DMS}+\mathrm{OH} \rightarrow \mathrm{SO}_{2}$ & Atkinson et al. (1989) \\
\hline $\mathrm{DMS}+\mathrm{OH} \rightarrow 0.6 \mathrm{SO}_{2}+0.4 \mathrm{DMSO}$ & Pham et al. (1995) \\
\hline $\mathrm{DMSO}+\mathrm{OH} \rightarrow 0.6 \mathrm{SO}_{2}+0.4 \mathrm{MSA}$ & Pham et al. (1995) \\
\hline $\mathrm{DMS}+\mathrm{NO}_{3} \rightarrow \mathrm{SO}_{2}$ & Atkinson et al. (1989) \\
\hline $\mathrm{CS}_{2}+\mathrm{OH} \rightarrow \mathrm{SO}_{2}+\mathrm{COS}$ & Pham et al. (1995) \\
\hline $\mathrm{COS}+\mathrm{OH} \rightarrow \mathrm{SO}_{2}$ & Pham et al. (1995) \\
\hline $\mathrm{SO}_{2}+\mathrm{OH}+\mathrm{M} \rightarrow \mathrm{H}_{2} \mathrm{SO}_{4}$ & Pham et al. (1995) \\
\hline MONOTER $+\mathrm{OH} \rightarrow 0.13$ SEC-ORG & Atkinson et al. (1989) \\
\hline MONOTER $+\mathrm{NO}_{3} \rightarrow 0.13$ SEC-ORG & Atkinson et al. (1989) \\
\hline MONOTER $+\mathrm{O}_{3} \rightarrow 0.13$ SEC-ORG & Atkinson et al. (1989) \\
\hline $\mathrm{HO}_{2}+\mathrm{HO}_{2} \rightarrow \mathrm{H}_{2} \mathrm{O}_{2}$ & Jones et al. (2001) \\
\hline
\end{tabular}

ing paper comparing GLOMAP-mode with GLOMAP-bin (Mann et al., 2010). The model description here refers to GLOMAP-mode version v1gm4c, used for the AEROCOM A2-CTRL simulation submitted in October 2009.

\subsection{Gas phase processes}

\subsubsection{Gas phase chemistry}

The aerosol precursor chemistry scheme used is shown in Table 1 with seven sulfur species (DMS, $\mathrm{SO}_{2}, \mathrm{H}_{2} \mathrm{SO}_{4}$, DMSO, MSA, COS and $\mathrm{CS}_{2}$ ), semi-prognostic $\mathrm{H}_{2} \mathrm{O}_{2}$, and secondary organic aerosol (SOA) produced via a condensing secondary organic species (SEC-ORG) from gas-phase oxidation of a terpene tracer (MONOTER). Dry and wet deposition of these species is included following the approach described in Giannakopoulos et al. (1999) with coefficients as in Spracklen et al. (2005).

As in previous GLOMAP papers, the "offline-oxidant" approach is used, with global fields of $\mathrm{OH}, \mathrm{NO}_{3}, \mathrm{O}_{3}, \mathrm{HO}_{2}$, $\mathrm{H}_{2} \mathrm{O}_{2}$ concentrations at each timestep being interpolations between monthly mean fields at 00:00, 06:00, 12:00, and 18:00 UT generated from a previous TOMCAT tropospheric chemistry simulation (Arnold et al., 2005). $\mathrm{H}_{2} \mathrm{O}_{2}$ is treated semi-prognostically, being depleted by aqueous reaction with $\mathrm{S}(\mathrm{IV})$ (see Sect. 2.1.2) and replenished by $\mathrm{HO}_{2}$ self-reaction up to an upper limit given by the background $\mathrm{H}_{2} \mathrm{O}_{2}$ concentration from the offline oxidant fields. Note that GLOMAP has now been coupled online to the TOMCAT tropospheric chemistry scheme (Breider et al., 2010) and this can be used as an alternative to the offline oxidant approach.

\subsubsection{Aqueous chemistry}

In gridboxes containing low-level clouds, $\mathrm{SO}_{2}$ and $\mathrm{H}_{2} \mathrm{O}_{2}$ dissolution into cloud droplets is calculated along with the heterogeneous chemical conversion of 
Table 2. Properties of the aerosol components used in the model. Note that although POM is listed as insoluble, an amount of water is associated with POM in soluble modes as described in Sect. 2.2.4.

\begin{tabular}{lllll}
\hline Component name & Abbreviation & $\begin{array}{l}\text { Density } \\
\left(\mathrm{kgm}^{-3}\right)\end{array}$ & $\begin{array}{l}\text { Molar mass } \\
\left(\mathrm{kgmol}^{-1}\right)\end{array}$ & Soluble? \\
\hline sulfate & SU & 1769.0 & 0.098 & Yes \\
sea-salt & SS & 1600.0 & 0.05844 & Yes \\
black carbon & BC & 1500.0 & 0.012 & No \\
particulate organic matter & POM & 1500.0 & 0.0168 & No \\
dust & DU & 2650.0 & 0.100 & No \\
water & WT & 1000.0 & 0.018 & - \\
\hline
\end{tabular}

$\mathrm{S}(\mathrm{IV})=\mathrm{SO}_{2} \cdot \mathrm{H}_{2} \mathrm{O}+\mathrm{HSO}_{3}^{-}+\mathrm{SO}_{3}^{2-}$ to $\mathrm{S}(\mathrm{VI})$ following an effective Henry's law approach, as described in Seinfeld and Pandis (1998). Henry's law coefficients for $\mathrm{SO}_{2}$ and $\mathrm{H}_{2} \mathrm{O}_{2}$ are calculated as:

$H_{i}(T)=H_{i, 298} \exp \left\{-\frac{\Delta H_{i}}{R}\left(\frac{1}{T}-\frac{1}{298}\right)\right\}$,

where $\quad H_{\mathrm{SO}_{2}, 298}=1.23 \mathrm{Matm}^{-1}$ and $\Delta H_{\mathrm{SO}_{2}}=$ $-26.1 \times 10^{3} \mathrm{~J} \mathrm{~mol}^{-1}, \quad H_{\mathrm{H}_{2} \mathrm{O}_{2}, 298}=7.45 \times 10^{4} \mathrm{Matm}^{-1}$ and $\Delta H_{\mathrm{H}_{2} \mathrm{O}_{2}}=60.7 \times 10^{3} \mathrm{~J} \mathrm{~mol}^{-1}$ and $R$ is the universal gas constant $=8.314 \mathrm{~J} \mathrm{~mol}^{-1} \mathrm{~K}^{-1}$. The rate of conversion of $\mathrm{S}(\mathrm{IV})$ to $\mathrm{S}(\mathrm{VI})$ via oxidation by $\mathrm{H}_{2} \mathrm{O}_{2}$ (in $\mathrm{Ms}^{-1}$ ) is then calculated as

$-\frac{d[\mathrm{~S}(\mathrm{IV})]}{\mathrm{d} t}=\frac{k_{1}\left[\mathrm{H}^{+}\right]\left[\mathrm{HSO}_{3}^{-}\right]\left[\mathrm{H}_{2} \mathrm{O}_{2}\right]}{1+k_{2}\left[\mathrm{H}^{+}\right]}$

where $k_{1}=7.5 \times 10^{7} \mathrm{M}^{-2} \mathrm{~s}^{-1}$, and $k_{2}=13 \mathrm{M}^{-1} . \quad \mathrm{H}_{2} \mathrm{O}_{2}$ dissociation is neglected, hence $\left[\mathrm{H}_{2} \mathrm{O}_{2}\right]=H_{\mathrm{H}_{2} \mathrm{O}_{2}}(T) p_{\mathrm{H}_{2} \mathrm{O}_{2}}$, where $p_{\mathrm{H}_{2} \mathrm{O}_{2}}$ is the partial pressure of $\mathrm{H}_{2} \mathrm{O}_{2}$. $\left[\mathrm{HSO}_{3}^{-}\right]$and [SO $\left.\mathrm{SO}_{3}^{2-}\right]$ are calculated as $K_{\mathrm{s}, 1} H_{\mathrm{SO}_{2}}(T) p_{\mathrm{SO}_{2}} /\left[\mathrm{H}^{+}\right]$and $K_{\mathrm{s}, 2}$ $\left[\mathrm{HSO}_{3}^{-}\right] /\left[\mathrm{H}^{+}\right]$, respectively, with $K_{\mathrm{s}, 1}$ and $K_{\mathrm{s}, 2}$ taken as $1.3 \times 10^{-2} \mathrm{M}$ and $6.6 \times 10^{-8} \mathrm{M}$. Capping at the available $\mathrm{SO}_{2}$ and $\mathrm{H}_{2} \mathrm{O}_{2}$, the production of $\mathrm{S}(\mathrm{VI})$ (in molecules $\mathrm{cm}^{-3} \mathrm{~s}^{-1}$ ) is given by

$\Delta S_{\text {cloud }}=F\left(\frac{d[\mathrm{~S}(\mathrm{IV})]}{\mathrm{d} t}\right) \cdot L \cdot N_{\mathrm{a}} \cdot \frac{1}{\rho_{\mathrm{W}}}$.

where $F$ is the cloud fraction, $L$ is the cloud liquid water content (assumed constant at $0.0002 \mathrm{~kg} \mathrm{~m}^{-3}$, typical of stratocumulus cloud), $N_{\mathrm{a}}$ is Avogadro's constant, and $\rho_{\mathrm{w}}$ is the density of water.

Production of $\mathrm{S}(\mathrm{VI})$ by aqueous oxidation of $\mathrm{S}(\mathrm{IV})$ by $\mathrm{O}_{3}$ is also calculated following Seinfeld and Pandis (1998) as:

$$
-\frac{d[\mathrm{~S}(\mathrm{IV})]}{\mathrm{d} t}=\left[\mathrm{O}_{3}\right]\left(k_{3} \mathrm{SO}_{2} \cdot \mathrm{H}_{2} \mathrm{O}+k_{4}\left[\mathrm{HSO}_{3}^{-}\right]+k_{5}\left[\mathrm{SO}_{3}^{2-}\right]\right)
$$

where $k_{3}=2.4 \times 10^{4} \mathrm{M}^{-1} \mathrm{~s}^{-1}$, and $k_{4}=3.7 \times 10^{5} \mathrm{M}^{-1} \mathrm{~s}^{-1}$ and $k_{5}=1.5 \times 10^{9} \mathrm{M}^{-1} \mathrm{~s}^{-1}$. Henry's law constants for ozone are calculated with $H_{\mathrm{O}_{3}, 298}=1.13 \times 10^{-2} \mathrm{Matm}^{-1}$ and $\Delta H_{\mathrm{O}_{3}}=-21.1 \times 10^{3} \mathrm{~J} \mathrm{~mol}^{-1}$. Unlike $\mathrm{H}_{2} \mathrm{O}_{2}$, ozone is not depleted in the model, since concentrations are not significantly reduced. Also, whereas in-cloud S(IV) oxidation by $\mathrm{H}_{2} \mathrm{O}_{2}$ has only a weak $\mathrm{pH}$-dependence, oxidation by ozone is strongly dependent on cloud $\mathrm{pH}$. The cloud $\mathrm{pH}$ is set to 4.0 or 5.0 depending on whether the local $\mathrm{SO}_{2}$ concentration is greater or less than $0.5 \mathrm{ppbv}$ as in Manktelow (2008).

Dissolved sulfate mass produced by these two aqueous reactions is partitioned between the soluble accumulation and coarse modes according to the ratio of their respective number concentrations to their sum (see Sect. 2.2.10).

\subsubsection{Sulfuric acid vapour}

The concentration of sulfuric acid vapour is a critical parameter in determining the binary nucleation rate in the model and hence on the rate of production of secondary particles. As described in Spracklen et al. (2005), GLOMAP includes a number of "competition sub-steps" within one chemistry time-step, where condensation and nucleation compete for the available $\mathrm{H}_{2} \mathrm{SO}_{4}$ vapour. Here, the production rate of condensable gases $\left(\mathrm{H}_{2} \mathrm{SO}_{4}\right.$ and SEC-ORG) calculated from the gas phase chemistry module is passed to the aerosol routines and their concentrations are only updated here on this shorter timestep, alongside condensation, coagulation and nucleation. For the simulations here 5 competition substeps are used within a chemistry time-step of $900 \mathrm{~s}$, which Spracklen (2005) found sufficient to adequately capture the competition between these processes.

\subsubsection{Trace gas emissions}

The model includes emissions of DMS from marine phytoplankton, $\mathrm{SO}_{2}$ from volcanoes, vegetation fires, industry, fossil-fuel and bio-fuel burning, and terpenes from vegetation. The DMS emission flux is updated every $6 \mathrm{~h}$ us(4) ing monthly sea-water DMS concentration fields from Kettle and Andreae (2000) driven by the ECMWF winds and the sea-air exchange parameterization from Nightingale et al. (2000). Anthropogenic $\mathrm{SO}_{2}$ emissions follow Cofala et al. (2005) (including industrial, power-plant, road-transport, 
Table 3. Standard aerosol configuration for GLOMAP-mode.

\begin{tabular}{llrlll}
\hline Index & Name & \multicolumn{1}{l}{ Size range } & Composition & Soluble? & $\sigma_{\mathrm{g}}$ \\
\hline 1 & Nucl-sol & $\bar{D}<10 \mathrm{~nm}$ & SU, POM & Yes & 1.59 \\
2 & Aitken-sol & $10<\bar{D}<100 \mathrm{~nm}$ & SU, BC, POM & Yes & 1.59 \\
3 & accum-sol & $100<\bar{D}<1 \mu \mathrm{m}$ & SU, BC, POM, SS, DU & Yes & 1.59 \\
4 & coarse-sol & $\bar{D}>1 \mu \mathrm{m}$ & SU, BC, POM, SS, DU & Yes & 2.0 \\
5 & Aitken-ins & $10<\bar{D}<100 \mathrm{~nm}$ & BC, POM & No & 1.59 \\
6 & accum-ins & $100<\bar{D}<1 \mu \mathrm{m}$ & DU & No & 1.59 \\
7 & coarse-ins & $\bar{D}>1 \mu \mathrm{m}$ & DU & No & 2.0 \\
\hline
\end{tabular}

off-road-transport and shipping sectors) and are representative of the year 2000. Volcanic $\mathrm{SO}_{2}$ from continuously (Andres and Kasgnoc, 1998) and explosively eruptive (Halmer et al., 2002) sources are included with injection heights following recommendations in Dentener et al. (2006) based on individual volcano-top altitudes. Monthly-varying biomass burning $\mathrm{SO}_{2}$ emissions are also included following GFED v1 (Van der Werf et al., 2003) for the year 2000, segregated into six altitude ranges $0-100 \mathrm{~m}, 100-500 \mathrm{~m}, 500 \mathrm{~m}-1 \mathrm{~km}$, $1-2 \mathrm{~km}, 2-3 \mathrm{~km}$ and 3-6 km as in AEROCOM (see Dentener et al., 2006). We also follow AEROCOM recommendations in assuming that $2.5 \%$ of the $\mathrm{SO}_{2}$ mass is emitted as primary sulfate particles (with size assumptions as modified by Stier et al., 2005). Monthly terpene emissions follow Guenther et al. (1995) and feed into the MONOTER tracer (see Sect. 2.1.1).

\subsection{Aerosol processes}

The prognostic variables in the aerosol model are the particle number concentration for each mode and the mass concentration of each component (sulfate, sea-salt, BC, OC, dust) present in each mode. The modes represent a dry diameter size range and can be water-soluble or insoluble. The size distribution is described by lognormal modes with geometric mean diameter $\bar{D}$ covering the nucleation $(\bar{D}<10 \mathrm{~nm})$, Aitken $(10-100 \mathrm{~nm})$, accumulation (100$1000 \mathrm{~nm})$ and coarse $(\bar{D}>1000 \mathrm{~nm})$ mode ranges.

The geometric mean dry diameter $\bar{D}_{i}$ for mode $i$ is calculated as:

$\bar{D}_{i}=\left(\frac{6 V_{\mathrm{dry}, i}}{\pi \exp \left(4.5 \log ^{2} \sigma_{\mathrm{g}, i}\right)}\right)^{\frac{1}{3}}$

where $V_{\mathrm{dry}, i}$ is the total dry volume for mode $i$ over all aerosol components $j$ :

$V_{\mathrm{dry}, i}=\sum_{j=1}^{\mathrm{ncp}}\left(\frac{m_{i j} M_{j}}{N_{\mathrm{a}} \rho_{j}}\right)$.

$m_{i j}$ is the number of molecules per particle of component $j$ in mode $i, \rho_{j}$ and $M_{j}$ are the density and molar mass of component $j$ and $N_{\mathrm{a}}$ is Avogadro's constant. The mode geometric standard deviations $\sigma_{\mathrm{g}, i}$ are assumed constant whilst the geometric mean diameter $\bar{D}_{i}$ can vary between the size ranges shown for each mode (see Table 3). Particle number and mass are transferred between modes when $\bar{D}$ exceeds the upper limit for the mode (see Sect. 2.2.9), referred to as mode-merging. In this subsection the aerosol processes are described. The model microphysics quantifies size-resolved and composition-resolved primary emissions, aerosol dry deposition, nucleation scavenging, impaction scavenging, coagulation, condensation, nucleation, cloud processing and hygroscopic growth. The process representations follow as closely as possible the methods applied for GLOMAP-bin with variations where necessary for the modal approach.

\subsubsection{Primary aerosol emissions}

Although the aerosol tracers are based on log-normal modes, primary emissions in GLOMAP-mode retain the binresolved fluxes from the sectional scheme (Spracklen et al., 2006). The emitted mass in each bin updates $n_{i}$ and $m_{i j}$ for the mode whose size range spans the dry radius of the emissions-bin.

Primary carbonaceous aerosol emissions are speciated to $\mathrm{BC}$ and $\mathrm{OC}$ with annual-mean fluxes for fossil-fuel and biofuel sources (Bond et al., 2004) and monthly-varying fluxes for biomass burning (Van der Werf et al., 2003). The AEROCOM recommended size settings are used, with modifications as in Stier et al. (2005), with geometric mean diameter for the emissions fluxes set at 150 and $60 \mathrm{~nm}$ for biomass/biofuel and fossil fuel respectively, with geometric standard deviation fixed at 1.59 for both emissions modes. Fossil fuel and bio-fuel emissions are added to the lowest model layer whereas biomass burning emissions are emitted in 6 altitude ranges between the surface and $6 \mathrm{~km}$ as described in Dentener et al. (2006).

Size-resolved emissions of mineral dust can be included in the model via two alternative wind-speed-driven emissions parameterizations (described in Pringle, 2006 and Manktelow et al., 2009b) or via prescribed daily-varying emissions fluxes provided for AEROCOM (Dentener et al., 2006). 
The AEROCOM prescribed emissions fluxes are used here, which are based on bin-resolved fluxes from the NASA Goddard Earth Observing System Data Assimilation System (Ginoux et al., 2001). For AEROCOM, the bin-resolved fluxes were mapped onto two emissions modes covering the accumulation and coarse size ranges with assumed standard deviations at 1.59 and 2.0, respectively.

Bin-resolved sea-salt emissions fluxes are calculated from a sea-spray source function of Gong (2003) as in Spracklen et al. (2005) with bins with dry diameters larger/smaller than 1 micron emitted into the soluble accumulation/coarse modes respectively.

\subsubsection{Aerosol dry deposition and sedimentation}

GLOMAP-mode follows the same approach as in Spracklen et al. (2005), calculating a dry deposition velocity $V_{\mathrm{d}}$ following Slinn (1982):

$V_{\mathrm{d}}=V_{\text {grav }}+\frac{1}{R_{\mathrm{a}}+R_{\mathrm{s}}}$.

The aerodynamic resistance $R_{\mathrm{a}}$ is calculated as

$R_{\mathrm{a}}=\frac{1}{k u_{*}} \log \left(\frac{z}{z_{0}}\right)$,

where $k$ is the von Karman constant, $z_{0}$ is the surface roughness length and $u_{*}$ is the surface friction velocity. Surface resistance $R_{\mathrm{S}}$ is given by

$R_{\mathrm{s}}=\frac{1}{3 u_{*}\left(E_{\mathrm{b}}+E_{\mathrm{im}}+E_{\mathrm{in}}\right)}$

where $E_{\mathrm{b}}, E_{\mathrm{im}}$ and $E_{\mathrm{in}}$ are collection efficiencies for Brownian diffusion, impaction and interception, calculated following Zhang et al. (2001). The collection efficiency for Brownian diffusion is size-dependent and is calculated as

$E_{\mathrm{b}}=S c^{Y_{\mathrm{r}}}$,

where $Y_{\mathrm{r}}$ is a surface-type dependent parameter and $S c$ is the particle Schmidt number:

$S c=\frac{v}{D_{\text {coff }}}$

with $v$ being the kinematic viscosity of air. The particle diffusion coefficient $D_{\text {coff }}$ is calculated as:

$D_{\text {coff }}=\frac{k_{\mathrm{B}} T}{3 \pi \mu D_{\mathrm{p}}} C_{\mathrm{f}}$

where $k_{\mathrm{B}}$ is Boltzmann's constant, $D_{\mathrm{p}}$ is the particle diameter and $\mu$ is the dynamic viscosity of air. The slip correction factor $C_{\mathrm{f}}$ is calculated as:

$C_{\mathrm{f}}=1+\frac{2 \lambda_{\mathrm{a}}}{D_{\mathrm{p}}}\left\{A+B \exp \left(C \frac{\lambda_{\mathrm{a}}}{D_{\mathrm{p}}}\right)\right\}$,

where $\lambda_{\mathrm{a}}$ is the mean free path of air molecules and $A, B$ and $C$ take the values $1.246,0.5$ and -0.55 .
The collection efficiency for impaction is also sizedependent and is calculated as

$E_{\mathrm{im}}=\frac{S n}{\alpha+S n}$

where $\alpha$ is a surface-type dependent parameter and $S n$ is the Stokes number, calculated as $S n_{\text {smooth }}$ and $S n_{\text {rough }}$ for smooth and vegetated surfaces:

$$
\begin{aligned}
S n_{\text {smooth }} & =\frac{V_{\text {grav }} u_{*}^{2}}{\mu} \\
S n_{\text {rough }} & =\frac{V_{\text {grav }} u_{*}}{g C_{\mathrm{r}}}
\end{aligned}
$$

where $C_{\mathrm{r}}$ is a surface-type dependent coefficient. Lastly, the collection efficiency by interception is calculated as

$E_{\text {in }}=0.5 \frac{D_{\mathrm{p}}^{2}}{C_{\mathrm{r}}^{2}}$.

Gravitational settling velocity $V_{\text {grav }}$ is calculated as

$V_{\text {grav }}=\frac{\rho_{\mathrm{p}} D_{\mathrm{p}}^{2} g}{18 \mu} C_{\mathrm{f}}$,

where $\rho_{\mathrm{p}}$ is the particle density, $D_{\mathrm{p}}$ is the mode geometric mean (wet) diameter, $g$ is the gravitational acceleration and $\mu$ is the dynamic viscosity of air

The removal of each mode's number and component masses are calculated using the 0th and 3rd moment averages for the two size-dependent parameters $V_{\text {grav }}$ and $D_{\text {coff }}$ calculated following the expressions in Binkowski and Shankar (1995):

$$
\begin{aligned}
V_{\text {grav }, k} & =V_{\text {grav }}\left\{\exp \left(\frac{(4 k+4)}{2} \log ^{2} \sigma_{\mathrm{g}}\right)\right. \\
& \left.+1.246 \frac{2 \lambda_{\mathrm{a}}}{D_{\mathrm{p}}} \exp \left(\frac{(2 k+1)}{2} \log ^{2} \sigma_{\mathrm{g}}\right)\right\}
\end{aligned}
$$

and

$$
\begin{aligned}
D_{\text {coff }, k} & =D_{\text {coff }}\left\{\exp \left(\frac{(-2 k+1)}{2} \log ^{2} \sigma_{\mathrm{g}}\right)\right. \\
& \left.+1.246 \frac{2 \lambda_{\mathrm{a}}}{D_{\mathrm{p}}} \exp \left(\frac{(-4 k+4)}{2} \log ^{2} \sigma_{\mathrm{g}}\right)\right\},
\end{aligned}
$$

with $D_{\mathrm{p}}$ the geometric mean (wet) diameter and $k$ the index of the moment.

Sedimentation from the lowest grid level is handled in the dry deposition expression above, whereas for other levels, sedimentation is applied using $V_{\text {grav }, k}$ following a 1 st order explicit scheme calculating fluxes of number and mass into and out of each box. Sedimentation is limited to only half a gridbox per timestep to ensure the Courant-Fredrichs-Levy condition is satisfied. 


\subsubsection{Aerosol scavenging}

Removal by nucleation scavenging is calculated for both large-scale and convective-scale precipitation based on rainrates diagnosed from successive ECMWF analysis fields. As in Spracklen et al. (2005), large-scale rain removes particles at a constant rate equivalent to $99.9 \%$ conversion of cloud water to rain over $6 \mathrm{~h}$. For convective-scale rain, the cloud-torainwater conversion rate is given by the Tiedtke et al. (1989) convection parameterization and removal is applied assuming a raining fraction of 0.3 . Note that nucleation scavenging only occurs where the precipitation is formed in that model level, determined by comparing the calculated rain-rate with that in the level above. Whereas in GLOMAP-bin, the rainout is applied to all particles larger than $103 \mathrm{~nm}$ dry radius in the mixed (soluble) distribution, in GLOMAP-mode this approach is approximated by only allowing the soluble accumulation and coarse to be subject to the process.

Impaction scavenging of aerosol via collection by falling raindrops is also simulated in the model in an analogous way to GLOMAP-bin. A look-up table for raindrop-aerosol collection efficiencies is used based on the geometric mean dry radius of the mode and a Marshall-Palmer raindrop size distribution as modified by Sekhon and Srivastava (1971) to take into account rainfall intensity. As in GLOMAP-bin, an empirical relationship from Easter and Hales (1984) is used to calculate the raindrop terminal velocity.

\subsubsection{Hygroscopic growth}

For each aerosol mode, water uptake by each component is calculated according to ZSR (Zadanovksii, 1948; Stokes and Robinson, 1966) using data from Jacobson et al. (1996) to calculate the binary electrolyte molalities. Any mass of POM present in the insoluble modes must be primary emitted material and is assumed to be non-hygroscopic. In soluble modes, POM is either secondary or primary organic material that has been aged. Hence we assign moderate hygroscopicity to POM in the soluble modes consistent with a water uptake per mole at $65 \%$ of sulfate assuming a molar mass of $0.15 \mathrm{~kg} / \mathrm{mol}$ for the aged organic molecule.

The density $\rho$ for each mode is calculated as a molar weighted mean of the aerosol components and water:

$\rho=\frac{\sum m_{i j} M_{j} \rho_{j}}{\sum m_{i j} M_{j}}$

where $m_{i j}, M_{j}$ and $\rho_{j}$ are respectively the molecules per particle, molar mass, and density of each aerosol component $j$ (including water) as given in Table 2.

The geometric mean wet diameter $D_{\text {wet }, i}$ of each mode $i$ is calculated as

$D_{\text {wet }, i}=\left(\frac{6}{\pi X_{i}} \sum V_{i j}\right)^{\frac{1}{3}}$ where $X_{i}=\exp \left(\frac{9}{2}\left\{\log \sigma_{\mathrm{g}, i}\right\}^{2}\right)$ and $V_{i j}$ are the partial volumes for each component and water calculated as:

$V_{i j}=\frac{m_{i j} M_{j}}{N_{\mathrm{a}} \rho_{X, i}}$

where $N_{\mathrm{a}}$ is Avogadro's constant and $\rho_{X, i}$ is the density of the solution for soluble components (and water) or the component densities listed in Table 2 for insoluble components.

\subsubsection{Nucleation of new sulfate aerosol}

The nucleation rate $J$ used to produce new particles in the nucleation mode follows Kulmala et al. (1998) as:

$J=\exp \left\{A \log \left(\frac{S}{S_{\text {crit }}}\right)+B X_{\mathrm{al}}+C\right\}$,

where $S$ is the molecular concentration of sulfuric acid vapour, $X_{\mathrm{al}}$ is the sulfuric acid mole fraction at the critical radius $(=D+0.012 \log S)$, and $S_{\text {crit }}$ is the value of $S$ above which nucleation occurs, calculated as

$S_{\text {crit }}=\exp \left(-14.5125+0.1335 T-10.5462 \mathrm{rh}+1958.4 \frac{\mathrm{rh}}{T}\right)$,

where $T$ is the air temperature and rh is the relative humidity (between 0 and 1 ). The coefficients $A, B, C$ and $D$ are calculated as in Kulmala et al. (1998). The rate of change of sulfuric acid vapour concentration due to nucleation is then in the form of a power law relationship

$\frac{\mathrm{d} S}{\mathrm{~d} t}_{\text {nucl }}=-n_{\mathrm{mol}} a S^{b}$

where $a$ and $b$ are given by

$a=\exp (B D+C)\left(\frac{1}{S_{\text {crit }}}\right)^{A}$

$b=A+0.0102 B$.

Equation (26) is then integrated to give

$S=\left\{S_{0}^{1-b}+a(b-1) n_{\mathrm{mol}} \Delta t\right\}^{\frac{1}{1-b}}$

and hence the change in sulfuric acid due to nucleation over time step $\Delta t$ is given by

$\Delta S_{\mathrm{nucl}}=S_{0}-\left\{S_{0}^{1-b}+a(b-1) n_{\mathrm{mol}} \Delta t\right\}^{\frac{1}{1-b}}$.

In the model, we follow Vignati et al. (2004) in calculating the change in the nucleation mode number concentration simultaneously with the change by coagulation, see Eq. (31) below. 


\subsubsection{Coagulation}

GLOMAP-mode includes both intra-modal (collisions of particles in the same mode) and inter-modal (collisions of particles in different modes) coagulation. For the soluble modes, the model simulates intra-modal coagulation and inter-modal coagulation with larger soluble modes and with larger insoluble modes. For the nucleation mode, the source of particles due to nucleation is also included. So the rate of change in particle number concentration $n_{i}$ in the four soluble modes $(i=1,2,3,4)$ can be expressed as:

$$
\frac{\mathrm{d} n_{i}}{\mathrm{~d} t}=-\frac{1}{2} K_{i i} n_{i}^{2}-n_{i}\left\{\sum_{j=i+1}^{4} K_{i j} n_{j}+\sum_{j=i+4}^{7} K_{i j} n_{j}\right\}+\delta_{i 1} \frac{\Delta S_{\text {nucl }}}{\Delta t n_{\text {mol }}}
$$

where $\delta_{i j}$ is the delta function, $K_{i j}$ is the coagulation kernel, $\Delta S_{\text {nucl }}$ is the change in sulfuric acid concentration due to nucleation over the time step $\Delta t$ (see Sect. 2.2.5) and $n_{\text {mol }}$ is the number of sulfuric acid molecules in a newly nucleated sulfuric acid particle (assumed to be 100 as in Spracklen et al., 2005).

For the insoluble modes $(i=5,6,7)$, only inter-modal coagulation with larger soluble modes is included $(j=i-2$ to 4 ) and the aerosol dynamic equation is

$\frac{\mathrm{d} n_{i}}{\mathrm{~d} t}=-\frac{1}{2} K_{i i} n_{i}^{2}-n_{i}\left\{\sum_{j=i-2}^{4} K_{i j} n_{j}\right\}$.

The coagulation kernel is calculated as in Spracklen et al. (2005) following Seinfeld and Pandis (1998):

$$
K_{i j}=\frac{4 \pi\left(\bar{r}_{i}+\bar{r}_{j}\right)\left(D_{i}+D_{j}\right)}{\frac{\bar{r}_{i}+\bar{r}_{j}}{\bar{r}_{i}+\bar{r}_{j}+\left(\Delta_{i}^{2}+\Delta_{j}^{2}\right)^{0.5}}+\frac{4\left(D_{i}+D_{j}\right)}{\left(v_{i}^{2}+v_{j}^{2}\right)^{0.5}\left(\bar{r}_{i}+\bar{r}_{j}\right)}},
$$

where the diffusion coefficients $D_{i}, D_{j}$ are calculated explicitly for each mode as in Eq. (12) and the parameters $\Delta_{i}, \Delta_{j}$ are calculated as:

$\Delta_{i}=\frac{\left(2 \bar{r}_{i}+\lambda_{i}\right)^{3}-\left(4 \bar{r}_{i}^{2}+\lambda_{i}^{2}\right)^{\frac{3}{2}}}{6 \bar{r}_{i} \lambda_{i}}-2 \bar{r}_{i}$.

The particle mean free paths $\lambda_{i}, \lambda_{j}$ for modes $i, j$ are calculated as

$\lambda_{i}=\frac{8}{\pi} \frac{D_{i}}{v_{i}}$,

where $v_{i}$ is the mean thermal velocity for particles in mode $i$ :

$$
v_{i}=\left(\frac{8 k_{\mathrm{B}} T}{\pi \rho_{i} V_{i}}\right)^{\frac{1}{2}}
$$

and $V_{i}$ is the mean wet volume for each mode given by the sum of the component partial volumes including water. Note that $\bar{r}_{i}=0.5 \bar{D}_{\text {wet }}$, as calculated in Sect. 2.2.4.
Equations (31) and (32) are both of the form

$\frac{\mathrm{d} n_{i}}{\mathrm{~d} t}=a n_{i}^{2}+b n_{i}+c$

with $a$ (negative or zero) referring to intra-modal coagulation in the mode, $b$ (negative or zero) referring to the sum over all inter-modal coagulation from the mode to another mode and $c$ (positive or zero) referring to nucleation of new sulfate aerosol. Coefficients $a, b$ and $c$ are independent of $n_{i}$, and although $b$ depends on $n_{j}$, it is calculated based on the number concentration at the start of the timestep. With this approach, both equations can then be solved analytically by evaluating the indefinite integral

$\int_{n_{0}}^{n} \frac{d x}{X}=\int_{0}^{\Delta t} \mathrm{~d} t=\Delta t$

where $X=a x^{2}+b x+c$. Two differing solutions are applied following Bronshtein and Semendyayev (1998) for cases where $\delta=4 a c-b^{2}$ is greater or less than zero. For $\delta>0$,

$\int \frac{d x}{X}=\frac{1}{(-\delta)^{0.5}} \log \left(\frac{2 a x+b-(-\delta)^{0.5}}{2 a x+b+(-\delta)^{0.5}}\right)$,

which reduces to

$n=\frac{1}{2 a}\left\{\frac{2(-\delta)^{0.5}}{1-\frac{\exp \left((-\delta)^{0.5} \Delta t\right)}{\left(\frac{2 a n_{0}+b+(-\delta)^{0.5}}{2 a n_{0}+b-(-\delta)^{0.5}}\right)}}-b+(-\delta)^{0.5}\right\}$.

For $\delta>0$, the solution is

$\int \frac{d x}{X}=\frac{2}{(\delta)^{0.5}} \arctan \left(\frac{2 a x+b}{(\delta)^{0.5}}\right)$

which reduces to

$n=\frac{1}{2 a}\left\{(\delta)^{0.5} \tan \left(\arctan \left(\frac{2 a n_{0}+b}{(\delta)^{0.5}}\right)+\frac{(\delta)^{0.5} \Delta t}{2}\right)-b\right\}$.

Where $a$ is zero (only inter-modal coagulation) in the $\delta<0$ case,

$\frac{\mathrm{d} n}{\mathrm{~d} t}=b n+c$

with solution

$n=\frac{\left(b n_{0}+c\right) \exp (b \Delta t)-c}{b}$,

which, in the absence of nucleation $(c=0)$, reduces to

$n=n_{0} \exp (b \Delta t)$

In the case where coagulation is switched off completely $(a=0, b=0), \delta=0$ and the simple equation

$n=n_{0}+c \Delta t$ 
is used. If $\delta=0$ and $a<0, b=0$ (i.e. only intra-modal coagulation), Eq. (38) becomes

$\frac{\mathrm{d} n}{\mathrm{~d} t}=a n^{2}$

which has solution

$n=\frac{1}{\frac{1}{n_{0}}-3 a \Delta t}$.

For each of the modes, coefficients $a$ and $b$ are calculated based on the sum over all coagulation included and the updated particle number concentrations for each mode are calculated. The inter-modal coagulations of each mode $i$ with larger modes $j$ (which combine to give the coefficient $b$ ) are stored to an array $b_{i j}=-K_{i j} n_{j}$ and the masses of each component $k$ to be exported calculated as

$\mu_{i j, k}=n_{0, i} m_{0, i k} \exp \left(-b_{i j} \Delta t\right)$

where $n_{0, i}$ is the number concentration and $m_{0, i k}$ the molecules per particle of component $k$ for mode $i$ at the start of the solving routine.

For each mode $i$, a total inter-modal coagulation export flux of each component mass $k$ is then calculated $\left(\mu_{i k,-}=\right.$ $\left.\Sigma_{j} \mu_{i j, k}\right)$. Each of the individual $i-j$ export fluxes $\left(\mu_{i j k}\right)$ are transferred to a receiver-mode whose index $l$ is set according to a "rules" array $l=l(i, j)$ which specifies which mode each $i-j$ inter-modal coagulation should be transferred to. The array $l$ is needed since mass coagulating onto insoluble modes is actually transferred directly to the corresponding soluble mode to account for ageing. Although insoluble modes do not receive any mass of soluble components, soluble-to-insoluble coagulation fluxes are stored and passed to the ageing routine where the coating of insoluble particles is determined by the total accommodation of soluble material in each timestep (see Sect. 2.2.8). The component mass concentrations in each mode are then updated due to the net mass transfer from the export and import fluxes described above. For the nucleation mode, there is no import by coagulation but the nucleated sulfate mass from Eq. (30) is added here.

\subsubsection{Condensation}

Condensation of $\mathrm{H}_{2} \mathrm{SO}_{4}$ and SEC-ORG onto all aerosol modes is simulated with the rate of change in molecular concentration $S$ given by

$\frac{\mathrm{d} S}{\mathrm{~d} t}$ cond $=-\left(\sum_{i=1,7} C_{i} n_{i}\right) S$

where $n_{i}$ is the particle number concentration and $C_{i}$ is the condensation coefficient for mode $i$, the latter calculated following Fuchs and Sutugin (1971) with correction factors $F(K n)$ for molecular effects and $A(K n)$ for limitations in interfacial mass transport:

$C_{i}=4 \pi D_{\mathrm{s}} \bar{r}_{i} F\left(K n_{i}\right) A\left(K n_{i}\right)$

$$
\begin{aligned}
F\left(K n_{i}\right) & =\frac{1+K n_{i}}{1+1.71 K n_{i}+1.33\left(K n_{i}\right)^{2}}, \\
A\left(K n_{i}\right) & =\frac{1}{1+1.33 K n_{i} F\left(K n_{i}\right)\left(\frac{1}{s}-1\right)} .
\end{aligned}
$$

$s$ is the accommodation coefficient (sticking efficiency) and $K n_{i}$ is the Knudsen number for mode $i$ given by

$K n_{i}=\frac{\lambda_{\mathrm{s}, \mathrm{a}, \mathrm{p}}}{\bar{r}_{i}}$

where $\bar{r}_{i}$ is the geometric mean (wet) radius for the mode as in Sect. 2.2.6 and $\lambda_{\mathrm{s}, \mathrm{a}, \mathrm{p}}$ is the mean free path of sulfuric acid vapour in a binary mixture with air,

$\lambda_{\mathrm{s}, \mathrm{a}, \mathrm{p}}=\frac{1}{\pi\left(1+\frac{M_{\mathrm{s}}}{M_{\mathrm{air}}}\right)^{0.5} N_{\mathrm{air}} D_{\mathrm{s}}^{2}}$.

Note that $s$ is set to 1 for the soluble modes (hence $A(K n)=1)$ and to 0.3 for the insoluble modes. The diffusion coefficient of $\mathrm{H}_{2} \mathrm{SO}_{4}$ and SEC-ORG in binary mixture with air are calculated as

$D_{\mathrm{s}}=\left(\frac{3}{8 N_{\mathrm{a}} D_{\mathrm{p}}^{2} \rho_{\mathrm{a}}}\right)\left\{\left(\frac{R T M_{\mathrm{air}}^{2}}{2 \pi}\right)\left(1+\frac{M_{\mathrm{air}}}{M_{\mathrm{s}}}\right)\right\}^{0.5}$.

The $\mathrm{SO}_{4}$ and POM component masses (and mode geometric mean radii) are then updated on the competition timestep according to the mass of $\mathrm{H}_{2} \mathrm{SO}_{4}$ and SEC-ORG condensing onto each mode. The two-moment scheme holds particle number concentration constant and hence condensation grows particles via the new $\bar{D}$ calculated by Eq. (5). The mass of $\mathrm{SO}_{4}$ and $\mathrm{POM}$ resulting from condensation of $\mathrm{H}_{2} \mathrm{SO}_{4}$ and SEC-ORG onto each insoluble mode on each timestep is stored and passed to the ageing routine (see below).

\subsubsection{Ageing}

Ageing is the process by which water-insoluble particles can become partly soluble by condensation of $\mathrm{H}_{2} \mathrm{SO}_{4}$ and SECORG and by accommodation of soluble material through inter-modal coagulation of particles from smaller soluble modes.

For each insoluble mode, the total flux of soluble material per timestep is calculated based on the stored mass fluxes from the coagulation and condensation routines. A particle ageing rate is then calculated which transfers a fraction of the particles in the mode to the corresponding soluble mode. The fraction is calculated consistent with a defined number of monolayers coating (here, assumed to be 10) being required to make a particle soluble. Note that in the model, the flux of soluble material to the insoluble modes is actually passed to the corresponding soluble mode, ensuring that the ageing process only changes the number concentration of the insoluble modes, leaving their size and composition unchanged. 
Table 4. Annual mean global mass burden, production fluxes and lifetime for each simulated aerosol precursor gas. For the sulfur species the mass is of sulfur (multiply by 1.94, 2, 3.06 for mass of DMS, $\mathrm{SO}_{2}$ and $\mathrm{H}_{2} \mathrm{SO}_{4}$, respectively), whereas for the organic species the mass is of carbon (multiply by 11.3 and 12.5 for mass of terpenes and condensable organic). The range shown in parentheses for $\mathrm{DMS}$ and $\mathrm{SO}_{2}$ are based on the literature values listed in Spracklen et al. (2005) except for the DMS conversion to $\mathrm{SO}_{2}$ which is based on the DMS oxidation fluxes to $\mathrm{SO}_{2}$ from Boucher et al. (2003) using a range of DMS climatologies, oxidant fields and sea-air transfer functions. For terpenes, the emissions total from Guenther et al. (1995) is shown in parentheses for reference. The (10-60 TgPOM/yr) range of SOA production quoted in Dentener et al. (2006) is also shown for reference.

\begin{tabular}{llccl}
\hline Species & $\begin{array}{l}\text { Burden } \\
(\mathrm{Tg})\end{array}$ & $\begin{array}{l}\text { Prod (prim) } \\
\left(\mathrm{Tg} \mathrm{a}^{-1}\right)\end{array}$ & $\begin{array}{l}\text { Prod }(\mathrm{sec}) \\
\left(\mathrm{Tg} \mathrm{a}^{-1}\right)\end{array}$ & $\begin{array}{l}\text { Lifetime } \\
(\text { days })\end{array}$ \\
\hline $\mathrm{DMS}$ & $0.027(0.02-0.15)$ & $18.1(10.7-23.7)$ & 0.0 & $0.6(0.5-3.0)$ \\
$\mathrm{SO}_{2}$ & $0.300(0.2-0.68)$ & $67.9(64.4-104.1)$ & $17.6(15.9-24.7)$ & $1.3(0.6-5.3)$ \\
$\mathrm{H}_{2} \mathrm{SO}_{4}$ & 0.0001 & 0.0 & $10.8(6.1-15.3)$ & 0.003 \\
$\mathrm{MONOTER}$ & 0.0078 & $146.2(127)$ & 0.0 & 0.02 \\
$\mathrm{SEC}-O R G$ & 0.0002 & 0.0 & $18.5(7.1-42.9)$ & 0.003 \\
\hline
\end{tabular}

Since the insoluble modes (see Table 3) are assumed to be non-hygroscopic and are not wet deposited via nucleation scavenging, the assumed monolayer thickness partially determines the timescale for wet removal of the $\mathrm{BC} / \mathrm{OC}$ and dust aerosol in the model.

\subsubsection{Mode-merging}

As described in Sects. 2.2.6 and 2.2.7, coagulation and condensation can increase the size of the modes. If this were allowed to continue indefinitely, the modes would eventually grow outside the specified ranges in Table 3. A modemerging approach is therefore used to prevent this problem.

After each call of the combined coagulation-nucleation subroutine, the mode-merging routine checks whether $\bar{D}$ is outside the range as in Table 3 , and if so, fractions $F_{\mathrm{n}}$ and $F_{\mathrm{m}}$ of the mode number and mass concentrations are transferred to the next largest mode as

$$
\begin{aligned}
& F_{\mathrm{n}}=1-0.5\left\{1+\operatorname{erf}\left(\frac{\log \left(\frac{r_{x}}{\bar{r}_{i}}\right)}{2^{0.5} \log \left(\sigma_{\mathrm{g}, i}\right)}\right)\right\} \\
& F_{\mathrm{m}}=1-0.5\left\{1+\operatorname{erf}\left(\frac{\log \left(\frac{r_{x}}{\exp \left\{\log \bar{r}_{i}+3\left(\log \sigma_{\mathrm{g}, i}\right)^{2}\right\}}\right)}{2^{0.5} \log \left(\sigma_{\mathrm{g}, i}\right)}\right)\right\}
\end{aligned}
$$

where $r_{x}$ is the upper limit for the mode and erf is the error function,

$\operatorname{erf}(x)=\frac{2}{\pi^{0.5}} \int_{0}^{x} \exp \left(-t^{2}\right) \mathrm{d} t$

\subsubsection{Cloud processing}

Cloud processing is defined here to be the growth of aerosol particles by uptake and chemical reaction of gases while the particles exist as water droplets in non-precipitating clouds. The process results in differential growth between activated and non-activated particles, creating a minimum in the particle size distribution (known as the Hoppel gap) defining the Aitken and accumulation modes which are frequently seen in observations of the size distribution in the marine boundary layer (e.g. Hoppel et al., 1994).

As described in Sect. 2.1.2, the model includes aqueous sulfate production in low level stratocumulus clouds. To simulate cloud-processing of aerosol, we follow Spracklen et al. (2005) in determining an activation dry radius $r_{\text {act }}$ which defines the smallest particles which are activated to cloud droplets. For the simulations shown here, $r_{\text {act }}$ is assumed to be globally constant at $37.5 \mathrm{~nm}$ dry radius, corresponding to a cloud supersaturation of $0.2 \%$ typical of marine stratocumulus clouds.

In the model, cloud processing is treated in two stages. First, the fractions of particle mass and number in the soluble Aitken mode from particles larger than $r_{\text {act }}$ is calculated (Eq. 57, with $r_{x}=r_{\text {act }}$ ) and transferred to the soluble accumulation mode. In the second stage, the sulfate mass produced by aqueous oxidation of $\mathrm{SO}_{2}$ is partitioned between the soluble accumulation and coarse modes according to their fractional contribution to the total particle number concentration over the two modes. Treating the cloud processing in this way ensures particles at the larger end of the Aitken size range can be activated and cloud-processed, and that the minimum between the soluble Aitken and accumulation modes is created at $r_{\text {act }}$.

\section{Model results and evaluation}

\subsection{Aerosol precursor gases}

Figure 1a, b and c shows global maps of simulated annual mean surface-level volume mixing ratios of the aerosol 

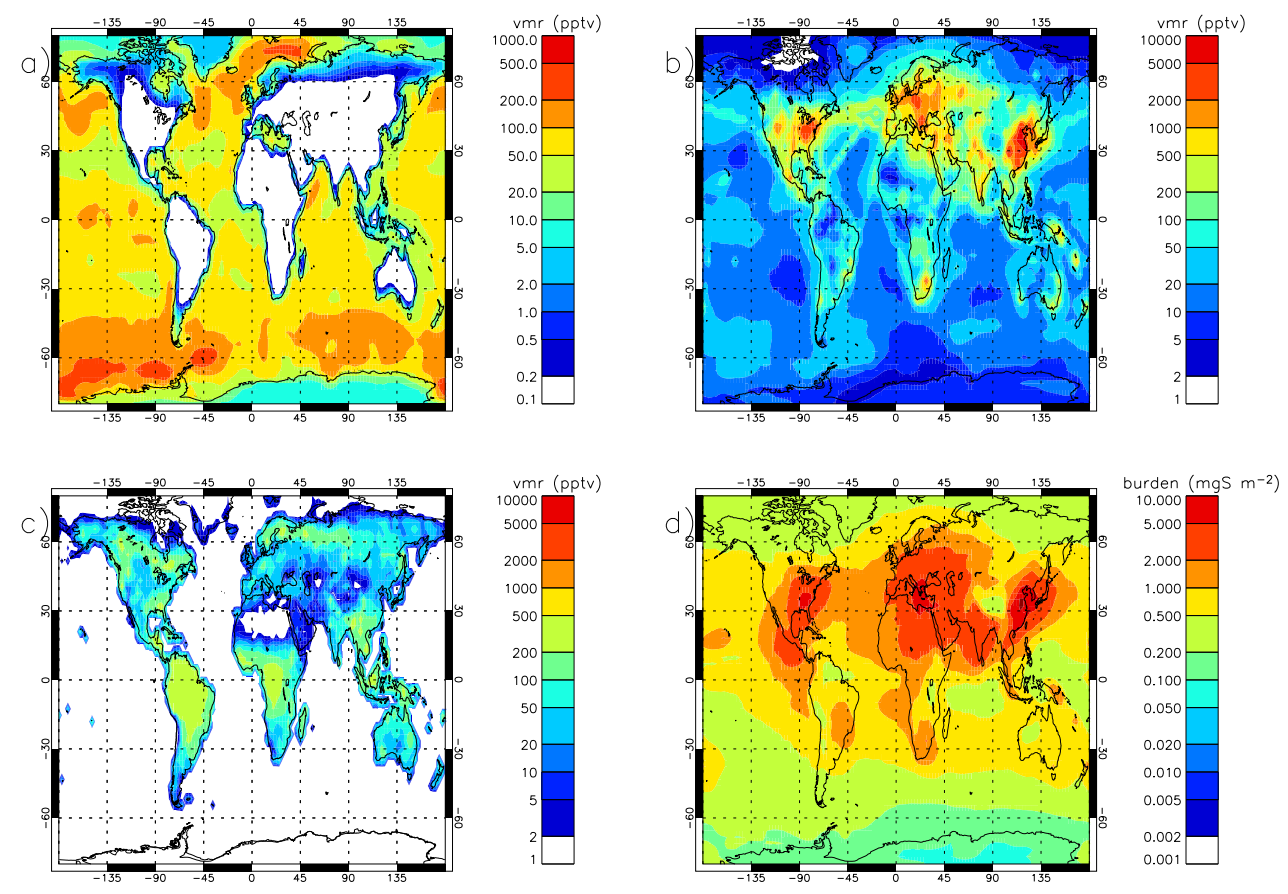

Fig. 1. Global maps of annual mean model surface vmr of (a) DMS; (b) $\mathrm{SO}_{2}$; (c) terpenes in the model lowest level. Annual mean model column integrated aerosol sulfate burden is shown in panel (d).

precursor gases DMS, $\mathrm{SO}_{2}$ and terpenes (respectively). High values of atmospheric DMS occur over oceans due to its marine source, and seawater DMS concentrations have a strong seasonal cycle. The local maxima in the annual mean atmospheric DMS concentration shown in Fig. 1a in the Southern Ocean and in the North Pacific and North Atlantic result from high seawater DMS concentrations in summer months. Moderate DMS concentrations occur throughout the year in tropical ocean regions. The atmospheric DMS distribution is driven by a combination of emissions flux and the $\mathrm{OH}$ and $\mathrm{NO}_{3}$ oxidant concentrations specified in the 6-h monthlymean oxidant fields (see Sect. 2.1) and is similar to that described in Spracklen et al. (2005). The highest $\mathrm{SO}_{2}$ concentrations (Fig. 1b) occur in industrialised regions due to very high anthropogenic emissions, but a local biogenic $\mathrm{SO}_{2}$ maxima also occurs over the Southern Ocean resulting from significant $\mathrm{SO}_{2}$ production from DMS oxidation during the summer. Atmospheric terpene concentrations are highest over tropical forests (Fig. 1c) but are also large in boreal forest regions.

Table 4 shows for reference the simulated global burden, production and average lifetime for the precursor gases shown in Fig. 1 and for $\mathrm{H}_{2} \mathrm{SO}_{4}$ and the condensing organic. The simulated global DMS and $\mathrm{SO}_{2}$ burden, emission and lifetime are well within the range of previous global model studies (as summarized in Spracklen et al., 2005) although the DMS lifetime is towards the low-end of other models, which could be indicative of too strong a chemical sink.
Global $\mathrm{SO}_{2}$ emissions are at the low end of the literature range but this is because the anthropogenic emissions used are those of IIASA (Cofala et al., 2005) which are representative of the year 2000. Some of the models quoted in Spracklen et al. (2005) used emissions inventories representative of the mid-1980s or 1990s which have higher global emissions fluxes. For instance the global anthropogenic $\mathrm{SO}_{2}$ emissions flux from the GEIA $1 b$ inventory (Benkowitz et al., 1996 ) is $21 \%$ higher than that given by IIASA (Manktelow et al., 2007).

For terpenes, the total annual emissions in the model is slightly larger than the $127 \mathrm{Tg}$ of carbon in Guenther et al. (1995). However, such emissions are subject to a factor 5 uncertainty, mainly due to uncertainties in tree-specific emissions factors/functions and in databases of land-cover, vegetation and tree abundance (Kanakidou et al., 2005). Simulated SOA production in the model is in the middle of the range given by Dentener et al. (2006). The fixed percentage yield from a first stage oxidation product based on alphapinene oxidation is a simple approach but gives a reasonable total production of SOA. We also note that our SOA is driven by simulated oxidants rather than being generated as a fixed fraction of the terpene emissions, as suggested in Dentener et al. (2006).

To assess the fate of the emitted gaseous aerosol precursors, it is important to examine the proportion which is removed by dry and wet deposition before being chemically converted to aerosol. Table 5 illustrates the fate of the aerosol 

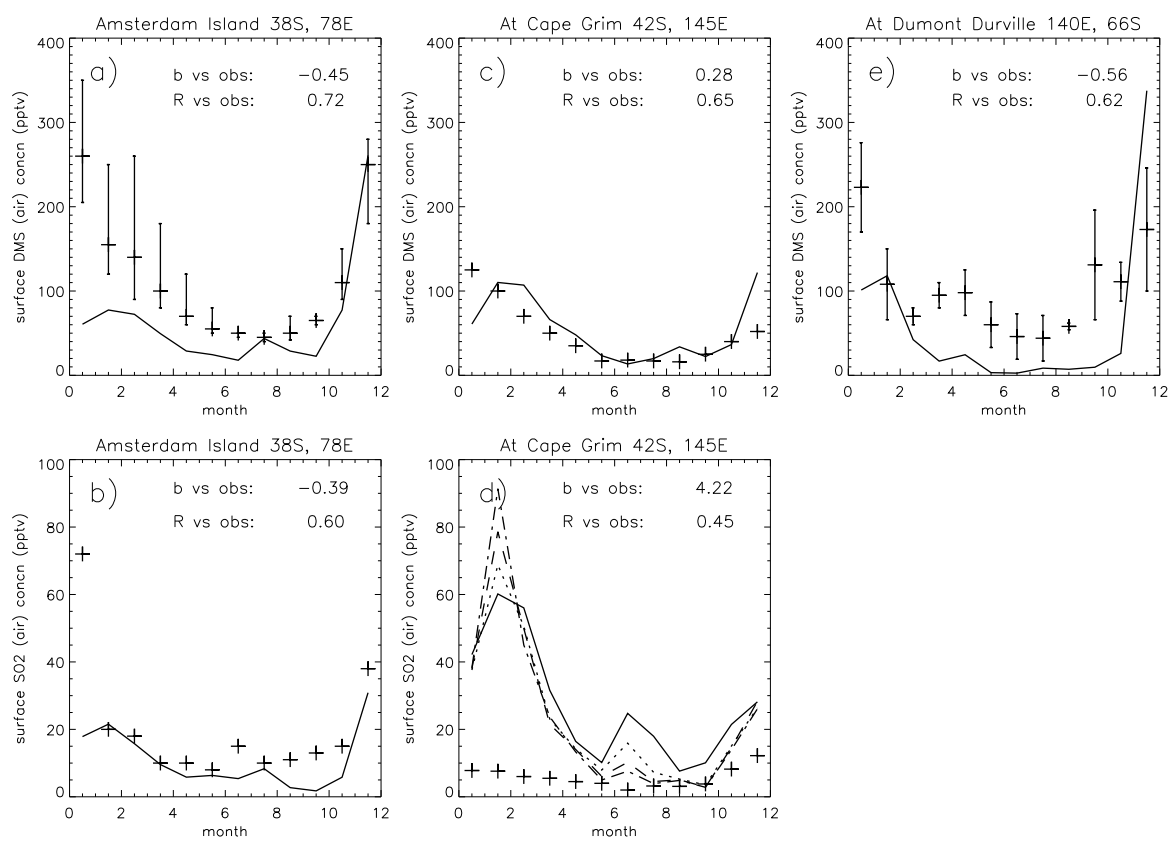

Fig. 2. Simulated (solid lines) and observed (plus symbols) annual cycle of (a) DMS and (b) $\mathrm{SO}_{2}$ at Amsterdam Island (Nguyen et al., 1992); (c) DMS and (d) $\mathrm{SO}_{2}$ at Cape Grim (Ayers et al., 1991); (e) DMS at Dumont D'Urville (Jourdain and Legrand, 2001). Normalised mean bias $(b)$ and Pearson regression coefficient $(R)$ are shown in each panel. Model values are monthly-mean volume mixing ratio in the lowest model level. Panel (d) also shows model surface $\mathrm{SO}_{2}$ at 1 (dotted), 2 (dashed) and 3 (dot-dashed) gridboxes to the South of Cape Grim).

Table 5. Annual mean global removal fluxes as a percentage of total removal for each of the simulated gas phase aerosol precursors. For $\mathrm{SO}_{2}$, the range as simulated in 14 previous global model studies (see Spracklen et al., 2005) is included in parentheses.

\begin{tabular}{lllll}
\hline Species & $\begin{array}{l}\text { Loss }(\rightarrow \text { gas }) \\
(\%)\end{array}$ & $\begin{array}{l}\text { Loss }(\rightarrow \text { aero }) \\
(\%)\end{array}$ & $\begin{array}{l}\text { Loss (ddep) } \\
(\%)\end{array}$ & $\begin{array}{l}\text { Loss (wdep) } \\
(\%)\end{array}$ \\
\hline $\mathrm{DMS}$ & 100 & & & \\
$\mathrm{SO}_{2}$ & $12.6(5.3-18.5)$ & $\begin{array}{l}43.5(27.1-57.1) \\
\mathrm{H}_{2} \mathrm{SO}_{4}\end{array}$ & $\begin{array}{l}30.7(26.7-46.3) \\
0.01\end{array}$ & $13.2(0.2-20.8)$ \\
MONOTER & 97.6 & & 2.4 & \\
SEC-ORG & & 99.10 & 0.13 & 0.8 \\
\hline
\end{tabular}

precursor gases, showing the percentage fluxes through each of the loss processes. For instance, it shows that $12.6 \%$ of $\mathrm{SO}_{2}$ loss is via in-air oxidation to sulfuric acid which can then either form new particles via nucleation or grow existing aerosol by condensation. Aqueous production of sulfate mass accounts for $43.5 \%$ of $\mathrm{SO}_{2}$ loss, forming more sulfate mass and growing existing accumulation and coarse soluble mode particles in the model. In total, removal processes account for $43.9 \%$ of the $\mathrm{SO}_{2}$ loss with dry deposition being the dominant removal process. For the $\mathrm{SO}_{2}$ loss processes, also included are the equivalent figures from Spracklen et al. (2005) who compared previous global model studies which simulated the sulfur-cycle.

Figure 2 shows the simulated annual cycle of DMS and $\mathrm{SO}_{2}$ at three Southern Hemisphere remote sites compared against observations from Nguyen et al. (1992), Ayers et al. (1991) and Jourdain and Legrand (2001). All three sites have a clear seasonal cycle in DMS, with elevated concentrations during summer, and this is captured quite well by the model with regressions coefficient $R$ of $0.72,0.65$ and 0.62 for Amsterdam Island, Cape Grim and Dumont D'Urville, respectively. The model compares well with observed DMS at Cape Grim (Fig. 2c) with normalised mean bias $b=0.28$ but is biased low $(b=-0.45)$ at Amsterdam Island (Fig. 2a) and also $(b=-0.56)$ at Dumont D'Urville (Fig. 2e). Simulated remote Southern Hemisphere $\mathrm{SO}_{2}$ compares well $(R=$ $0.60, b=-0.39)$ with observations at Amsterdam Island (Fig. 2b) but is strongly biased high $(b=4.22)$ at Cape Grim (Fig. 2d) throughout the year. However, the Cape Grim observations are filtered to only include the "baseline marine 
Table 6. Annual mean global mass burden ( $\mathrm{Tg}$ ), production fluxes (Tg/yr) and lifetime (days) for each simulated aerosol component. Also shown in the \% removal by wet deposition for each component. In parentheses are shown the median burdens and lifetimes simulated by AEROCOM models as documented in Textor et al. (2006). Note that the figures quoted for sulfate as in $\mathrm{Tg}$ of sulfur.

\begin{tabular}{lcrcll}
\hline Species & $\begin{array}{l}\text { Burden } \\
(\mathrm{Tg})\end{array}$ & $\begin{array}{r}\text { Prod (prim) } \\
\left(\mathrm{Tg} \mathrm{a}^{-1}\right)\end{array}$ & $\begin{array}{l}\text { Prod (sec) } \\
\left(\mathrm{Tg} \mathrm{a}^{-1}\right)\end{array}$ & $\begin{array}{l}\text { Lifetime } \\
(\text { days })\end{array}$ & $\begin{array}{l}\text { loss by wdep } \\
(\%)\end{array}$ \\
\hline Sulphate & $0.52(0.66)$ & $1.7(59.6)$ & 48.4 & $3.7(4.1)$ & $89.6(88.5)$ \\
Sea-salt & $4.93(6.39)$ & $8380(6280)$ & 0.0 & $0.2(0.4)$ & $21.2(30.3)$ \\
BC & $0.14(0.21)$ & $7.7(11.3)$ & 0.0 & $6.6(6.5)$ & $80.0(79.5)$ \\
POM & $1.15(1.21)$ & $46.9(69.9)$ & 22.4 & $6.1(6.1)$ & $84.6(78.9)$ \\
Mineral dust & $16.6(20.5)$ & $1810(1640)$ & 0.0 & $3.4(4.0)$ & $17.1(31.7)$ \\
\hline
\end{tabular}

sector" (Ayers et al., 1991), whereas the model includes all air masses. Additionally, model values are grid-box averages which will have had any emissions in the same 2.8 degree box mixed in. To try to reduce this second bias, the Cape Grim comparison also shows model $\mathrm{SO}_{2}$ at more southerly gridboxes (the dotted, dashed and dot-dashed lines are 1, 2 and 3 boxes to the South, respectively). In winter, the model high bias is removed when comparing against gridboxes to the south, but summer $\mathrm{SO}_{2}$ in the model remains biased high compared to the marine sector measurements at Cape Grim.

Figure 3 compares simulated continental $\mathrm{SO}_{2}$ over Europe and North America against observations from the EMEP (European Monitoring and Evaluation Programme, Loevblad et al., 2004) and CASTNET (Clean Air Status and Trends Network, Malm et al., 2002) monitoring sites. The simulated conversion of $\mathrm{SO}_{2}$ to sulfate in the US and Europe in GLOMAP-mode was investigated by Manktelow et al. (2007) and shown to reproduce the observed seasonal cycle in 2000. Here, we restrict our evaluation to the annual mean at the monitoring sites. The modelled and observed annual mean $\mathrm{SO}_{2}$ correlate quite well spatially in both regions ( $R=0.86$ for the US and 0.61 for Europe) although the model is biased high $(b=1.94)$ over Europe on average.

In summary, the sulfate aerosol precursor gases are well simulated in the model, giving further confidence to the validity of the evaluation of the aerosol mass and number concentrations in the next two sections.

\subsection{Speciated aerosol mass}

Figures $1 \mathrm{~d}$ and $4 \mathrm{a}, \mathrm{b}, \mathrm{c}$ and $\mathrm{d}$ show the simulated global distributions of the annual mean column-integrated mass of sulfate, BC, POM, sea-salt and dust, respectively. Annual mean column sulfate mass exceeds $5 \mathrm{mgS} \mathrm{m}^{-2}$ over eastern USA, Europe, North Africa, East Asia and South Asia and is controlled by a combination of oxidant limitation and $\mathrm{SO}_{2}$ emissions strength (see e.g. Manktelow et al., 2007). Simulated annual mean column burdens of BC and POM are highest over biomass regions where emissions fluxes are strongest, while industrialised regions also have high burdens. Secondary biogenic production of POM via terpene oxidation also contributes considerably to the organic matter burden. Sea-salt and dust aerosol have the highest simulated mass burdens in the model with concentrations reflecting the sources in high-wind-speed oceanic regions and arid regions, respectively.

Table 6 shows the annual mean global burden, production, lifetime, and fraction removed by wet deposition for each aerosol component. Also given in parentheses are the multimodel medians as simulated by AEROCOM models (Textor et al., 2006). The simulated global burdens are well within the range simulated by the AEROCOM models (not shown) and are slightly lower than the median for each species. The lifetime of each species is very close to the AEROCOM multi-model median, although dust and sea-salt have a slightly shorter lifetime. In terms of the removal processes, the sulfate, BC and POM simulated in the model are very close to the AEROCOM median values although sea-salt and dust have a slightly lower fraction by wet removal. A recent study by Vignati et al. (2010) with the same BC ageing approach (Wilson et al., 2001), but a single-monolayer ageing threshold, finds a similar global BC burden $(0.14 \mathrm{Tg})$ and lifetime (6.6 days) to this study, which uses a 10 monolayer thickness. This study includes as soluble material both sulfuric acid and secondary organic material, whereas Vignati et al. (2010) consider only sulfuric acid. The fact that the lifetimes are similar for the different monolayer thickness assumption suggests that secondary organic material plays a key role in determining the ageing timescale and needs to be considered in models which use this approach.

Figure 5 compares model annual mean surface sulfate concentrations over N. America, Europe and remote marine sites against those observed at sites in the IMPROVE (Interagency Monitoring of Protected Visual Environments, Malm et al., 2004) EMEP and University of Miami (as in Stier et al., 2005) networks. Overall, the spatial variability in the model compares very well $(R=0.92)$ with the observations (Fig. 5d) with only a slight high bias on average $(b=0.25)$. Considering each of the networks in turn (not shown), the statistics for the annual-mean comparisons are also good with $b=0.30,0.05$ and 0.12 and $R=0.73,0.98$ and 0.96 for 

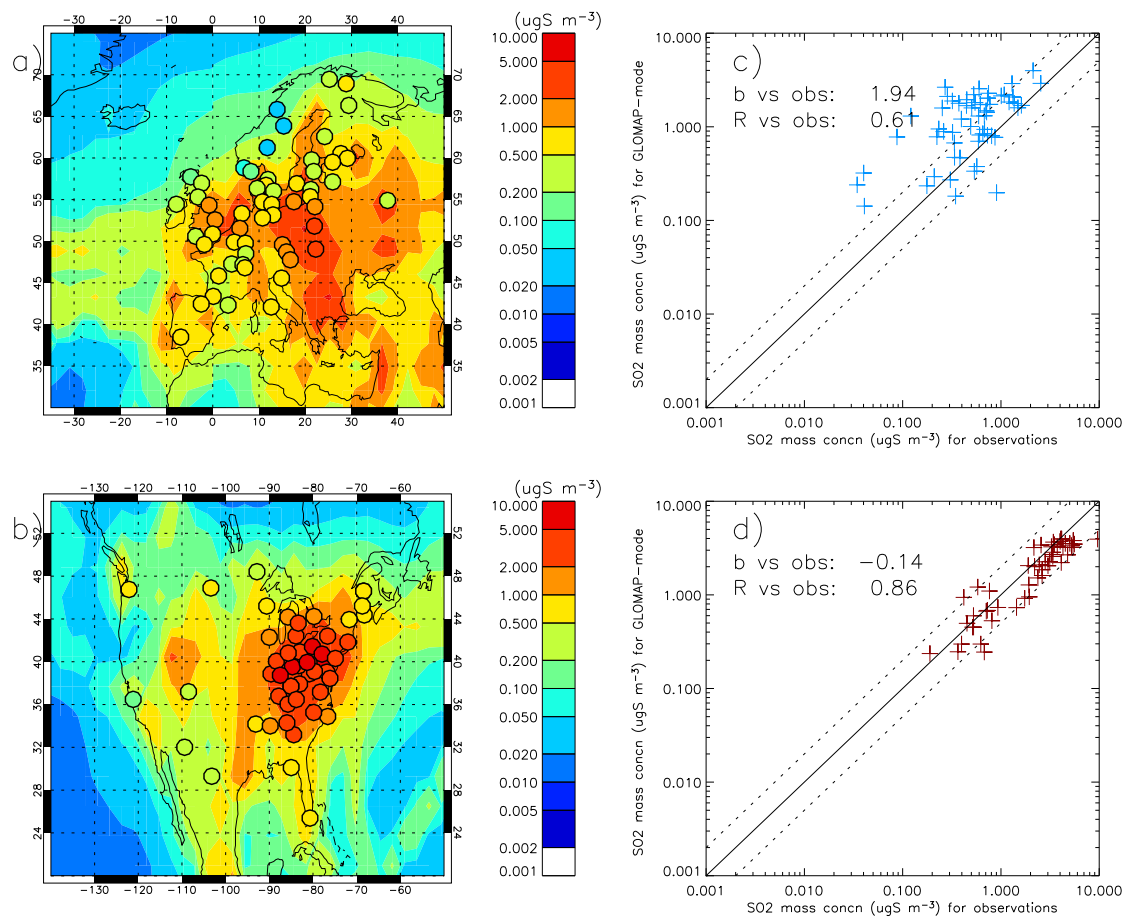

Fig. 3. Maps of simulated annual-mean $\mathrm{SO}_{2}$ concentration in the lowest model level over (a) Europe and (b) North America with year2000 surface observations from sites in the EMEP and IMPROVE networks respectively over-plotted. Scatter plots for the model (y-axis) compared to the observations (x-axis) are shown in panels (c) and (d) with $b$ and $R$ values for each region. Observations are for the year 2000 with only sites where the height above sea-level is within $250 \mathrm{~m}$ of that calculated for the lowest model level included.
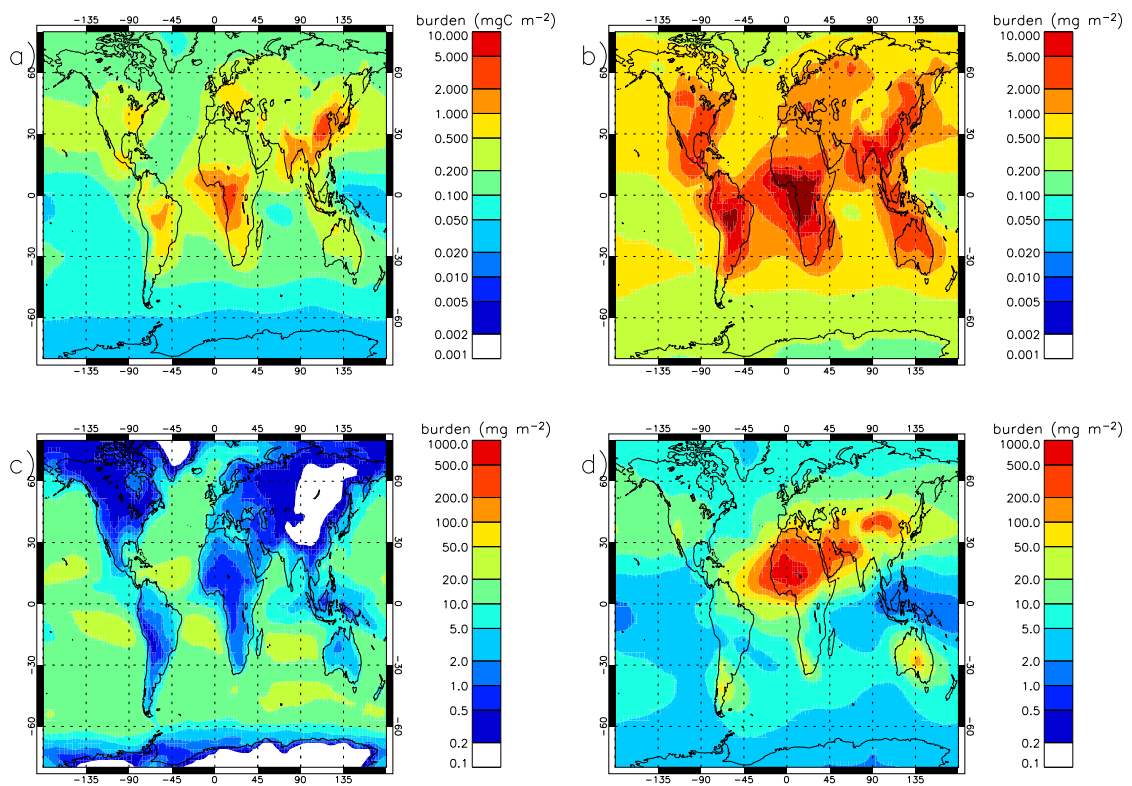

Fig. 4. Global maps of annual mean model column-integrated aerosol burden of (a) black carbon, (b) particulate organic matter, (c) sea-salt and (d) dust. 

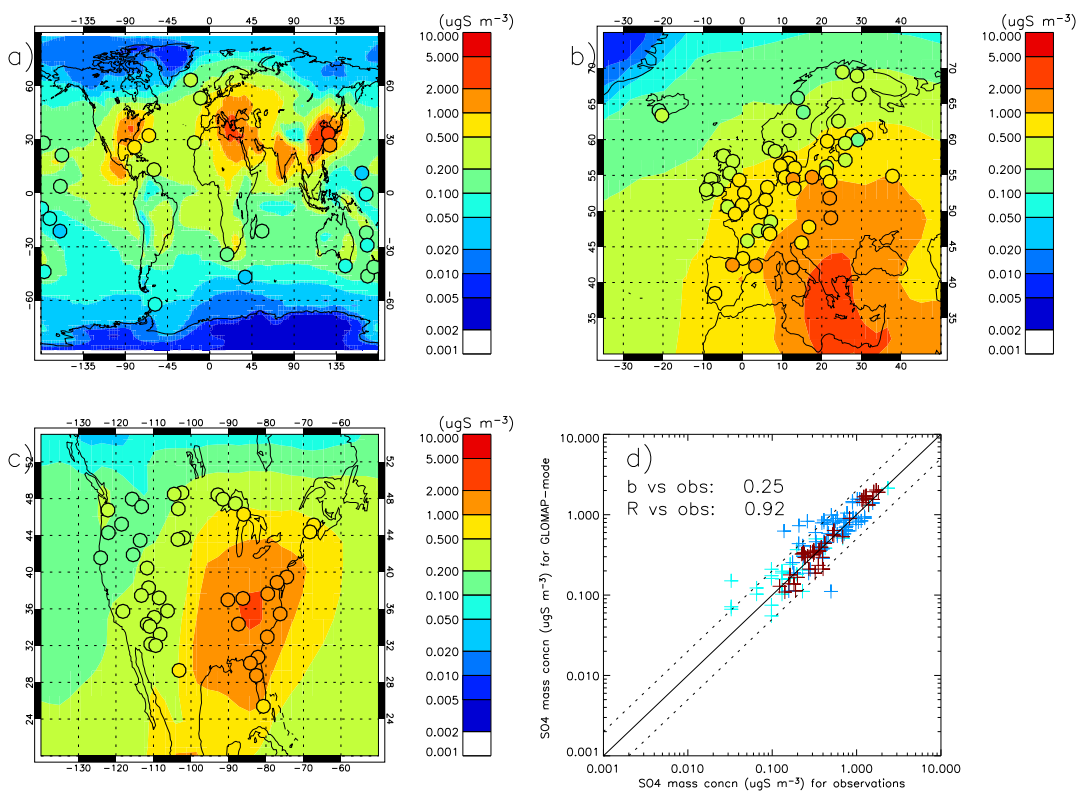

Fig. 5. Maps of simulated annual-mean sulfate concentration in the lowest model level (a) globally, (b) over Europe and (c) over North America with year-2000 surface observations from sites in the University of Miami, EMEP and IMPROVE networks respectively overplotted. Scatter plots for the model (y-axis) compared to the observations (x-axis) are shown in panel (d) with cyan, blue and red plus symbols corresponding to the University of Miami, EMEP and IMPROVE regions respectively. $b$ and $R$ values shown in panel $\mathrm{d}$ are for the the model-observation comparison over all three networks. Observations are for the year 2000 with only sites where the height above sea-level is within $250 \mathrm{~m}$ of that calculated for the lowest model level included.
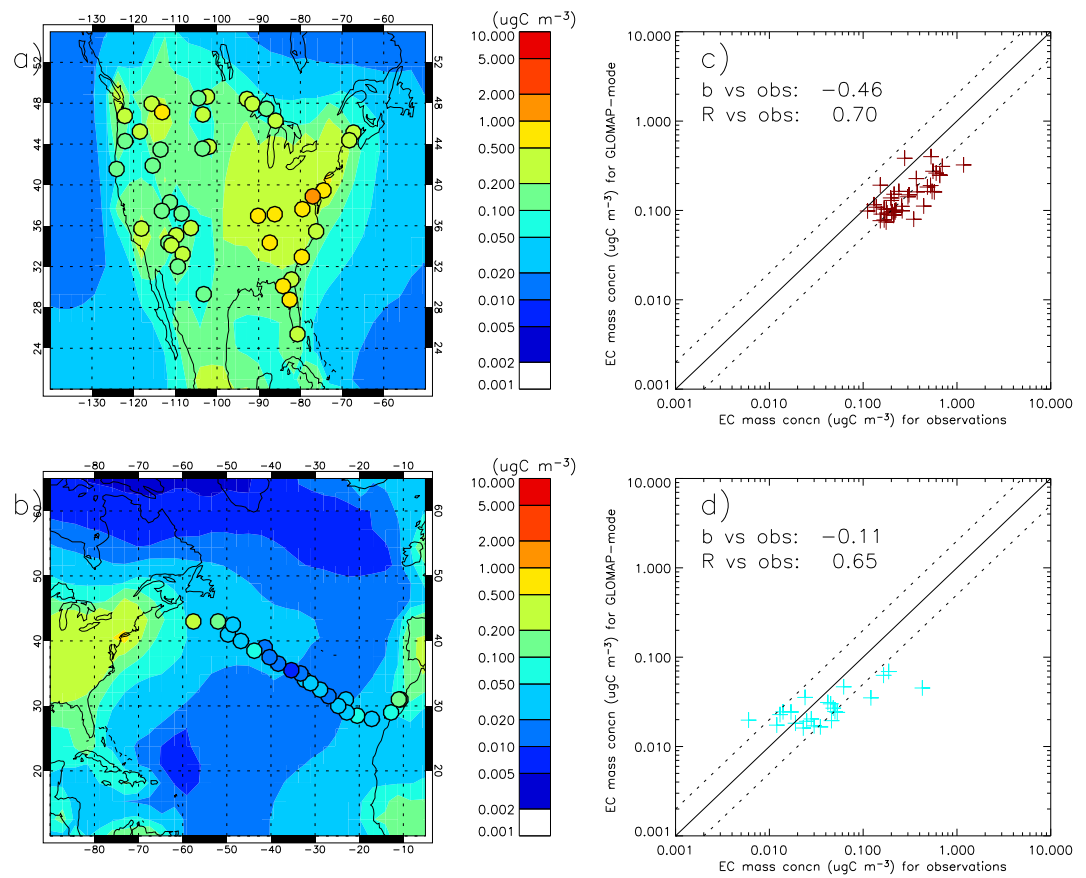

Fig. 6. Maps of simulated annual-mean black carbon concentration in the lowest model level (a) over Europe and (b) over the North Atlantic with surface observations from IMPROVE sites and cruise observations from Van Dingenen et al. (1995) respectively over-plotted. Scatter plots for the model (y-axis) compared to the observations (x-axis) are shown in panels (c) and (d) with $b$ and $R$ values also shown. IMPROVE observations are for the year 2000 with only sites where the height above sea-level is within $250 \mathrm{~m}$ of that calculated for the lowest model level included. 

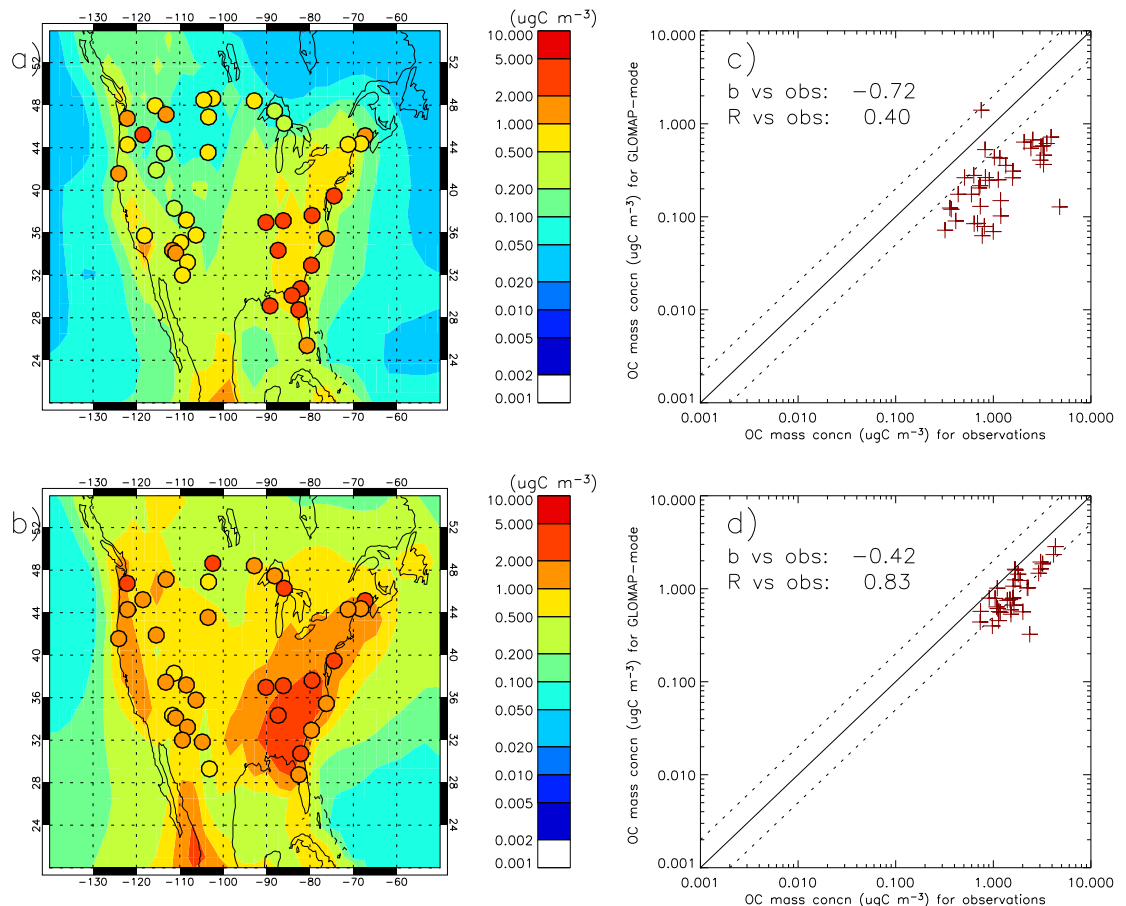

Fig. 7. Maps of simulated annual-mean organic carbon concentration in the lowest model level over North America for (a) December and (b) June with observations from IMPROVE sites over-plotted. Scatter plots for the model (y-axis) compared to the observations (x-axis) are shown in panels (c) and (d) with $b$ and $R$ values also shown. Observations are for the year 2000 with only sites where the height above sea-level is within $250 \mathrm{~m}$ of that calculated for the lowest model level included.
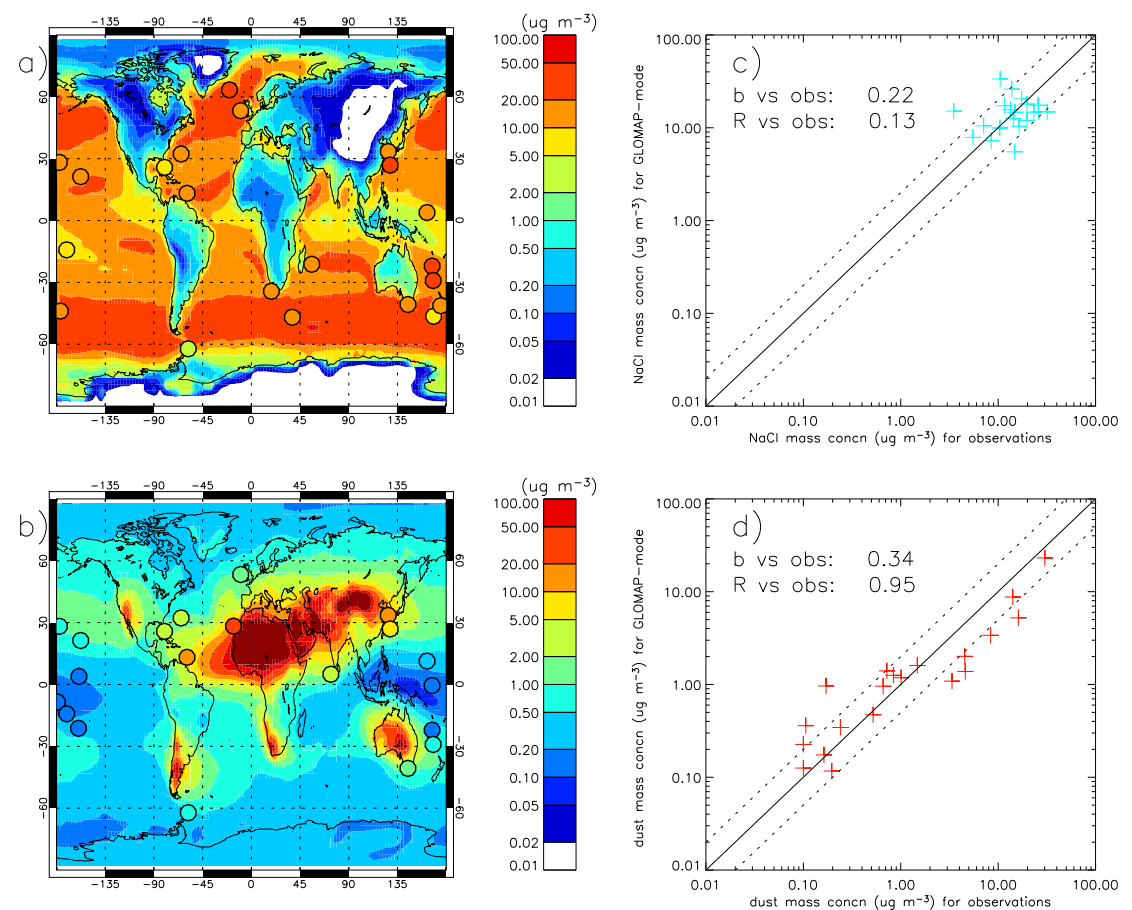

Fig. 8. Global maps of simulated annual-mean mass concentration in the lowest model level of (a) sea-salt and (b) dust with surface observations from University of Miami sites over-plotted. Scatter plots for the model (y-axis) compared to the observations (x-axis) are shown in panels (c) and (d) with $b$ and $R$ values also shown. 
EMEP, IMPROVE and University of Miami, respectively. It should be noted however that over Europe and North America, winter and summer simulated sulfate has a low and high bias respectively (not shown), see Manktelow et al. (2007) for details.

Figure 6 shows model surface-level BC concentrations over North America (annual mean) and over the North Atlantic (September and October mean). Over-plotted are annual mean BC observations from IMPROVE sites (from optical analysis of $\mathrm{PM}_{2.5}$ filter measurement) and derived from aethalometer measurements made on the $\mathrm{N}$. Atlantic transect cruise in the JGOFS campaign in 1992 (Van Dingenen et al., 1995). Shown in Fig. 8c and d are scatter plots indicating the model-observation correlation and bias. The model reproduces the spatial variability seen in the annual-mean observations over North America quite well $(R=0.70)$ although the model is biased low by almost a factor of two $(b=-0.46)$. For the N. Atlantic comparison, measurements are between 5 and $48 \mathrm{~h}$ duration, whereas the model is a two-month mean. However, the model captures the general pattern seen in the observations $(b=-0.11, R=0.65)$ suggesting the $\mathrm{BC}$ export from North America is being captured quite well with the 10 monolayer ageing assumption (see Sect. 2.2.8).

Figure 7 compares model surface-level organic carbon (OC) concentrations in December and June over North America with observations at IMPROVE sites. The model captures fairly well the observed spatial variability $(R=0.40$ and 0.83 for December and June) but strongly underestimates the OC burden with an $72 \%$ low bias in winter and a $42 \%$ low bias in summer. A possible cause of this discrepancy is underestimation of SOA production, although this cannot be confirmed without further analysis. Increasing the yield might result in a better comparison with observations in the summer, but not the winter since terpene-derived SOA is only a small fraction of the winter OC in the model.

Figure 8 compares annual mean surface-level sea-salt mass concentrations with observations from the University of Miami sites (from Stier et al., 2005). The model is within a factor of 2 of the observations at 17 of the 21 sites, although on average it is slightly biased high $(b=0.22)$ and is only weakly correlated with the observations $(R=0.13)$. The simulated annual mean surface-level global dust distribution (Fig. 8c) is within a factor two of the observations for 12 of the 20 University of Miami dust sites (from Woodward et al., 2001). The spatial variability seen in the observations is captured well by the model $(R=0.95)$ although overall the model is biased slightly high biased on average $(b=0.34)$, particularly at sites with a high dust loading.

Further investigations into the annual cycle of these aerosol components is warranted, but the evaluation in this paper is focused on documenting the general performance in terms of the annual mean. In this respect, the model has been found to simulate surface mass concentrations very well for each of the main components of the global aerosol.

\subsection{Global distributions of size-resolved number concentration and size}

Many global models (see e.g. Textor et al., 2006) report and evaluate the global distribution of speciated aerosol mass, but only the aerosol microphysics models (e.g. Adams and Seinfeld, 2002; Easter et al., 2004; Lauer et al., 2005; Liu et al., 2005; Spracklen et al., 2005, 2007; Stier et al., 2005) have attempted to evaluate the distribution of size-resolved particle number concentrations. In general, the models reproduce the observed variability in mass concentrations much more accurately than they do the particle number concentrations, possibly because number concentrations are determined by more processes and because of uncertainties in the size distribution of primary particles.

Figure 9 shows surface maps of annual mean particle number concentrations for each of the four soluble modes. As found in other studies (e.g. Spracklen et al., 2005), surface-level nucleation mode number concentrations are much lower than in the free and upper troposphere where the production rate by binary homogeneous nucleation is strongest.

The soluble Aitken mode has highest number concentrations of around $1000 \mathrm{~cm}^{-3}$ over China and generally are between 200 and $500 \mathrm{~cm}^{-3}$ in other industrialised regions due to emissions of primary $\mathrm{BC} / \mathrm{OC}$ from fossil fuel and biofuel burning (aged from the insoluble mode) and of primary sulfate particles. Moderate Aitken mode number concentrations $\left(30-70 \mathrm{~cm}^{-3}\right)$ are maintained in marine regions (e.g. $30-70 \mathrm{~cm}^{-3}$ in the Southern Ocean and around $100 \mathrm{~cm}^{-3}$ in the tropical Pacific) due to entrainment of particles that have nucleated and grown in the free troposphere.

The soluble accumulation mode also contains both primary and secondary particles. Primary carbonaceous particles from biomass burning sources are emitted at larger sizes than those from biofuel and fossil fuel combustion sources and Fig. 9c shows how the originally insoluble biomass aerosol has been aged, residing in the soluble accumulation mode (the local maxima off the West coast of Central Africa and in Amazonia) whereas the biofuel and fossil-fuel carbonaceous particles reside mainly in the soluble Aitken mode (Fig. 9b). Higher oxidant concentrations (stronger photochemistry) in tropical regions and subsequent production of sulfuric acid vapour and condensing organics will also have contributed to enhanced growth and more efficient processing to the soluble accumulation mode. Minima in Aitken soluble mode number concentrations indicate where the modemerging of the biomass aerosol has occurred. In marine regions, the larger particles in the Aitken soluble mode are also transferred to the soluble accumulation mode via cloud processing in the persistent stratocumulus cloud deck.

Accumulation mode number concentrations in polluted regions are similar to those in the Aitken mode (200$1000 \mathrm{~cm}^{-3}$ ). Concentrations over ocean regions are around $100 \mathrm{~cm}^{-3}$ between $30^{\circ} \mathrm{N}$ and $30^{\circ} \mathrm{S}$, around $50-75 \mathrm{~cm}^{-3}$ 

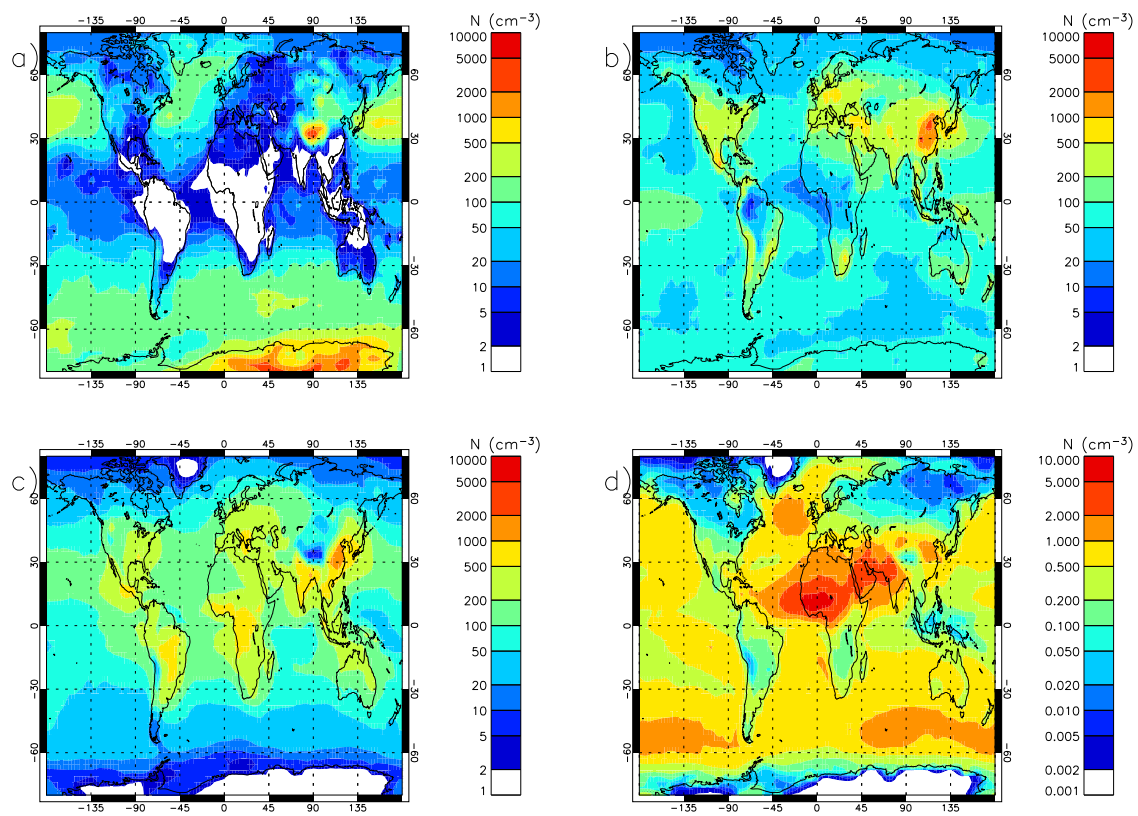

Fig. 9. Global maps of simulated annual-mean particle number concentration in the lowest model level for (a) nucleation mode, (b) Aitkensoluble mode, (c) accumulation-soluble mode and (d) coarse-soluble mode.
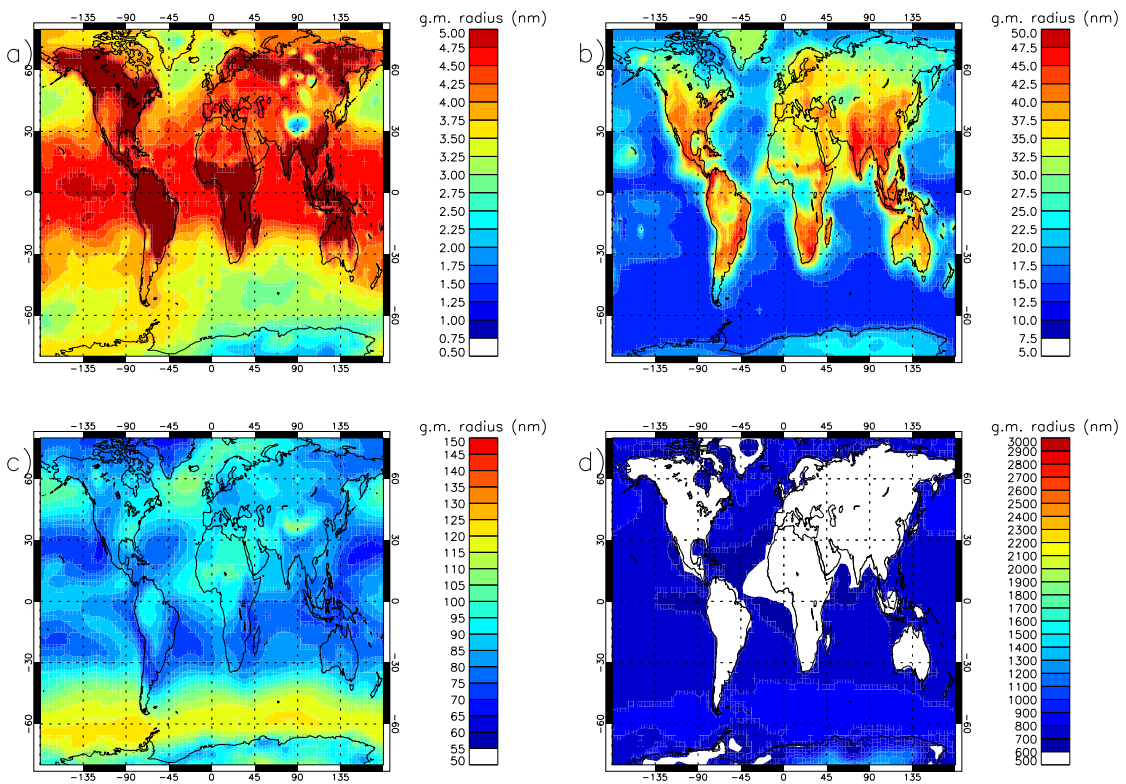

Fig. 10. Global maps of simulated annual-mean geometric mean radius in the lowest model level for (a) nucleation mode, (b) Aitken-soluble mode, (c) accumulation-soluble mode and (d) coarse-soluble mode. 

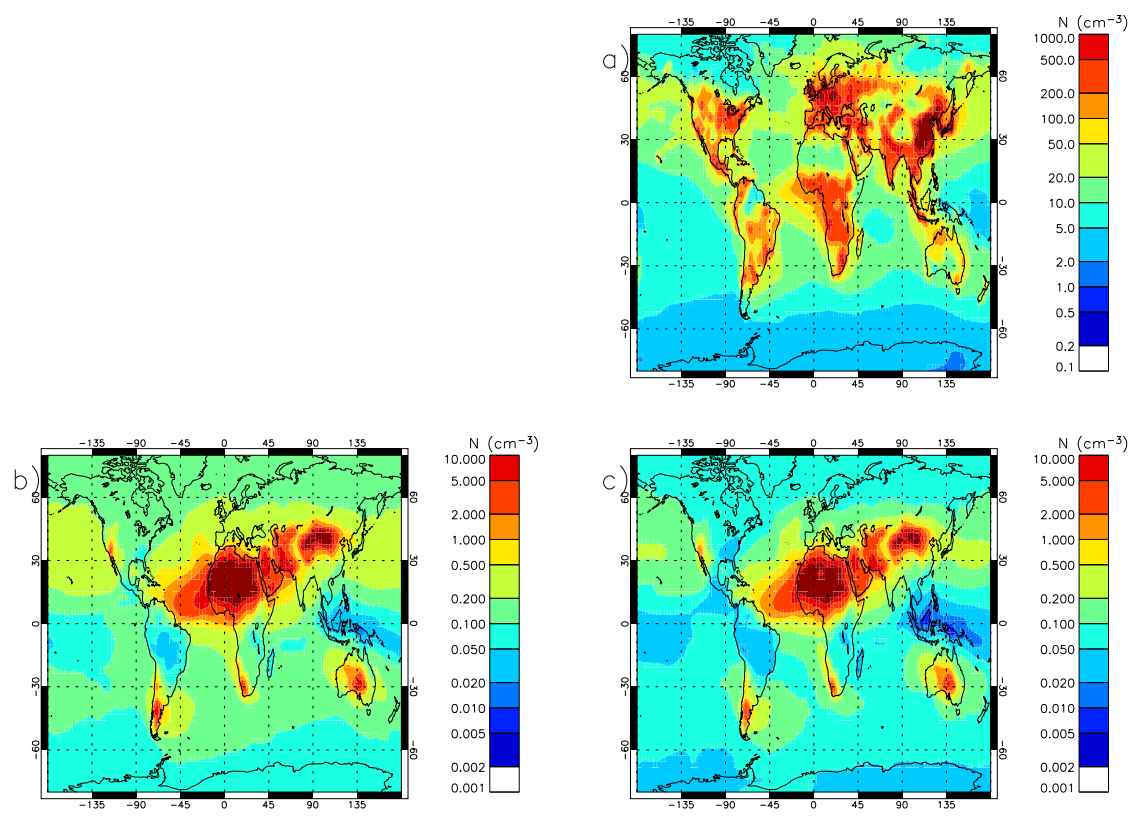

Fig. 11. Global maps of simulated annual-mean particle number concentration in the lowest model level for (a) Aitken-insoluble mode, (b) accumulation-insoluble mode and (c) coarse-insoluble mode.
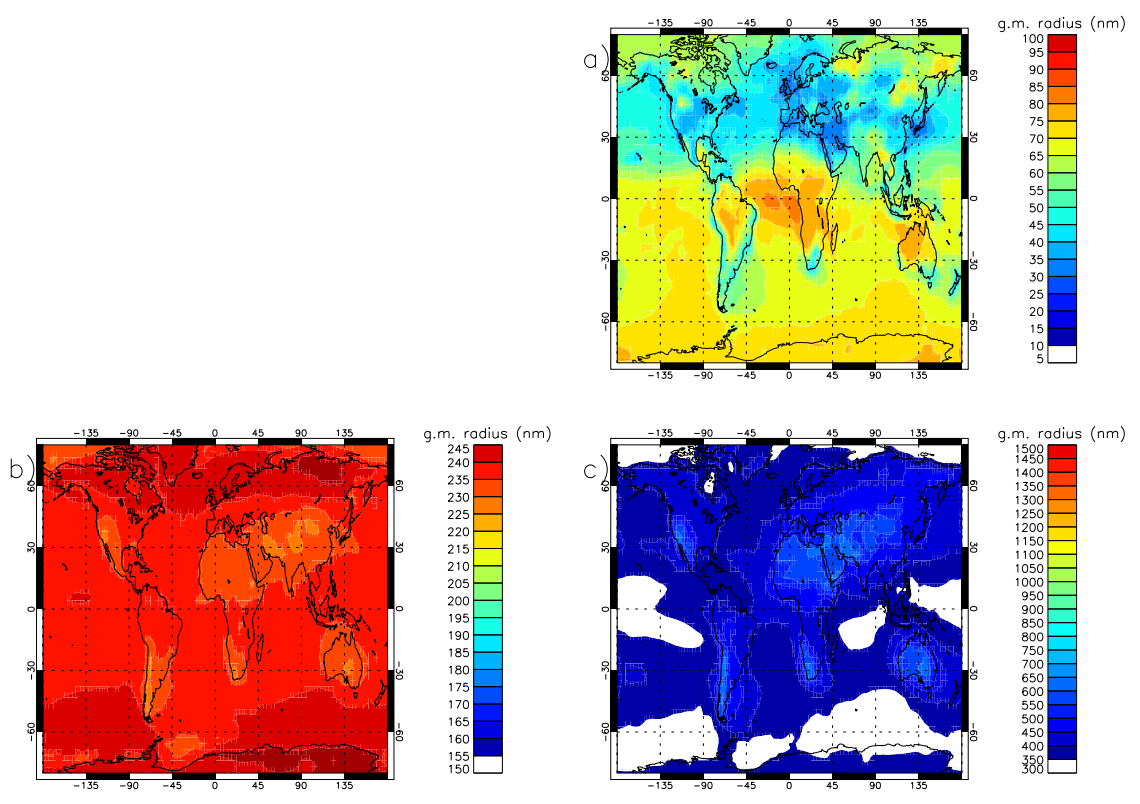

Fig. 12. Global maps of simulated annual-mean geometric mean radius in the lowest model level for (a) Aitken-insoluble mode, (b) accumulation-insoluble mode and (c) coarse-insoluble mode. 

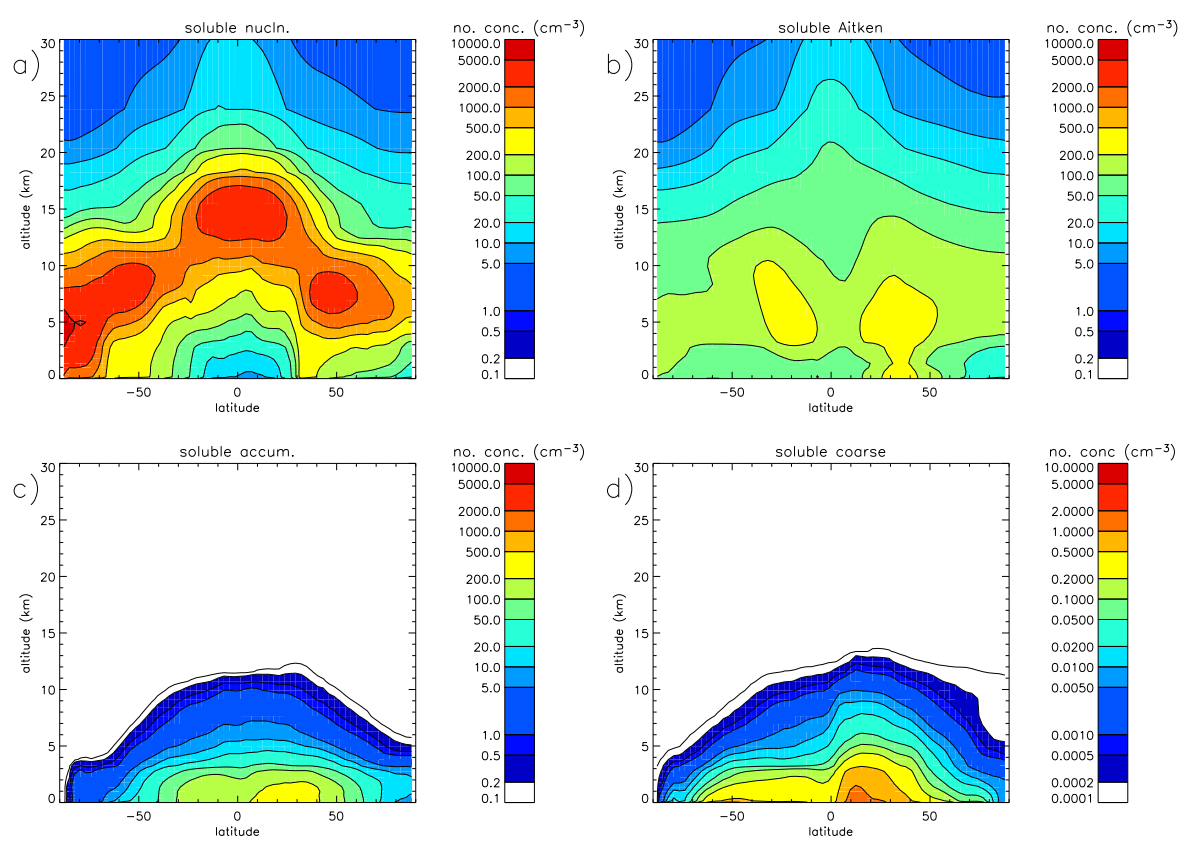

Fig. 13. Latitude-altitude plots of simulated zonal-means of annual-mean particle number concentrations for (a) nucleation mode, (b) Aitken-soluble mode, (c) accumulation-soluble mode and (d) coarse-soluble mode.
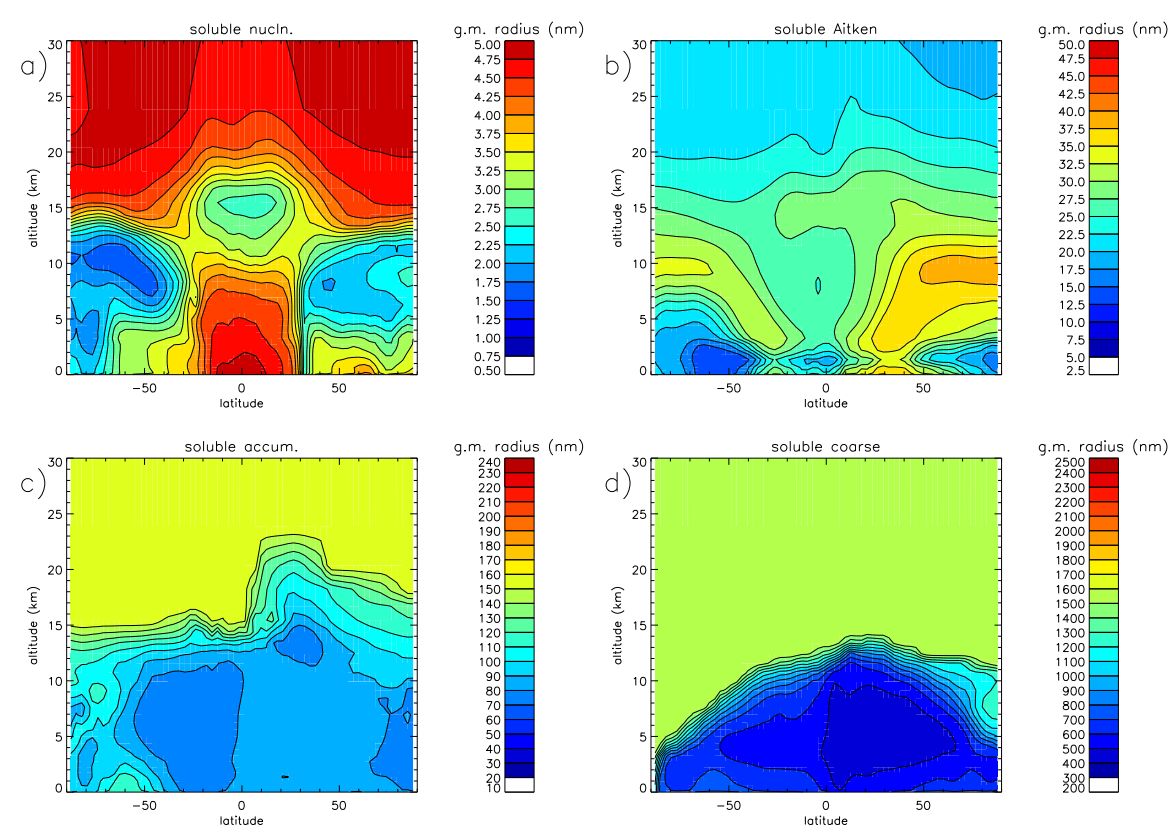

Fig. 14. Latitude-altitude plots of simulated zonal-means of annual-mean particle geometric mean radius for (a) nucleation mode, (b) Aitken-soluble mode, (c) accumulation-soluble mode and (d) coarse-soluble mode.

between 30 and 45 degrees in both hemispheres, and around $10-30 \mathrm{~cm}^{-3}$ at higher latitudes.

The global distribution of number concentrations in the soluble coarse mode reflects the dominant source regions for dust and sea-salt aerosol. Minima are seen in the sub-tropics indicating strong wet removal in the Inter-tropical Convergence Zone (ITCZ).

Examining the simulated particle sizes (Fig. 10) also helps to understand the role of various processes in the model. The smallest nucleation mode particles at the surface occur over 
Antarctica where temperatures are low enough for new particle formation to occur. In the tropics, the mean nucleation mode size is at the upper end of the allowed range, because of growth due to uptake of photochemically produced vapours. Soluble Aitken mode particles are largest (geometric mean radius, $r_{\mathrm{p}} \approx 40 \mathrm{~nm}$ ) over the continents where primary aerosol emissions are strong, whereas in marine regions, the Aitken mode aerosol is mainly secondary and much smaller (10$20 \mathrm{~nm}$ ), having been transferred from the nucleation mode.

The soluble accumulation mode particles are smallest $\left(r_{\mathrm{p}} \approx 70 \mathrm{~nm}\right)$ in tropical marine regions where strong photochemistry and effective growth of secondary particles to the Aitken mode is combined with high cloud amounts and subsequent cloud processing into the soluble accumulation mode. Tropical marine regions affected by biomass aerosol, and mid-latitude oceans with strong sea-spray emissions have a slightly larger accumulation mode $\left(r_{\mathrm{p}} \approx 100-120 \mathrm{~nm}\right)$.

For the soluble coarse mode, continental regions have smaller particles $\left(r_{\mathrm{p}} \approx 500 \mathrm{~nm}\right)$ than marine regions since aged dust aerosol tends to be smaller than freshly emitted sea-salt. The highest mean radii for the coarse soluble mode $(\approx 800 \mathrm{~nm})$ occur in the strongest sea-spray emissions regions whereas weaker wind-speed regions have slightly smaller mean sizes $(\approx 700 \mathrm{~nm})$, probably due to sedimentation preferentially removing larger particles. The simulated mean size in the Aitken and accumulation mode range is compared against observations in Sect. 3.5.

Figure 11 shows annual mean surface-level number concentration of the three insoluble modes. Aitken insoluble mode number concentrations peak at around $1000 \mathrm{~cm}^{-3}$ in biomass burning regions and where there are strong sources of carbonaceous aerosol from fossil fuel and biofuel combustion. Apart from the biomass outflow plume from West Africa, Aitken insoluble number concentrations over the ocean are less than $50 \mathrm{~cm}^{-3}$, and over the Southern Ocean less than $10 \mathrm{~cm}^{-3}$. Accumulation and coarse insoluble mode number concentrations are highest in arid dust emission source regions. Figure 9 a shows that accumulation mode insoluble dust has a longer lifetime than coarse insoluble dust and both show minima in the ITCZ as a result of effective impaction scavenging in those regions. Over ocean, dust number concentrations in the insoluble accumulation and coarse modes are less than $1 \mathrm{~cm}^{-3}$, aside from the strong dust outflow from the Sahara and Sahel regions where number concentrations in both modes are around $5-10 \mathrm{~cm}^{-3}$.

The mean size of the Aitken insoluble mode (Fig. 12a) follows the assumed sizes of the freshly emitted primary carbonaceous aerosol. For instance over N. America, Europe and East Asia, the mean radius is around $40 \mathrm{~nm}$ where fossil fuel combustion dominates. Regions with the largest biofuel combustion sources (e.g. South Asia) have larger primary $\mathrm{BC} / \mathrm{OC}$ particles $(\approx 50 \mathrm{~nm})$ than US and Europe since the ratio of biofuel sources (larger particles) to fossil fuel sources (smaller particles) is larger. The particle size in biomass burning regions are larger $(\approx 75 \mathrm{~nm})$, again reflect- ing the larger assumed size of the freshly emitted biomass $\mathrm{BC} / \mathrm{OC}$ aerosol.

The insoluble accumulation mode (Fig. 12b) has a fairly uniform particle size $(\approx 240 \mathrm{~nm}$ mean radius) since sedimentation is weak in this size range, removal being dominated by impaction scavenging and ageing. By contrast, the insoluble coarse mode (Fig. 12c) has larger mean radius $(\approx 800 \mathrm{~nm})$ near dust source regions than in the far-field $(\approx 300-500 \mathrm{~nm})$ because of preferential removal of the largest particles by the model's two-moment sedimentation scheme (see Sect. 2.2.2).

Figure 13 shows zonal mean soluble mode number concentrations and geometric mean dry radii against latitude and altitude. As mentioned earlier, binary homogeneous nucleation of new sulfate aerosol is strongest in the free and upper troposphere and explains why the highest number concentrations (1000-5000 per $\mathrm{cm}^{-3}$ ) and smallest mean radius $(2-3 \mathrm{~nm})$ for the nucleation mode occur there. Outside of the particle formation belt aerosol can grow large enough to be mode-merged to the Aitken soluble mode. However, intra-modal coagulation reduces number concentrations in the mode considerably before merging to the Aitken mode occurs.

Aitken soluble mode number concentrations peak at 200 $500 \mathrm{~cm}^{-3}$ in two lobes at about $35^{\circ} \mathrm{N}$ and $25^{\circ} \mathrm{S}$ where high precursor emissions and strong photochemistry produce plenty of sulfuric acid vapour for growth. Impaction scavenging is also weaker at these latitudes than in the subtropics. In contrast to the nucleation mode, the regions where the Aitken soluble mode particles are largest $\left(r_{\mathrm{p}} \approx 30-35 \mathrm{~nm}\right)$ coincides with regions where the number concentrations are highest. Convective uplift and subsequent poleward transport of these particles is evident in the Aitken mode size in Fig. 14b. During this transport, coagulation among particles in the mode (intra-modal) reduces the mode number concentration and increases $r_{\mathrm{p}}$. Inter-modal coagulation may also contribute to the growth seen in the figure due to collection of nucleation mode particles which are present in high number concentrations in the free troposphere.

A maximum in Aitken-soluble mode number concentration occurs at $\approx 5 \mathrm{~km}$ since particle concentrations are depleted at lower altitudes by cloud-processing in marine stratocumulus to the accumulation soluble mode. Figure 14b also shows how the Aitken mode $r_{\mathrm{p}}$ decreases in the cloudprocessed regions since particles larger than $r_{\text {act }}$ are modemerged to the accumulation mode.

Although the vast majority of primary aerosol emissions are from the surface, a small contribution to the soluble Aitken mode number concentrations above the boundary layer is from primary sulfate aerosol from volcanic and biomass emissions (see Sect. 2.1.4). Wildfire particles in boreal and temperate regions are mostly emitted above the boundary layer, up to $6 \mathrm{~km}$ in altitude (Dentener et al., 2006). However, their contribution is likely to be small overall, and Merikanto et al. (2009) found that above $4 \mathrm{~km}$, binary nucleation contributes over $95 \%$ of the $\mathrm{CN}$ concentration. 

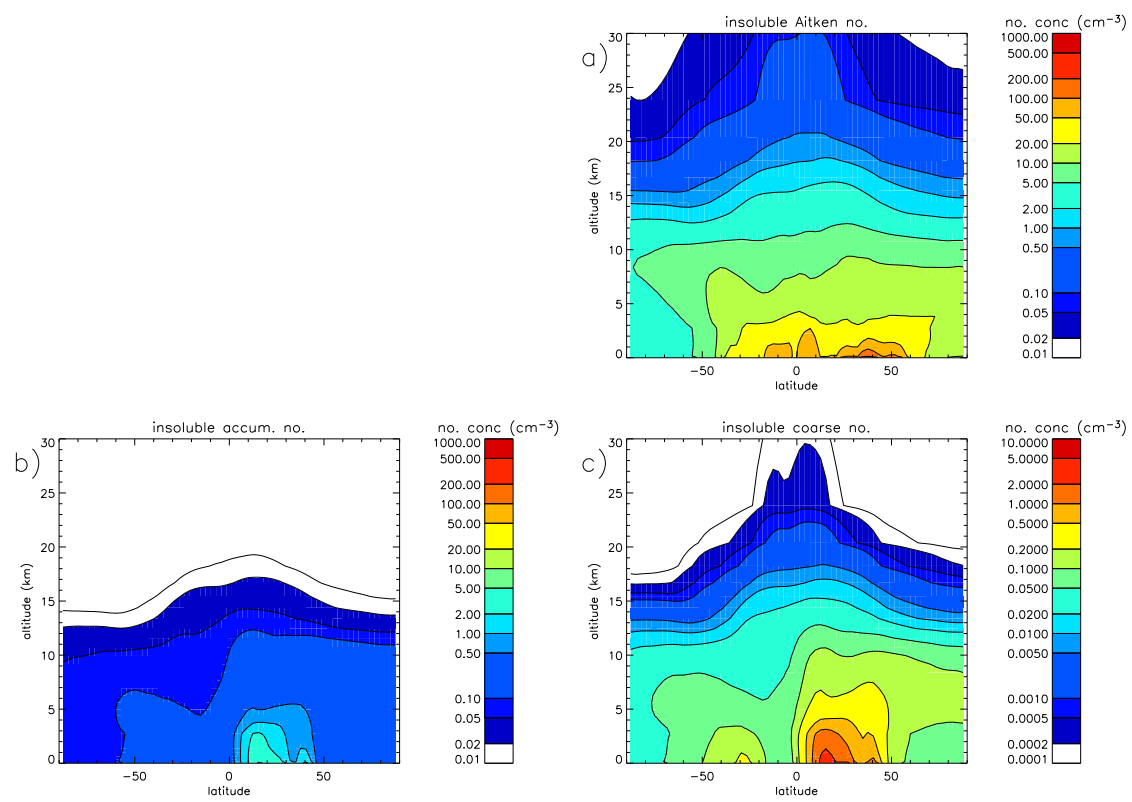

Fig. 15. Latitude-altitude plots of simulated zonal-means of annual-mean particle number concentrations for (a) Aitken-insoluble mode, (b) accumulation-insoluble mode and (c) coarse-insoluble mode.
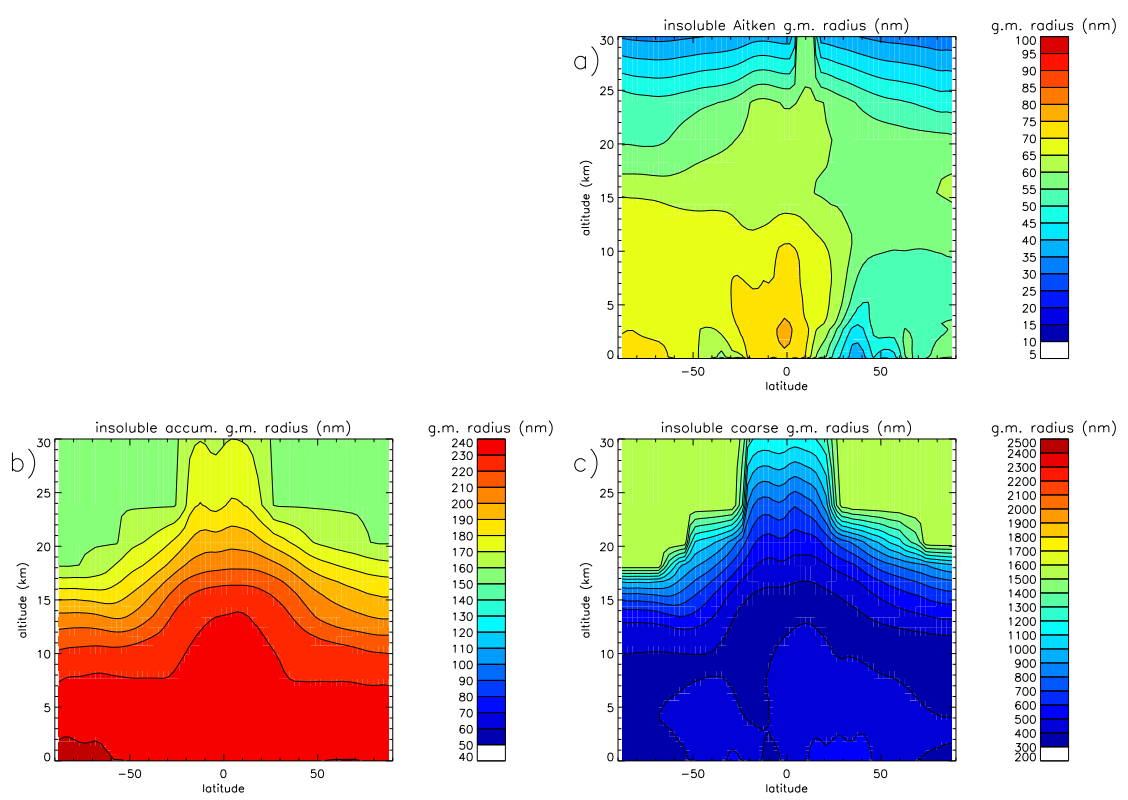

Fig. 16. Latitude-altitude plots of simulated zonal-means of annual-mean particle geometric mean radius for (a) Aitken-insoluble mode, (b) accumulation-insoluble mode and (c) coarse-insoluble mode. 
Table 7. Global Atmospheric Watch (GAW) sites used in the comparison against CN concentrations. Sites are categorized as either free troposphere (FT), marine boundary layer (MBL) or continental boundary layer (CBL). The condensation nuclei counters at Cape Grim and Hohenpeissenberg had cut-off diameters of $3 \mathrm{~nm}$ whilst observed $\mathrm{CN}$ at all other sites refer to particles larger than $10 \mathrm{~nm}$. All data were downloaded from the World Data Centre for Aerosols webpage (http://wdca.jrc.ec.europa.eu/data/parameters/datacnc.html).

\begin{tabular}{lllrrrl}
\hline Station & Code & Type & Latitude & Longitude & H.a.s.l. & Years \\
\hline Jungfraujoch & JFJ & FT & $46.5^{\circ} \mathrm{N}$ & $7.99^{\circ} \mathrm{E}$ & 3580.0 & $1995-2006$ \\
Mauna Loa & MLO & FT & $19.5^{\circ} \mathrm{N}$ & $155.6^{\circ} \mathrm{W}$ & 3397.0 & $1975-1999$ \\
South Pole & SPO & FT & $89.997^{\circ} \mathrm{S}$ & $24.8^{\circ} \mathrm{W}$ & 2841.0 & $1974-1999$ \\
Mace Head & MHT & MBL & $53.3^{\circ} \mathrm{N}$ & $9.9^{\circ} \mathrm{W}$ & 5.0 & $1991-1994$, \\
& & & & & & 2000, \\
& & & & & & $2002-2004$ \\
Neumayer & NEU & MBL & $70.7^{\circ} \mathrm{S}$ & $8.3^{\circ} \mathrm{W}$ & 42.0 & $1993-2006$ \\
Barrow & $\mathrm{BRW}$ & $\mathrm{MBL}$ & $71.3^{\circ} \mathrm{N}$ & $156.6^{\circ} \mathrm{W}$ & 11.0 & $1976-2007$ \\
Samoa & $\mathrm{SMO}$ & $\mathrm{MBL}$ & $14.2^{\circ} \mathrm{S}$ & $170.6^{\circ} \mathrm{W}$ & 77.0 & $1977-1992$, \\
& & & & & & $1994-1997$ \\
& & & & & & $2004-2006$ \\
Trinidad Head & $\mathrm{THD}$ & $\mathrm{MBL}$ & $41.1^{\circ} \mathrm{N}$ & $124.2^{\circ} \mathrm{W}$ & 107.0 & $2002-2007$ \\
Cape Grim & $\mathrm{CGR}$ & $\mathrm{MBL}$ & $40.7^{\circ} \mathrm{S}$ & $144.7^{\circ} \mathrm{E}$ & 94.0 & $1999-2006$ \\
S. Great Plains & $\mathrm{SGP}$ & $\mathrm{CBL}$ & $36.6^{\circ} \mathrm{N}$ & $97.5^{\circ} \mathrm{W}$ & 318.0 & $1996-2007$ \\
Bondville & $\mathrm{BND}$ & $\mathrm{CBL}$ & $40.1^{\circ} \mathrm{N}$ & $88.4^{\circ} \mathrm{W}$ & 213.0 & $1994-2007$ \\
Pallas & $\mathrm{PAS}$ & $\mathrm{CBL}$ & $68.0^{\circ} \mathrm{N}$ & $24.1^{\circ} \mathrm{E}$ & 560.0 & $1996-2002$ \\
Hohenpeissenberg & $\mathrm{HOP}$ & $\mathrm{CBL}$ & $47.8^{\circ} \mathrm{N}$ & $11.0^{\circ} \mathrm{E}$ & 985.0 & $1995-2005$ \\
\hline
\end{tabular}

The relative number concentrations in the nucleation and Aitken soluble modes at these altitudes (Fig. 13) is consistent with this finding.

Zonal annual mean accumulation mode number concentrations are largest $\left(100-200 \mathrm{~cm}^{-3}\right)$ in the boundary layer of the Northern Hemisphere mid-latitudes and contain contributions from primary particles and secondary particles that have been cloud processed from the Aitken soluble mode Accumulation mode $r_{\mathrm{p}}$ is fairly constant meridionally in the Northern Hemisphere $(\approx 80-90 \mathrm{~nm})$ and has little variation with altitude. Mid-latitude Southern Hemisphere accumulation mode particles are slightly smaller $\left(r_{\mathrm{p}} \approx 70-80 \mathrm{~nm}\right)$ and Fig. 10c shows that there is considerable zonal variation in particle size at the surface. The enhancement in accumulation mode size seen at 50-65 South was also seen at the surface in Fig. 10c and could be due to larger mean size of sea-spray aerosol which dominates this region.

Coarse soluble mode number concentrations have a strong vertical gradient, decreasing rapidly due to particle sedimentation, with the 2-moment representation also giving a small decrease in particle size with increasing height $\left(r_{\mathrm{p}} \approx 600\right.$ to $\approx 500 \mathrm{~nm}$ ) as larger particles are preferentially removed.

Figures 15 and 16 shows the same plots as Figs. 13 and 14, but for the 3 insoluble modes. Aitken insoluble mode particles are carbonaceous and zonal mean number concentrations in the free troposphere show little variation between hemispheres (around $10-50 \mathrm{~cm}^{-3}$ ). However, the particle size suggests that these $\mathrm{BC} / \mathrm{OC}$ particles in the Northern Hemisphere originate mainly from fossil fuels $\left(r_{\mathrm{p}} \approx 30\right.$
$40 \mathrm{~nm}$ ) whereas in the Southern Hemisphere and tropics the particles are mainly produced from biomass and biofuel combustion $\left(r_{\mathrm{p}} \approx 75 \mathrm{~nm}\right)$. Particle concentrations in the insoluble accumulation mode (fine, fresh dust) only exceed $1 \mathrm{~cm}^{-3}$ in latitudes containing dust source regions. The number peak at $10-30^{\circ} \mathrm{N}$ due to strong dust sources in North Africa and the middle East while that at $40^{\circ} \mathrm{N}$ comes mainly from deserts in East Asia. Insoluble coarse particles have a similar horizontal distribution but fall off more rapidly at higher altitudes due to sedimentation.

\subsection{Evaluation of simulated $\mathrm{CN}$ and CCN concentrations}

In-situ measurements of total particle number concentrations (larger than 3 or $10 \mathrm{~nm}$ diameter) have been made by Condensation Nuclei Counters on field campaigns and at Global Atmospheric Watch (GAW) and Atmospheric Radiation Measurements (ARM) sites over many years. Measurements of $\mathrm{CCN}$ concentrations have been made in numerous field campaigns from aircraft and ground based instrumentation although routine measurements over many years are only available at a small number of monitoring sites. Differential and Scanning Mobility particle sizers (DMPS, SMPS) have also been used to measure particle size distribution in field campaigns for many years and have now been installed at several aerosol monitoring super-sites (e.g. the European Supersites for Atmospheric Aerosol Research, see http://www.eusaar.net). 


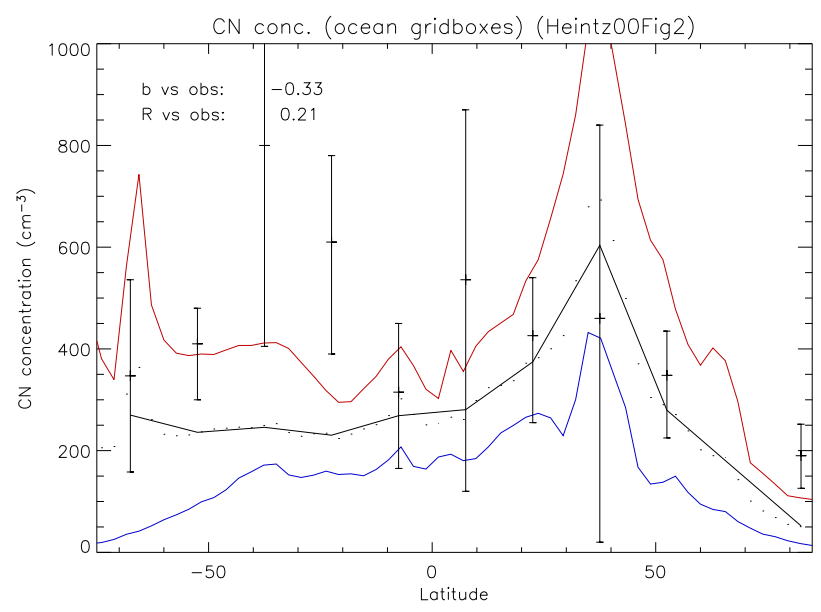

Fig. 17. Simulated marine zonal mean surface $\mathrm{CN}$ concentrations (solid lines) compared to an observed climatology over several field campaigns (Heintzenberg et al., 2000). Model values are from the lowest model level over ocean averaged into 15degree latitude ranges to match the observations. The black line shows the model annual mean and the red/blue lines show minimum/maximum monthly-mean values. Values of $R$ and $b$ are also shown.

Figure 17 compares modelled $\mathrm{CN}$ concentrations against a climatology of observed $\mathrm{CN}$ concentrations in the marine boundary layer compiled by Heintzenberg et al. (2000) from measurements made over 30 years. Overall, the model is biased slightly low against the observations $(b=-0.33)$ with only a weak correlation coefficient $(R=0.21)$. However, the model compares well with the observations between $15 \mathrm{~S}$ and $60 \mathrm{~N}$ with a local maximum in $\mathrm{CN}$ concentration at around $40 \mathrm{~N}$ as in the measurements. Similarly to other models (e.g. Easter et al., 2004; Spracklen et al., 2005) simulated CN are substantially biased low against these observations over the Southern Ocean. This could be an indication that the model is underestimating sub-micron sea-spray or new particle formation in the marine boundary layer. However, as noted in Spracklen et al. (2005), the Southern Ocean average is mostly based on observations during Southern Hemisphere summer. It should be noted that the red line (representing the highest simulated monthly-mean) are from summer months in this region and these compare more favourably with the observations, although the model is still biased low.

Figures 18, 19, and 20 compare the simulated $\mathrm{CN}$ annual cycle against observations at Global Atmospheric Watch (GAW) monitoring stations separated into free troposphere, marine boundary layer and continental boundary layer sites respectively (see Table 7). These sites are essentially a subset of the 25 sites used in a recent study by Spracklen et al. (2010a). That study showed that particle formation is important for global aerosol concentrations, but found that even when binary nucleation was included in the model (without a boundary layer nucleation mechanism), $\mathrm{CN}$ concen- trations were underpredicted $(b=-0.66)$ and the seasonal cycle was not well captured ( $R=0.3$ ) compared to observations at 25 surface sites.

The set-up of the model here is equivalent to the BHN experiment in Spracklen et al. (2009) but using GLOMAPmode rather than GLOMAP-bin. The performance of the model here is generally consistent with the BHN experiment in Spracklen et al. (2010a) with underprediction being lowest at FT sites (Fig. 18) with a fairly good comparison at Jungfraujoch $(b=-0.14)$ and Mauna Loa $(b=0.44)$ and reasonable correlation at South Pole $(R=0.74)$ with strongly elevated summer concentrations as observed (although the model is strongly biased high then). We do not directly compare GLOMAP-mode and GLOMAP-bin here as this is the subject of a separate study (Mann et al., 2010). However, when comparing to the BHN results from Spracklen et al. (2010a), one should note that the version of GLOMAPmode described here is equivalent to GLOMAP-bin v1.0 (e.g. used in Spracklen et al., 2007) whereas Spracklen et al. (2010a) used v1.1 which had an updated treatment of vapour diffusion compared to v1.0. Comparison with $\mathrm{CN}$ concentrations simulated by GLOMAP-bin v1.0 (not shown) suggest the differences at Jungfraujoch are associated with the change to the diffusion rather than differences between the modal and bin-resolved aerosol dynamics.

For three of the six GAW sites in the marine boundary layer (Fig. 19), the model is strongly biased low ( $b$ from -0.78 to -0.72$)$, but compares well at Samoa $(b=0.05)$, Neumayer $(b=-0.11)$ and Trinidad Head $(b=-0.29)$. At Neumayer, the observed strong $\mathrm{CN}$ seasonal cycle is reproduced very well by the model $(R=0.88)$ with the summer high bias at South Pole not present at this Antarctic coastal site. The low bias at Barrow is expected since Korhonen et al. (2008b) showed that, in common with many other global models, GLOMAP underestimates considerably the ultra-fine aerosol observed in the Arctic. At Mace Head, O'Dowd et al. (1998) showed that strong new particle formation events at low tide lead to greatly elevated $\mathrm{CN}$ concentrations. The new particle formation there has been linked to the release of iodine-containing compounds (e.g. McFiggans et al., 2004) and such events will clearly not be simulated in these experiments.

As with GLOMAP-bin BHN (Spracklen et al., 2010a), the $\mathrm{CN}$ low bias is greatest for sites in the continental boundary layer (Fig. 20), with $b$ ranging from -0.74 to -0.68 for Hohenpeissenberg (Germany) and the two US sites Southern Great Plains and Bondville. At Pallas, the low bias is less $(b=-0.38)$ but the seasonal cycle is not at all captured $(R=-0.59)$ with low biases in spring and summer of $\approx 5$ and 10, respectively. Spracklen et al. (2009) demonstrate how the low bias is improved if the number emissions of anthropogenic primary particles is increased or an empirical BL particle formation mechanism is used, with the latter giving best comparison with the observed seasonal cycle. In a future study (Mann et al., 2010) we will investigate the 

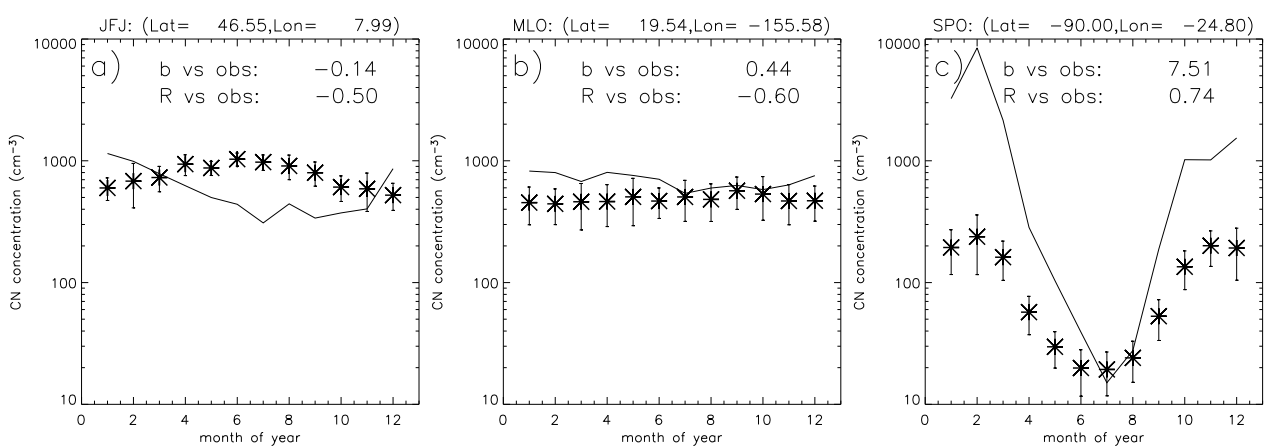

Fig. 18. Simulated monthly-mean $\mathrm{CN}$ concentrations (solid lines) compared to observations (asterisks) at GAW monitoring sites classified as free troposphere. Sites are (a) Jungfraujoch, (b) Mauna Loa and (c) South Pole. Values of $b$ and $R$ are shown for each site. Error bars show the standard deviation for each month over the range of years shown in Table 7. Model values are taken from the level that best matches the height above sea-level for the station.
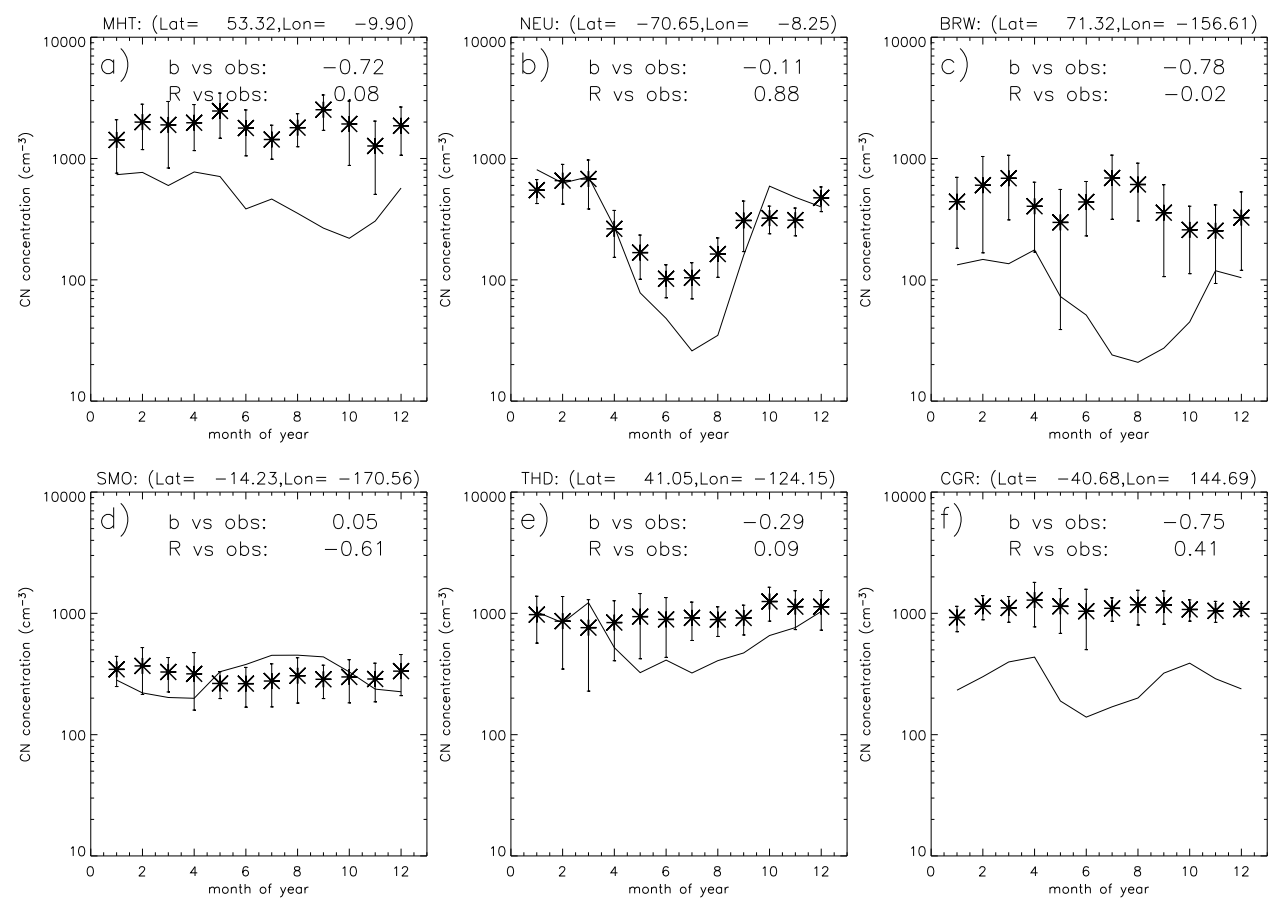

Fig. 19. As Fig. 18 for GAW monitoring stations classified as marine boundary layer sites. Sites are (a) Mace Head, (b) Neumayer, (c) Barrow, (d) Samoa, (e) Trinidad Head, and (f) Cape Grim.

improved performance of GLOMAP-mode when the BL nucleation mechanism is included.

Figure 21 evaluates the simulated vertical profile of $\mathrm{CN}$ concentrations by comparing against the observational climatology from Clarke and Kapustin (2002) who synthesised aircraft measurements over the Pacific and Southern Hemisphere oceans to produce average profiles at $1 \mathrm{~km}$ vertical resolution in the latitude ranges $70^{\circ} \mathrm{S}-20^{\circ} \mathrm{S}, 20^{\circ} \mathrm{S}-20^{\circ} \mathrm{N}$ and $20^{\circ} \mathrm{N}-70^{\circ} \mathrm{N}$. In all three regions, the observed maximum in $\mathrm{CN}$ in the upper troposphere is also produced by the model, caused by binary nucleation. In the $20^{\circ} \mathrm{S}-20^{\circ} \mathrm{N}$ re- gion (sub-tropical Pacific) the $\mathrm{CN}$ maximum is at $\approx 11 \mathrm{~km}$ whereas the model has it at around $16-17 \mathrm{~km}$, and there is a persistent low $\mathrm{CN}$ bias up to $11 \mathrm{~km}(b=-0.57)$. Simulated $\mathrm{CN}$ are in much better agreement with the observations at 20-70S $(b=-0.15, R=0.84)$ and the modelled CN peak of about $4000 \mathrm{~cm}^{-3}$ at $10 \mathrm{~km}$ agrees very well with the observations. At $20-70^{\circ} \mathrm{N}$, the model peak in annual mean $\mathrm{CN}$ is lower than observed in magnitude and in altitude, but overall simulates the vertical profile quite well $(b=-0.28$, $R=0.92$ ). Not captured by model is the observed $\mathrm{CN}$ maximum in the marine boundary layer in the $20^{\circ} \mathrm{S}-20^{\circ} \mathrm{N}$ and 

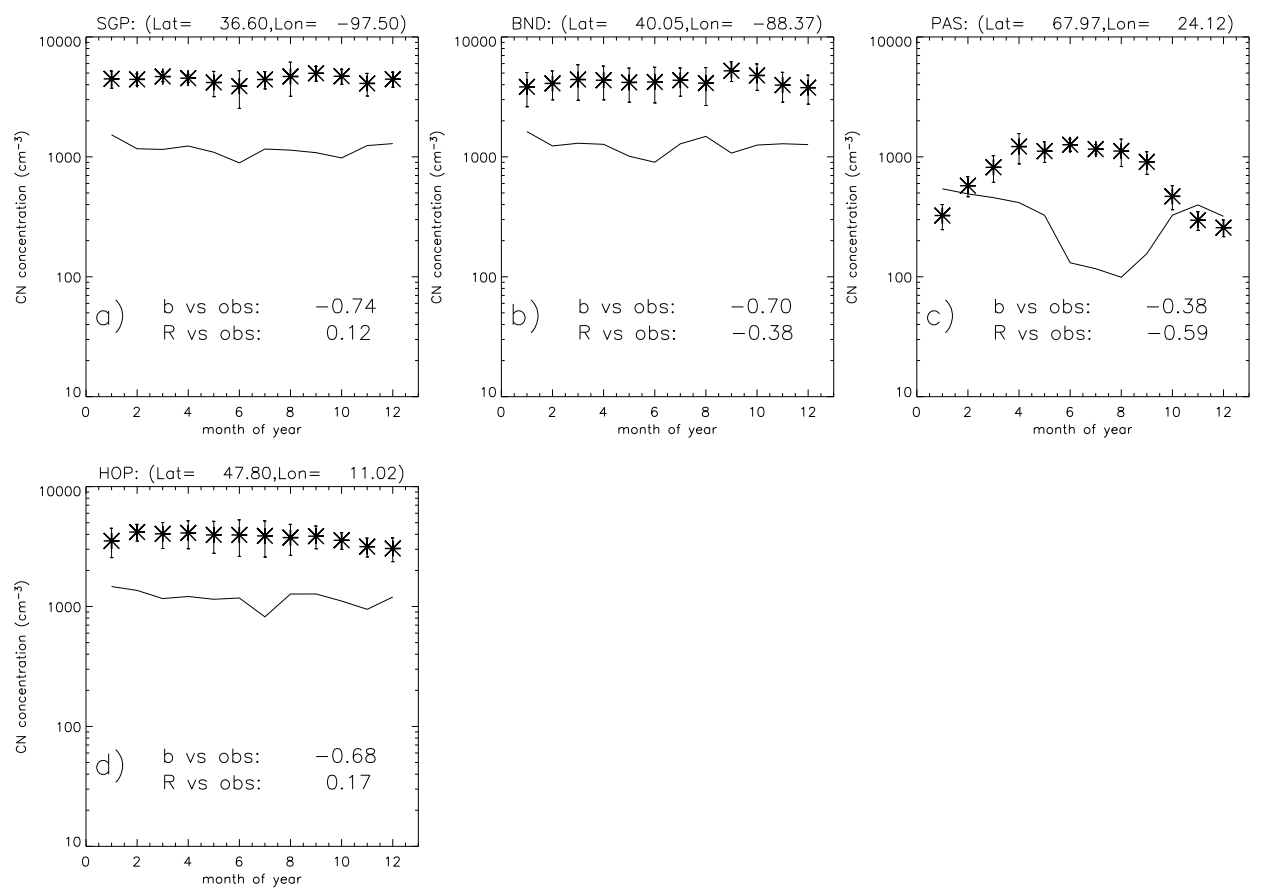

Fig. 20. As Fig. 18 for GAW monitoring stations classified as continental boundary layer sites. Sites are (a) Southern Great Plains, (b) Bondville, (c) Pallas, and (d) Hohenpeissenberg.
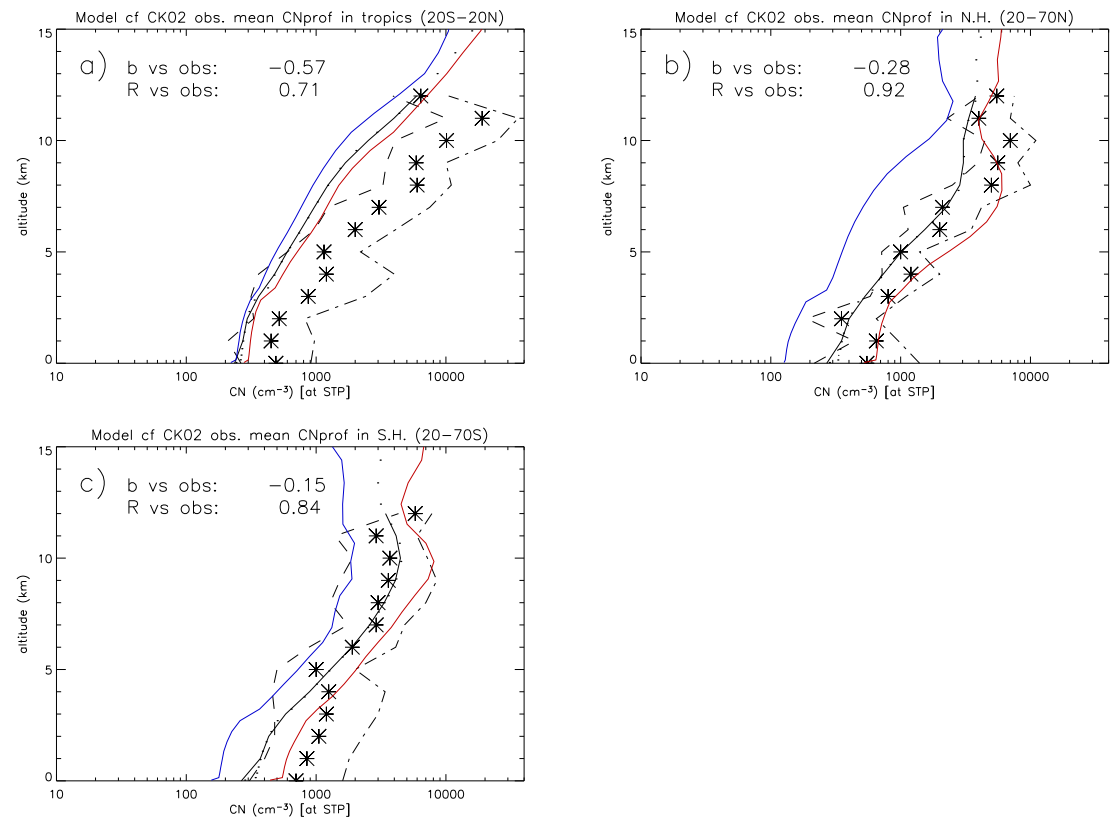

Fig. 21. Simulated CN profiles (solid lines) over the Pacific and Southern Oceans compared to aircraft observations (asterisks are median, dashed/dot-dashed lines represent \pm 1 standard deviation) in the latitude ranges (a) $135-180^{\circ} \mathrm{E}$, (b) $175-270^{\circ} \mathrm{E}$ and (c) $200-240^{\circ} \mathrm{E}$ (Clarke and Kapustin, 2002). Simulated CN (particles larger than $3 \mathrm{~nm}$ dry diameter) were averaged on each model level for the three regions, as in Spracklen et al. (2005). Values of $b$ and $R$ are shown for each region from model values interpolated to a $1 \mathrm{~km}$ grid to match the observations. The black line shows simulated annual mean profile and the blue/red lines show minimum/maximum monthly-mean values. 

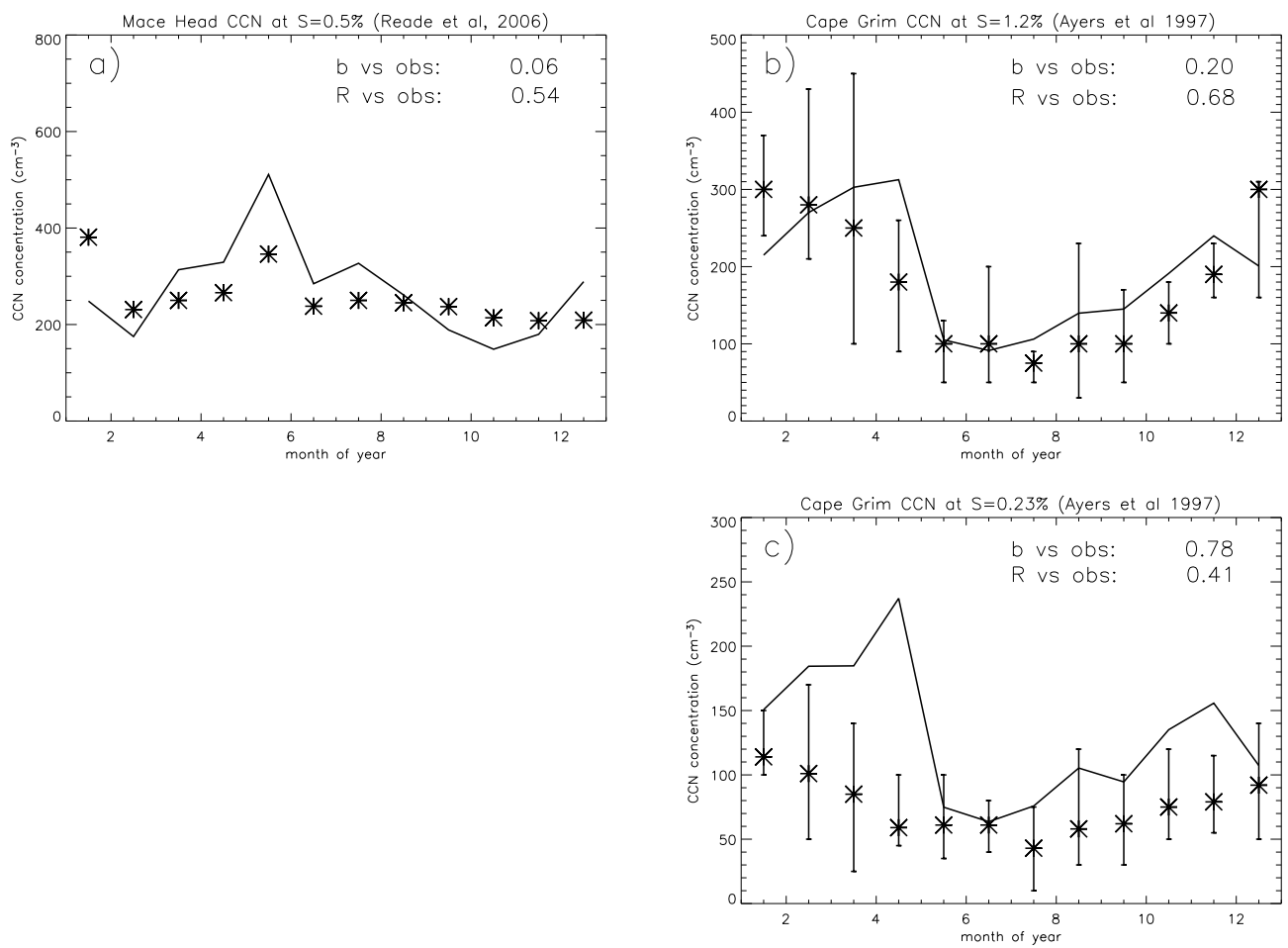

Fig. 22. The simulated annual cycle of CCN concentrations (solid lines) against observations (asterisks) at Mace Head and Cape Grim. The measurements at Mace Head (a) are with $0.5 \%$ superstaturation whilst the comparison at Cape Grim is shown for measured CCN concentrations at supersaturations of (b) $1.2 \%$ and (c) $0.23 \%$. Vertical bars around the Cape Grim observations show the observed range from 1981-1989 (Ayers and Gras, 1991).

$20^{\circ} \mathrm{N}-70^{\circ} \mathrm{N}$ regions, indicating missing marine sources of particle number, possibly due to ultra-fine sea-spray or an alternative nucleation mechanism.

The low $\mathrm{CN}$ bias in the sub-tropics was not found in Spracklen et al. (2005), which used the single-component version of GLOMAP-bin, different emissions and ECMWF analyses from 1997. However, simulated CN profiles with GLOMAP-bin v1.0 with equivalent aerosol types, emissions and meteorology do show a similar low bias (although it is slightly less than here). Revisions to the representation of diffusion at v1.1 of the model (e.g. Merikanto et al., 2009) have resulted in improved comparison with these $20^{\circ} \mathrm{S}-$ $20^{\circ} \mathrm{N}$ observations.

To evaluate simulated $\mathrm{CCN}$ concentrations, we compare against a compilation of CCN observations from Spracklen et al. (2010b). The observations span both hemispheres and cover both oceanic and continental regions. Model values are interpolated to the location for the relevant monthly mean and are based on the supersaturation quoted for the measurement. We use Kohler theory to determine a critical dry radius corresponding to the instrument supersaturation, with model CCN being all soluble mode aerosol larger than this size. A figure showing the comparison is not included here but the dataset of observed $\mathrm{CCN}$ is the same as described in Spracklen et al. (2010b). Overall, the model compares quite well $(R=0.68)$ with the observations (although slightly biased high on average, $b=0.49$ ), with $63 \%, 92 \%, 99 \%$ of model CCN concentrations within a factor of 2,5 and 10 , respectively of the measured values. The model performs better for measured CCN concentrations below $1000 \mathrm{~cm}^{-3}$, with most of the simulated values within a factor of two. For concentrations above $1000 \mathrm{~cm}^{-3}$, the model is biased low, with 5 of the observed $\mathrm{CCN}$ concentrations exceeding $10000 \mathrm{~cm}^{-3}$, whereas simulated $\mathrm{CCN}$ at these sites peak at $7000 \mathrm{~cm}^{-3}$. However, this may be due to the model not resolving urban scale pollution. As expected from the findings in Korhonen et al. (2008b), the one Arctic CCN observation is greatly underpredicted by the model.

Of the sites in Spracklen et al. (2010b), only Cape Grim and Mace Head have observations over the full annual cycle, and the model comparison against observations is shown in Fig. 22. While CN concentrations at Mace Head were underestimated by a factor 5-10 throughout the year (Fig. 19b), CCN concentrations at the site are captured quite well $(b=0.06)$, within a factor of two throughout the year (Fig. 22a). Although the variability in the model CCN is considerably higher than in the observations, observed local maxima in January and May are matched by elevated concentrations in the model. 

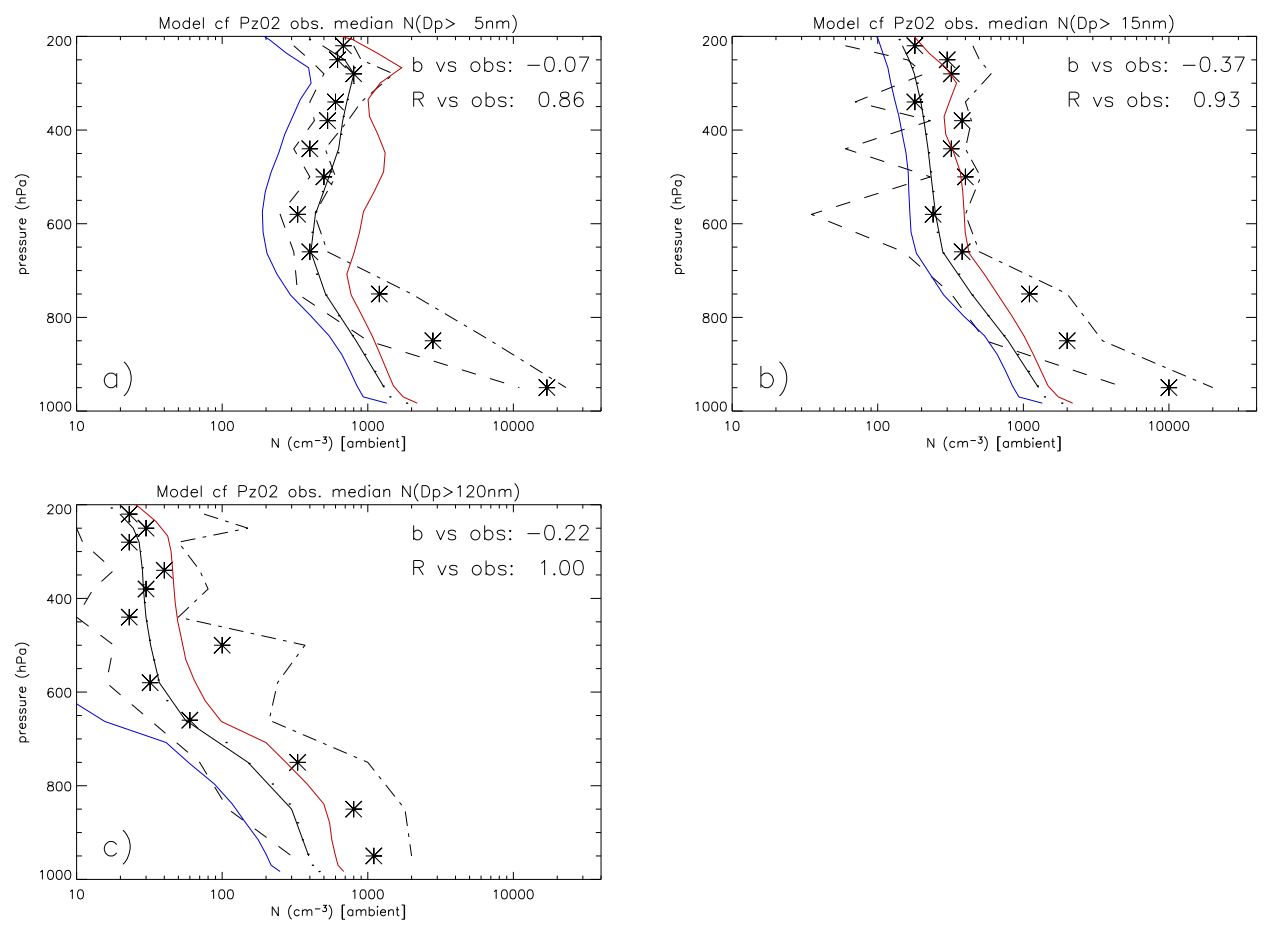

Fig. 23. Simulated vertical profiles of size-resolved number concentration compared to aircraft observations (Petzold et al., 2002) over NE Germany $\left(13.5-14.5^{\circ} \mathrm{E}, 51.5-52.7^{\circ} \mathrm{N}\right)$ for particles larger than (a) $5 \mathrm{~nm}$, (b) $15 \mathrm{~nm}$, and (c) $120 \mathrm{~nm}$ dry diameter $\left(D_{\mathrm{p}}\right)$. Values of $b$ and $R$ are shown for each size-range from model values interpolated to a 1-km grid to match the observations. The black line shows simulated annual mean profile and the blue/red lines show minimum/maximum monthly-mean values. For the observations, the asterisks are median values whereas the dashed/dot-dashed lines are the 25 th/75th percentiles as in Lauer et al (2005).

At Cape Grim, a clear seasonal CCN cycle is observed (Fig. 22b and c), with concentrations from May to October much lower than in late spring and summer. This feature is captured quite well by the model $(R=0.68)$ at $1.2 \%$ supersaturation but only moderately well correlated $(R=0.41)$ at $0.23 \%$ supersaturation. Simulated $\mathrm{CCN}$ at $1.2 \%$ (Fig. 22b) also capture the general magnitude well $(b=0.2)$ and are within the observed inter-annual variability for most of the year, although a high bias $(b=0.78)$ is seen at $0.23 \%$ supersaturation. Nevertheless, overall the model skill is good, with observed and modelled CCN concentrations at both concentrations mostly within a factor of two.

Korhonen et al. (2008a) showed that the elevated summer $\mathrm{CCN}$ concentrations at Cape Grim can be explained by enhanced DMS seawater concentrations in the Southern Ocean leading to stronger new particle formation in the free troposphere and subsequent growth and entrainment into the boundary layer. It should be noted that the modelled CCN peak in March and April is caused by carbonaceous aerosol from wildfire activity in South Australia in the GFED emissions for the year 2000 .

\subsection{Evaluation of simulated size-resolved number concentrations}

The final section of the model evaluation focuses on sizeresolved number concentrations in continental and marine regions.

During the Lindenberg Aerosol Characterization Experiment (LACE) field campaign in 1998, airborne measurements of size-resolved number concentrations were made over continental Europe (Petzold et al., 2002). Lauer et al. (2005) synthesised these measurements into vertical profiles of concentrations of particles larger than 5, 15, and $120 \mathrm{~nm}$ dry diameter $\left(D_{\mathrm{p}}\right)$ and Fig. 23 compares GLOMAPmode against the median values from this dataset.

At altitudes above $700 \mathrm{hPa}$, the model annual mean compares very well against the observations for each of the size ranges. This gives confidence that new particle formation and growth in the free troposphere is performing well in the model. Below $700 \mathrm{hPa}$ however, the model underestimates observed particle concentrations for each size range by a factor 2 for sizes larger than $120 \mathrm{~nm}$ dry diameter, and a factor 2-10 for particles larger than 5 and $15 \mathrm{~nm}$. On average however, the low bias is quite small $(b=-0.07,-0.37$ and $-0.22)$ with good correlation coefficient $(R=0.86,0.93$, and 

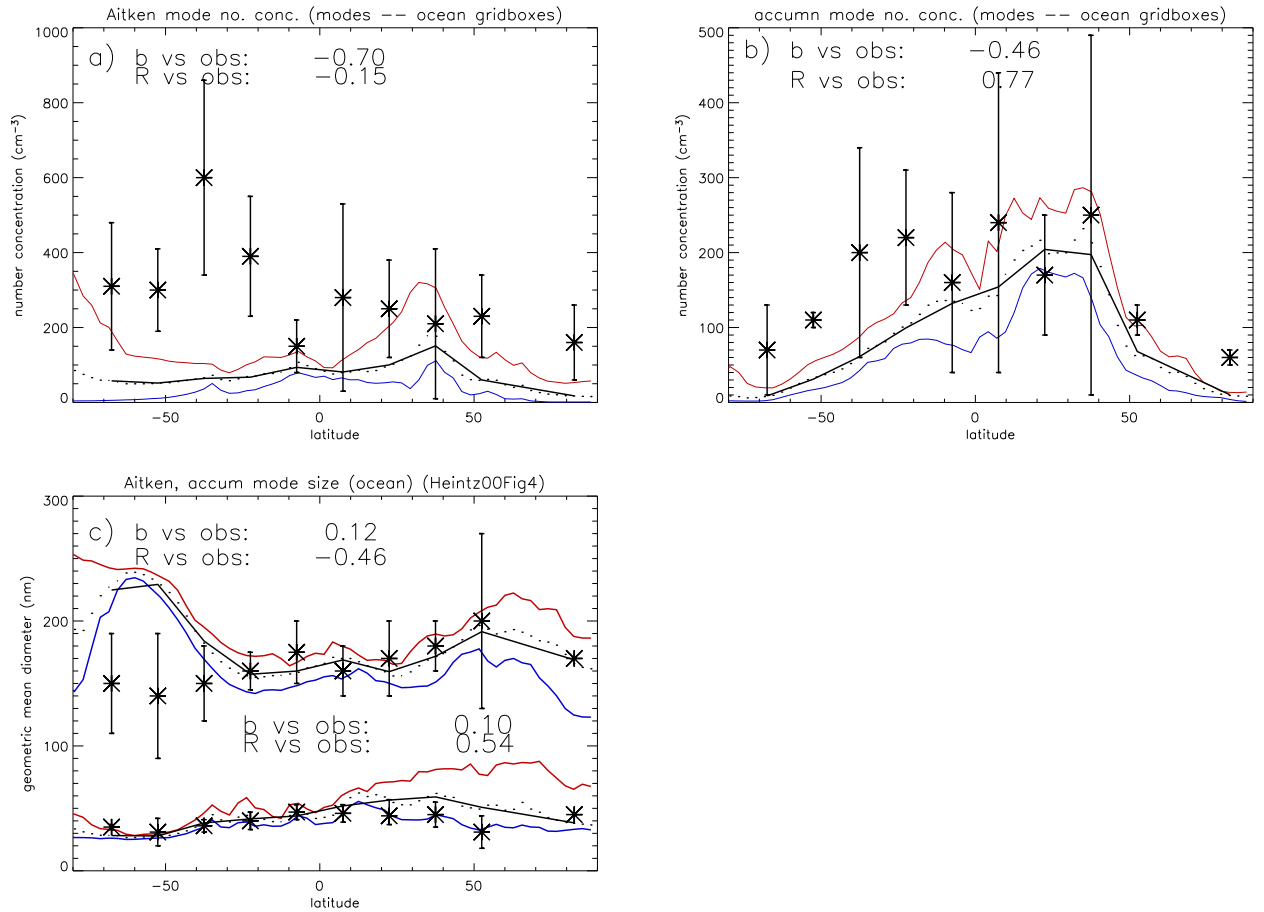

Fig. 24. Simulated marine surface zonal-mean size-resolved number concentration in (a) Aitken mode and (b) accumulation mode, and (c) geometric mean particle diameters in each mode compared to those in an observed climatology (Heintzenberg et al., 2000). Values of $b$ and $R$ are shown for the simulated zonal-mean values averaged into 15-degree latitude-ranges to match the observations. The black line shows simulated annual mean profile (averaged to the 15-degree grid) and the blue/red lines show minimum/maximum monthly-mean values. Dotted lines show the values on the model latitude grid.

$0.996)$ for $D_{\mathrm{p}}>5,15$, and $120 \mathrm{~nm}$, respectively. Spracklen et al. (2010a) found a similar low bias in the continental boundary layer in the equivalent BHN simulation, and found that it could be reduced substantially by assuming a finer particle size for primary emissions or including an empirical boundary layer nucleation mechanism.

To evaluate the model particle size-distribution in marine regions, we again compare against the observed climatology of Heintzenberg et al. (2000). Size-resolved aerosol concentration measurements from many field campaigns were combined to produce an observed climatology of number concentrations and mean size in the Aitken and accumulation size ranges. Figure 24 compares GLOMAP-mode against this dataset. In the Northern Hemisphere, the simulated number concentrations in both modes agree well the observations except in polar regions where the model is biased low. The simulated size of the accumulation mode also agrees very well with the observations in the Northern Hemisphere although the Aitken mode is biased large by around $10-20 \mathrm{~nm}$ at latitudes $>20^{\circ} \mathrm{N}$. As seen in Fig. 17 for $\mathrm{CN}$, simulated number concentrations in both Aitken and accumulation size ranges are biased low with $b=-0.70$ and -0.46 , respectively, possibly related to ultra-fine sea-spray or a missing new particle formation mechanism. Overall however, the model Aitken mode size compares favourably to the observations $(b=0.10$, $R=0.54$ ) matching particularly well in the Southern Hemisphere. Simulated accumulation mode size has poor correlation with the observations $(R=-0.46)$ due to a severe high (large) bias in the Southern Hemisphere.

For a second constraint on simulated marine particle concentrations, we compare (Fig. 25) against ship-borne observed CCN (defined here as particles larger than $50 \mathrm{~nm}$ ) from DMPS measurements over the North Atlantic (Van Dingenen et al., 1995). The measurements are means over 12$48 \mathrm{~h}$, whilst the model field is a mean over September and October (the campaign period). Consequently, the observations have a much higher variability than the model leading to only a moderate correlation coefficient of 0.45 . However, on average, the 2-month simulated CCN (>50 nm) compare well with the observations, the majority being within a factor 2 of the measured $\mathrm{CCN}$ and only a very slight low bias on average $(b=-0.12)$.

\section{Conclusions}

We have described and evaluated a new version of the global size-resolved aerosol microphysics model GLOMAP, that uses a modal aerosol representation as opposed to the 

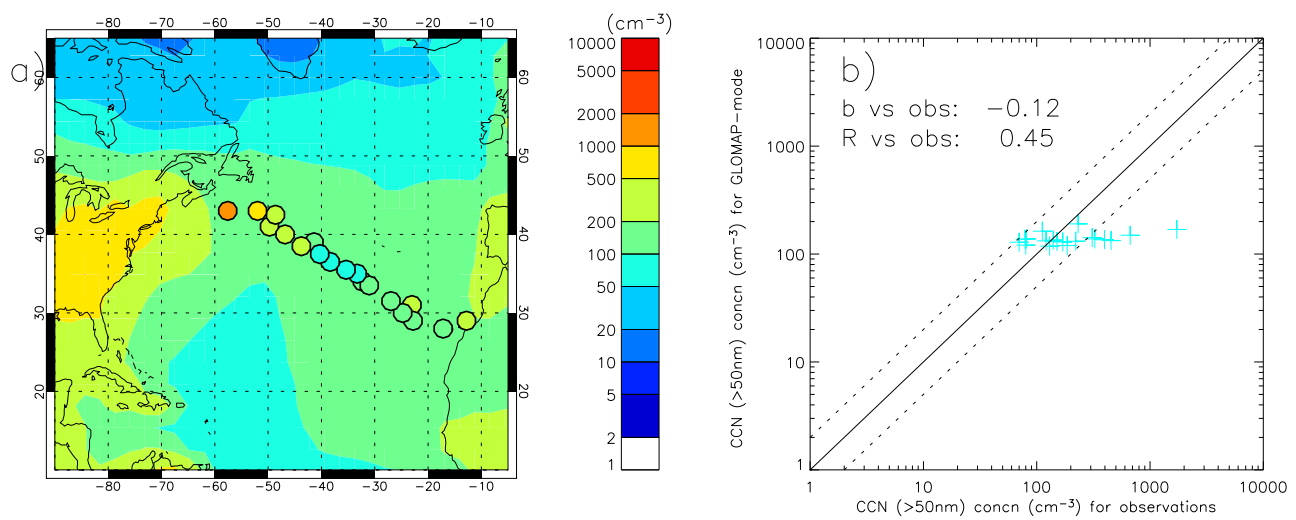

Fig. 25. Simulated marine CCN concentrations (particles larger than $50 \mathrm{~nm}$ ) over the North Atlantic compared to ship-borne observations from Van Dingenen et al. (1995). Values of $b$ and $R$ are shown comparing the observations with interpolated values from the model mean over September and October.

original bin scheme. The treatment of the size-resolved aerosol microphysical processes (new particle formation, coagulation, condensation, cloud-processing) is described in detail along with the emissions, gas phase chemistry and removal by dry deposition, in-cloud and below-cloud scavenging. GLOMAP-mode transports multi-component aerosol masses (sulfate, sea-salt, BC, POM and dust) and number concentrations in 7 log-normal modes runs giving 26 aerosol tracers, compared to around 150-200 for an equivalent aerosol configuration in GLOMAP-bin.

The first part of the model evaluation is against surface observations of aerosol precursor gases and chemically speciated mass concentrations. Sulphate mass is well represented in the model on the annual mean, with normalised mean biases $(b)$ of $0.30,0.05$ and 0.12 and correlation coefficients $(R)$ of $0.73,0.98$, and 0.96 against surface observations over Europe, North America, and marine regions. Mass of BC and POM over North America is underestimated $(b=-0.46$ and -0.57 , respectively) but correlates well spatially with the observations $(R=0.89$ and 0.82$)$. Simulated sea-salt and dust concentrations perform well in marine regions against surface observations $(b=0.22$ and $0.34 ; R=0.13$ and 0.95 , respectively).

We have shown simulated global burden, lifetime and fraction of deposition by wet removal of the simulated species, and find each of them lie close to the median values simulated by global models participating in the AEROCOM model intercomparison exercise. We have also shown the general behaviour of the model by presenting surface maps and zonal mean latitude-altitude plots of particle concentrations and geometric mean radii in each of the seven modes.

The second part of the model evaluation has examined simulated surface $\mathrm{CN}, \mathrm{CCN}$ and size-resolved number concentrations in marine and continental regions and also against profiles from aircraft observations. Surface $\mathrm{CN}$ concentrations compare reasonably well in free troposphere and ma- rine sites, but are strongly underestimated at continental and coastal sites related to underestimation of either primary particle emissions or nucleation events. Vertical $\mathrm{CN}$ profiles over the Pacific ocean are captured quite well $(R=$ $0.71-0.92)$ with maximum in the free troposphere due to binary nucleation, although a low bias is evident $(b=-0.15$ to -0.57$)$. The model compares well $(b=0.49, R=0.68)$ against a compilation of $\mathrm{CCN}$ observations covering a range of environments and also captures vertical profiles of sizeresolved particle concentrations over Europe $(b=-0.37$ to $-0.07, R=0.86-0.95)$ although a low bias of around a factor $2-5$ is seen in boundary layer number concentrations.

Overall, the evaluation finds the simplified version of GLOMAP performs well against the observation datasets, but two main deficiencies are found. Simulated continental boundary layer number concentrations are low, likely caused by boundary layer nucleation and too large primary particle size assumed in the model. Particle concentrations in the Southern Hemisphere marine boundary layer are underpredicted, with a high bias in simulated accumulation mode size, likely due to an underprediction of ultra-fine sea-spray emissions. These model deficiencies will be addressed in the next revision of the model and the performance improvements measured against the benchmark datasets assembled in this paper. A separate paper to be submitted soon (Mann et al., 2010) will re-examine the performance of GLOMAP-mode with the deficiencies addressed and using the more sophisticated GLOMAP-bin scheme as a global benchmark against which the impact of the simplified aerosol dynamics will be assessed.

Acknowledgements. This work is supported by the Natural Environment Research Council (NERC) through the National Centre for Atmospheric Science. We also acknowledge funding from NERC project AEROFORM (NE/D01395X/1), the NERC Directed Research Programme APPRAISE (Theme 3) and the NERC QUEST programme (Earth System Modelling). C. E. Johnson 
and part of the development of UKCA is supported by the DECC and Defra Integrated Climate Programme - DECC/Defra (GA01101). We also gratefully acknowledge AEROCOM and GEIA for providing emissions datasets, ISCCP for the monthly low cloud fields and ECMWF for the ERA-40 re-analysis fields. We thank the scientists and data providers associated with the EMEP, CASTNET, IMPROVE and University of Miami networks. We also thank the data PIs for the $\mathrm{CN}$ and $\mathrm{CCN}$ surface measurements at the WMO-GAW sites (J. Ogren, NOAA, ESRL; J. Gras, CSIRO; U. Baltensberger, PSI; U. Kaminski, DWD; G. Jennings, NUI Galway; R. Weller, AWI; Y. Viisanen, FMI) for making their data available via the World Data Centre for Aerosols website. We thank S. Woodward (UK Met Office Hadley Centre) for providing the University of Miami dust observations dataset. We are also grateful to F. O' Connor (UK Met Office Hadley Centre) for providing the TOMCAT oxidant fields.

Edited by: O. Boucher

\section{References}

Ackermann, I. J., Hass, H., Memmesheimer, M., et al.: Modal aerosol dynamics model for Europe: Development and first applications, Atmos. Environ., 32, 17, 2981-2999, 1998.

Adams, P. J. and Seinfeld, J. H.: Predicting global aerosol size distributions in general circulation models, J. Geophys. Res., 107(D19), 4370, doi:10.1029/2001JD001010, 2002

Andres, R. J. and Kasgnoc, A. D.: A time-averaged inventory of subaerial volcanic sulfur emissions, J. Geophys. Res., 103(D19), 25251-25261, 1998.

Arnold, S., Chipperfield, M., and Blitz, M.: A three-dimensional model study of the effect of new temperature-dependent quantum yields for acetone photolysis, J. Geophys. Res., 110, D22305, doi:10.1029/2005JD005998, 2005.

Atkinson, R., Baulch, D., Cox, A., et al.: Evaluated kinetics and photochemical data for atmospheric chemistry: Supplement III, J. Phys. Chem. Ref. Data, 88, 881-1097, 1989.

Ayers, G., Ivey, J., and Gillett, R.: Coherence between seasonal cycles of dimethylsulfide, methanesulfonate, and sulfate in marine air, Nature, 349, 404-406, 1991.

Ayers, G. and Gras, J.: Seasonal relationship between cloud condensation nuclei and aerosol methanesulphonate in marine air, Nature, 353, 834-835, 1991.

Benkowitz, C. M., Scholtz, M. T., Pacyna, J., et al.: Global gridded inventories of anthropogenic emissions of sulfur and nitrogen, J. Geophys. Res., 101(D22), 29329-29253, 1996.

Binkowski, F. S. and Shankar, U.: The Regional Particulate Matter Model: 1. Model description and preliminary results, J. Geophys. Res., 100(D12), 26191-26209, 1995.

Boucher, O., Moulin, C., Belviso, S., et al.: DMS atmospheric concentrations and sulphate aerosol indirect radiative forcing: a sensitivity study to the DMS source representation and oxidation, Atmos. Chem. Phys., 3, 49-65, doi:10.5194/acp-3-49-2003, 2003.

Breider, T. J., Chipperfield, M. P., Richards, N. A. D., et al.: Impact of $\mathrm{BrO}$ on dimethylsulfide in the remote marine boundary layer, Geophys. Res. Lett., 37, L02807, doi:10.1029/2009GL040868, 2010 .
Bronshtein, I. N. and Semendyayev, K. A.: Handbook of Mathematics, 3rd edn., Springer, 973 pp., 1998.

Chipperfield, M. P.: New version of the TOMCAT/SLIMCAT offline chemistry transport model, Q. J. Roy. Meteor. Soc. 132, 1179-1203, 2006.

Clarke, A. D. and Kapustin, V. N.: A Pacific Aerosol Survey. Part 1: A decade of data on particle production, transport, evolution and mixing in the troposphere, J. Atmos. Sci., 59, 363-382, 2002.

Cofala, J., Amann, M., Klimont, Z., and Schopp, W.: Scenarios of World Anthropogenic Emissions of $\mathrm{SO}_{2}, \mathrm{NO}_{\mathrm{x}}$ and $\mathrm{CO}$ up to 2030, Internal report of the Transboundary Air Pollution Programme, International Institute for Applied Systems Analysis, Laxenburg, Austria, 2005.

Debry, E., Fahey, K., Sartelet, K., et al: Technical Note: A new SIze REsolved Aerosol Model (SIREAM), Atmos. Chem. Phys., 7, 1537-1547, doi:10.5194/acp-7-1537-2007, 2007.

Dentener, F., Kinne, S., Bond, T., et al.: Emissions of primary aerosol and precursor gases in the years 2000 and 1750 prescribed data-sets for AeroCom, Atmos. Chem. Phys., 6, 43214344, doi:10.5194/acp-6-4321-2006, 2006.

Easter, R. C., Ghan, S. J., Zhang, Y., et al.: MIRAGE: Model description and evaluation of aerosols and trace gases, J. Geophys. Res., 109, D20210, doi:10.1029/2004JD004571, 2004.

Easter, R. C. and Hales, J. M.: Precipitation scavenging, dry deposition and resuspension, Chapter: Interpretation of the OSCAR data for reactive gas scavenging, Elsevier, New York, 649-662, 1983.

Forster, P., Ramaswamy, V., Artaxo, P., et al.: Changes in Atmospheric Constituents and in Radiative Forcing. Chapter: Climate Change 2007: The Physical Science Basis, in: Contribution of Working Group I to the Fourth Assessment Report of the Intergovernmental Panel on Climate Change Cambridge University Press, Cambridge, UK and New York, USA, 129-234, 2007.

Fuchs, N. A. and Sutugin, A. G.: Highly dispersed aerosols, Chapter: Topics in current aerosol research, Pergamon, New York, 1-60, 1971.

Ghan, S., Laulainen, N., Easter, R., et al.: Evaluation of aerosol direct radiative forcing in MIRAGE, J. Geophys. Res., 106(D6), 5295-5316, 2001.

Giannakopoulos, C., Chipperfield, M. P., Law, K. S., and Pyle, J. A.: Validation and intercomparison of wet and dry deposition schemes using $\mathrm{Pb}-210$ in a global three-dimensional off-line chemical transport model, J. Geophys. Res., 104, 23761-23784, 1999.

Ginoux, P., Chin, M., Tegen, I., et al.: Sources and distributions of dust aerosols simulated using the GOCART model, J. Geophys. Res., 106(D17), 20255-20273, 2001.

Gong, S.: A parameterization of sea-salt aerosol source function for sub and super-micron particles, Global Biogeochem. Cy., 17(4), 1097, doi:10.1029/2003GB002079, 2003.

Guenther, A., Hewitt, N., Erickson, D., et al.: A global model of natural volatile organic compound emissions, J. Geophys. Res., 100(D5), 8873-8892, 1995.

Halmer, M. M., Schminke, H.-U., and Graf, H.-F.: The annual volcanic gas input into the atmosphere, in particular into the stratosphere: a global data set for the past 100 years, J. Volcanol. Geotherm. Res., 115, 511-528, 2002.

Haywood, J., Roberts, D., Slingo A., et al.: General Circulation Model Calculations of the Direct Radiative Forcing by 
Anthropogenic Sulfate and Fossil-Fuel Soot Aerosol, J. Climate, $10,1562-1577$.

Heintzenberg, J., Covert, D., and Van Dingenen, R.: Size distribution and chemical composition of marine aerosols: a compilation and review, Tellus B, 52, 1104-1122, 2000.

Heintzenberg, J., Birmili, W., Wiedensohler, A., et al.: Structure, variability and persistence of the sub-micron marine aerosol, Tellus B, 56, 357-367, 2004.

Holtslag, A. and Boville, B.: Local versus nonlocal boundary layer diffusion in a global climate model, J. Climate, 6, 1825-1842, 1993.

Hoppel, W. A., Frick, G. M., Fitzgerald, J. W., and Larson, R. E.: Marine boundary-layer measurements of new particle formation and the effects nonprecipitating clouds have on aerosol size distribution, J. Geophys. Res., 99(D7), 14443-14459, 1994.

Jacobson, M.: Development and application of a new air pollution modeling system - II. Aerosol module structure and design, Atmos. Environ., 31(2), 131-144, 1997.

Jacobson, M. Z., Tabazadeh, A., and Turco, R. P.: Simulating equilibrium within aerosols and nonequilibrium between gases and aerosols, J. Geophys. Res., 101(D4), 9079-9091, 1996.

Jones, A., Roberts, D. L., Woodage, M. J., and Johnson, C. E.: Indirect sulfate aerosol forcing in a climate model with an interactive sulfur cycle, J. Geophys. Res., 106(D17), 20293-20310, 2001.

Jourdain, B. and Legrand, M.: Seasonal variations of atmospheric dimethylsulfide, dimethylsulfoxide, sulfur dioxide, methanesulfonate, and non-sea-salt sulfate aerosols at Dumont d'Urville (coastal Antartctica) (December 1998 to July 1999), J. Geophys. Res., 106, 14391-14408, 2001.

Kanakidou, M., Seinfeld, J. H., Pandis, S. N., et al.: Organic aerosol and global climate modelling: a review, Atmos. Chem. Phys., 5, 1053-1123, doi:10.5194/acp-5-1053-2005, 2005.

Kettle, A. J. and Andreae, M. O.: Flux of dimethylsulfide from the oceans: A comparison of updated data sets and flux models $\mathrm{J}$. Geophys. Res., 105(D22), 26793-26808, 2000.

Korhonen, H., Carslaw, K. S., Spracklen, D. V., et al.: Influence of ocean dimethyl sulfide emissions on cloud condensation nuclei concentrations and seasonality over the remote Southern Hemisphere oceans: A global model study, J. Geophys. Res., 113, doi:10.1029/2007JD009718, 2008a.

Korhonen, H., Carslaw, K. S., Spracklen, D. V., et al.: A global model study of processes controlling aerosol size distributions in the Arctic spring and summer J. Geophys. Res., 113, doi:10.1029/2007JD009114, 2008b.

Kulmala, M., Laaksonen, A., and Pirjola, L.: Parameterizations for sulfuric acid/water nucleation rates, J. Geophys. Res., 103(D7), 8301-8307, 1998.

Kulmala, M., Vehkamaki, H., Petajda, T., et al.: Formation and growth rates of ultrafine atmospheric particles: a review of observations, J. Aerosol Sci., 35, 143-176, 2004.

Lauer, A., Hendricks, J., Ackermann I., et al.: Simulating aerosol microphysics with the ECHAM/MADE GCM Part I: Model description and comparison with observations, Atmos. Chem. Phys., 5, 3251-3276, doi:10.5194/acp-5-3251-2005, 2005.

Liu, X., Penner, J. E., and Herzog, M.: Global modeling of aerosol dynamics: Model description, evaluation, and interactions between sulfate and nonsulfate aerosols, J. Geophys. Res., 110, D18206, doi:10.0129/2004JD005674, 2005.

Loevblad, G., Tarrason, L., Torseth, K. et al.: Sulphur, in EMEP As- sessment, Part 1: European Perspective, edited by: Loevblad, G., Tarrason, L., Torseth, K. and Dutchak, S., Norwegian Meteorol. Inst., Oslo, 15-46, 2004.

Malm, W. C., Schichtel, B. A., Ames, R. B., and Gebhart, K. A.: A 10-year spatial and temporal trend of sulfate across the United States, J. Geophys. Res., 107(D22), 4627, doi:10.1029/2002JD002107, 2002.

Manktelow, P. T., Mann, G. W., Carslaw, K. S., et al.: Regional and global trends in sulfate aerosol since the 1980s, Geophys. Res. Lett., 34, L14803, doi:10.1029/2006GL028668, 2007.

Manktelow, P. T.: Understanding the complex fate of the sulfate aerosol, Ph.D. thesis, University of Leeds, UK, 2008.

Manktelow, P. T., Carslaw, K. S., Mann G. W., et al.: Variable CCN formation potential of regional sulfur emissions, Atmos. Chem. Phys., 9, 3253-3259, doi:10.5194/acp-9-3253-2009, 2009.

Manktelow, P. T., Carslaw, K. S., Mann G. W., et al.: The impact of dust on sulfate aerosol, $\mathrm{CN}$ and $\mathrm{CCN}$ during an East Asian dust storm, Atmos. Chem. Phys., 10, 365-382, doi:10.5194/acp-10365-2010, 2010.

Mann, G. W., Carslaw, K. S., Spracklen, D. V., et al.: Evaluation of a 3D global aerosol microphysics model using modal aerosol dynamics against a bin-resolved scheme and benchmark observational datasets, in preparation, 2010.

Martensson E. M., Nilsson, E. D., de Leeuw, G., et al.: Laboratory simulations and parameterization of the primary marine aerosol production, J. Geophys. Res., 108(D9), 4297, doi:10.1029/2002JD002263, 2003.

McFiggans, G., Coe, H., Burgess, R., et al.: Direct evidence for coastal iodine particles from Laminaria macroalgae - linkage to emissions of molecular iodine, Atmos. Chem. Phys., 4, 701-713, doi:10.5194/acp-4-701-2004, 2004.

Merikanto, J., Spracklen, D. V., Mann, G. W., et al.: Impact of nucleation on global CCN, Atmos. Chem. Phys., 9, 8601-8616, doi:10.5194/acp-9-8601-2009, 2009.

Morgenstern, O., Braesicke, P., O'Connor, F., et al.: Evaluation of the new UKCA climate-composition model Part 1: The stratosphere, Geosci. Model Dev., 2, 43-57, doi:10.5194/gmd-2-432009, 2009.

Nguyen, B., Mihalopoulos, N., Putaud, J., et al.: Covariations in oceanic dimethyl sulfide, its oxidation products and rain acidity at Amsterdam Island in the southern Indian Ocean, J. Atmos. Chem., 15, 39-53, 1992.

Nightingale, P. D., Malin, G., Law, C. S., et al.: In situ evaluation of air-sea gas exchange parameterizations using novel conservative and volatile tracers, Global Biogeochem. Cy., 14(1), 373-387, 2000.

O’Dowd, C. D., Geever, M., Hill, M. K., et al.: New particle formation: Spatial scales and nucleation rates in the coastal environment, Geophys. Res. Lett., 25, 1661-1664, 1998.

Petzold, A., Fiebig, M., Flentje, H., et al.: Vertical variability of aerosol properties observed at a continental site during the Lindenberg Aerosol Characterization Experiment (LACE98), J. Geophys. Res., 107(D21), 8128, doi:10.1029/2001JD001043, 2002.

Pham, M., Muller, J.-F., Brasseur, G. P., et al.: A three-dimensional study of the tropospheric sulfur cycle, J. Geophys. Res., 100, 26061-26092, 1995.

Prather, M. J.: Numerical advection by conservations of secondorder moments, J. Geophys. Res., 91, 6671-6681, 1986. 
Pringle, K. J.: Aerosol-cloud interactions in a global model of aerosol microphysics, Ph.D. thesis, University of Leeds, UK, 2006.

Pringle, K. J., Carslaw, K. S., Spracklen, D. V., et al.: The relationship between aerosol and cloud drop number concentrations in a global aerosol microphysics model, Atmos. Chem. Phys., 9, 4131-4144, doi:10.5194/acp-9-4131-2009, 2009.

Raes, F.: Entrainment of free tropospheric aerosols as a regulating mechanism for cloud condensation nuclei in the remote marine boundary layer, J. Geophys. Res., 100(D2), 2893-2903, 1995.

Reddy, M. S., Boucher, O., Bellouin, N., et al.: Estimates of global multicomponent aerosol optical depth and direct radiative perturbation in the Laboratoire de Meteorologie Dynamique general circulation model, J. Geophys. Res., 110, D10S16, doi:10.1029/2004JD004757, 20.

Rossow, W. and Schiffer, R.:, Advances in understanding clouds from ISCCP, B. Am. Meteorol. Soc., 80, 2261-2287, 1999.

Schmidt, A., Carslaw, K. S., Mann, G. W., et al.: The impact of the 1783-1784 AD Laki eruption on global aerosol formation processes and cloud condensation nuclei, Atmos. Chem. Phys., 10, 6025-6041, doi:10.5194/acp-10-6025-2010, 2010

Sekhon, R. and Srivastava, R.: Doppler observations of drop size distributions in a thunderstorm, J. Atmos. Sci., 28, 983-994, 1971.

Seinfeld, J. H. and Pandis, S. N.: Atmospheric Chemistry and Physics: From Air Pollution to Climate Change, WileyInterscience, 1326 pp., 1998.

Slinn, W. G. N.: Predictions for particle deposition to vegetative surfaces, Atmos. Environ., 16, 1785-1794, 1982.

Spracklen, D. V.: Development and application of a Glomap Model of Aerosol Processes (GLOMAP) Ph.D. thesis, University of Leeds, UK, 2005.

Spracklen, D. V., Pringle, K. J., Carslaw, K. S., et al.: A global off-line model of size-resolved aerosol microphysics: I. Model development and prediction of aerosol properties, Atmos. Chem. Phys., 5, 2227-2252, doi:10.5194/acp-5-2227-2005, 2005.

Spracklen, D. V., Carslaw, K. S., Kulmala, M., et al.: The contribution of boundary layer nucleation events to total particle concentrations on regional and global scales, Atmos. Chem. Phys., 6, 5631-5648, doi:10.5194/acp-6-5631-2006, 2006.

Spracklen, D. V., Pringle, K. J., Carslaw, K. S., et al.: Evaluation of a global aerosol microphysics model against size-resolved particle statistics in the marine atmosphere, Atmos. Chem. Phys., 7, 2073-2090, doi:10.5194/acp-7-2073-2007, 2007.

Spracklen, D. V., Carslaw, K. S., Kulmala, M., et al.: Contribution of particle formation to global cloud condensation nuclei concentrations, Geophys. Res. Lett., 35, L06808, doi:10.1029/2007GL033038, 2008a

Spracklen, D. V., Bonn, B., and Carslaw, K. S.: Boreal forests, aerosols and the impacts on clouds and climate, Philos. T. R. Soc. A., 366, 4613-4626, 2008 b.

Spracklen, D. V., Carslaw, K. S., Merikanto, J., et al.: Explaining global surface aerosol number concentrations in terms of primary emissions and particle formation, Atmos. Chem. Phys., 10, 4775-4793, doi:10.5194/acp-10-4775-2010, 2010.
Spracklen, D. V., Carslaw, K. S., Poeschl, U., et al.: Observational constraint on the global cloud albedo effect of soot particles, submitted, 2010.

Stier, P., Feichter, J., Kinne, S., et al.: The aerosol-climate model ECHAM5-HAM, Atmos. Chem. Phys., 5, 1125-1156, doi:10.5194/acp-5-1125-2005, 2005.

Stokes, R. H. and Robinson, R. A.: Interactions in aqueous nonelectrolyte solutions. I. Solute-solvent equilibria, J. Phys. Chem., 70, 2126-2130, 1966.

Textor, C., Schulz, M., Guibert, S., et al.: Analysis and quantification of the diversities of aerosol life cycles within AeroCom, Atmos. Chem. Phys., 6, 1777-1813, doi:10.5194/acp-6-1777-2006, 2006.

Tiedtke, M.: A comprehensive mass flux scheme for cumulus parameterization in large-scale models, Mon. Weather Rev., 117, 1779-1800, 1989.

Van Der Werf, G. R., Randerson, J. T., Collatz, G. C., et al.: Carbon emissions from fires in tropical and subtropical ecosystems, Global Change Biol., 9(4), 547-562, 2003.

Van Dingenen, R., Raes, F., and Jenson, N. R.: Evidence for anthropogenic impact on number concentration and sulfate content of cloud-processed aerosol particles over the North Atlantic, J. Geophys. Res., 100(D10), 21057-21067, 1995.

Vignati, E., Wilson, J., and Stier, P.: M7: An efficient size-resolved aerosol microphysics module for large-scale aerosol transport models, J. Geophys. Res., 109, D22202, doi:10.1029/2003JD004485, 2004.

Vignati, E., Karl, M., Krol, M., et al.: Sources of uncertainties in modelling black carbon at the global scale, Atmos. Chem. Phys., 10, 2595-2611, doi:10.5194/acp-10-2595-2010, 2010.

Whitby, E. and McMurry, P.: Modal aerosol dynamics modeling, Aerosol. Sci. Tech., 27, 673-688, 1997.

Wilson, J., Cuvelier, C., and Raes, F.: A modeling study of global mixed aerosol fields, J. Geophys. Res., 106, D24106, 34,08134,108, 2001.

Woodhouse, M. T., Mann, G. W., and Carslaw, K. S.: The impact of oceanic iron fertilisation on cloud condensation nuclei, Atmos. Environ., 42, 5728-5730, 2008.

Woodhouse, M. T., Carslaw, K. S., Mann, G. W., et al.: Low sensitivity of cloud condensation nuclei to changes in the sea-air flux of dimethyl-sulphide, Atmos. Chem. Phys., 10, 7545-7559, doi:10.5194/acp-10-7545-2010, 2010.

Woodward, S.: Modeling the atmospheric life cycle and radiative impact of mineral dust in the Hadley Centre climate model, J. Geophys. Res., 106(D16), 18115-18166, 2001.

Zadanovskii, A. B.: New methods for calculating solubilities of electrolytes in multicomponent systems, Zh. Fiz. Khim., 22, 1475-1485, 1948.

Zhang, L., Gong, S., Padro, J., and Barrie, L.: A size-segregated particle dry deposition scheme for an atmospheric aerosol module, Atmos. Environ., 35, 549-560, 2001. 